\title{
Review of the New World Erythroneurini (Hemiptera: Cicadellidae: Typhlocybinae)
}

\section{Genera Erythroneura, Erasmoneura, Rossmoneura, and Hymetta}

Dmitry A. Dmitriev and Christopher H. Dietrich 
Illinois Natural History Survey, David L. Thomas, Chief

A Division of the Illinois Department of Natural Resources

\author{
Illinois Natural History Survey \\ Distribution Office \\ I-Building \\ 1816 South Oak Street \\ Champaign, IL 61820
}

Citation:

Review of the New World Erythroneurini (Hemiptera: Cicadellidae: Typhlocybinae). I. Genera Erythroneura, Erasmoneura, Rossmoneura, and Hymetta. Illinois Natural History Survey Bulletin 38(2):59-128.

\title{
Editor: Charles Warwick
}

US ISSN 0073-4918

\section{US ISBN 1-882932-14-5}

Printed by authority of the State of Illinois

(C) 2007

Ref. \# B382807-.75M-08-07

Printed with soy ink on recycled and recyclable paper.

Equal opportunity to participate in programs of the Illinois Department of Natural Resources (IDNR) and those funded by the U.S. Fish and Wildlife Service and other agencies is available to all individuals regardless of race, sex, national origin, disability, age, religion, or other non-merit factors. If you believe you have been discriminated against, contact the funding source's civil rights office and/or the Equal Employment Opportunity Officer, IDNR, One Natural Resources Way, Springfield, IL 62702-1271; 217/785-0067; TTY 217/782-9175. 


\section{Review of the New World Erythroneurini}

I. Genera Erythroneura, Erasmoneura, Rossmoneura, and Hymetta

Dmitry A. Dmitriev and Christopher H. Dietrich

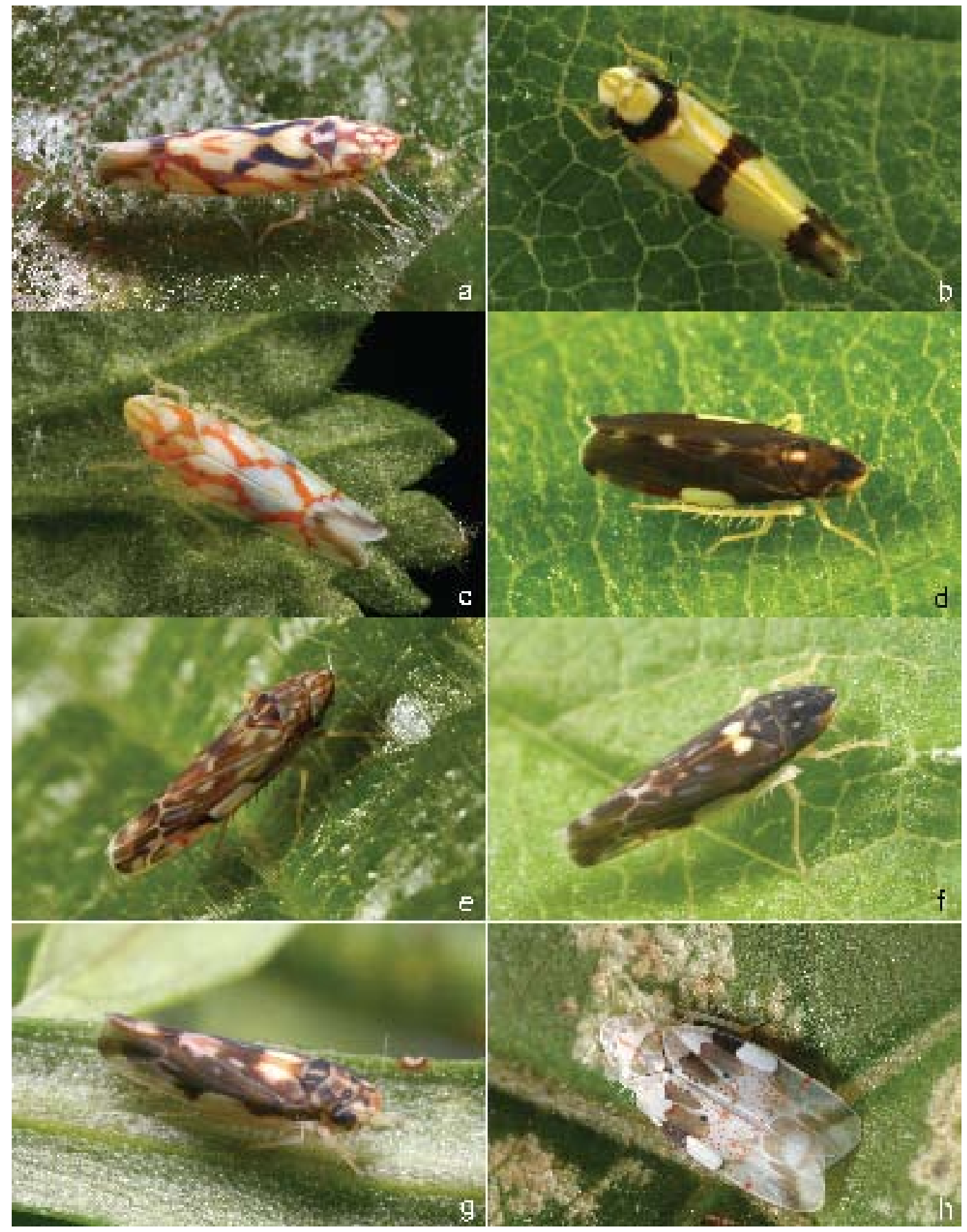

Plate1. Photos of Erythroneurini. a - Erythroneura palimpsesta McAtee; b - E. calycula McAtee; c - E. acuticephala Robinson; d - E. infuscata Gillette; e - Erasmoneura vulnerata Fitch; f - E. nigra Gillette; g - Rossmoneura carbonata McAtee; $\mathrm{h}$ - Hymetta balteata McAtee. $\mathrm{h}$ - photo by Claude Pilon. 


\section{Acknowledgments}

For lending specimens, we are grateful to Norman Penny (California Academy of Sciences), K.G.A. Hamilton (Canadian National Collection, Ottawa), Boris Kondratieff (Colorado State University), Richard Brown (Mississippi State University), Stuart McKamey and Warren Steiner (National Museum of Natural History, Washington, D.C.), Luciana Musetti and Creighton Freeman (Ohio State University), and Zachary Falin (University of Kansas). Stuart McKamey kindly provided access to his Leafhoppers of the World Database, which included much of the nomenclatural information incorporated into our Erythroneurini database. Claude Pilon contributed a photo of Hymetta balteata McAtee. Unpublished drawings by L.W. Hepner included in this work are used with permission of the Mississippi Entomological Museum. Other previously published drawings reproduced in this work are in the public domain. Irena Dworakowska, Sterling Southern, and Herbert Nickel provided constructive criticism that greatly improved the manuscript. This work was supported in part by NSF grants DEB0315373 and DEB050529679, and Hatch award ILLU-875-361 to CHD. 


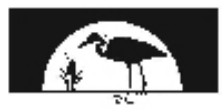

ILLINOIS

NATURAL

HIS TORY

SURVEY

\section{Review of the New World Erythroneurini (Hemiptera: Cicadellidae: Typhlocybinae)}

\section{Genera Erythroneura, Erasmoneura, Rossmoneura, and Hymetta}

Dmitry A. Dmitriev and Christopher H. Dietrich 


\section{CONTENTS}

Plate 1 (Photos of Erythroneurini) $\ldots \ldots \ldots \ldots \ldots \ldots \ldots \ldots \ldots$ Frontis

Acknowledgements............................. ii

Abstract................................... 59

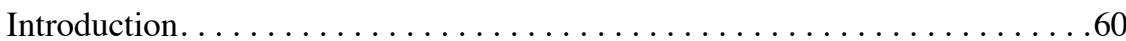

Materials and Methods ............................61

Results. ....................................63

Plate $2(50 \%$ majority rule tree from phylogenetic analysis) . . . . . . . 64 64

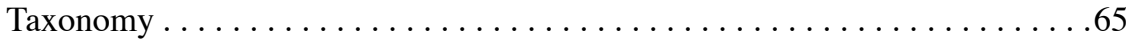

Genus Erythroneura Young, 1952 . . . . . . . . . . . . . . . . . . 665

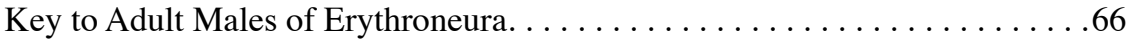

Erythroneura kanwakae ......................70

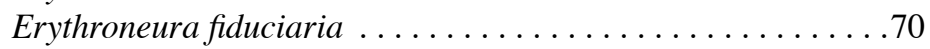

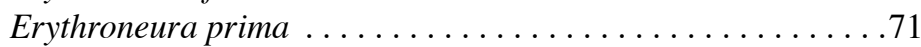

Erythroneura diva ....................... 72

Erythroneura browni.........................72

Erythroneura comes ........................74

Erythroneura octonotata......................75

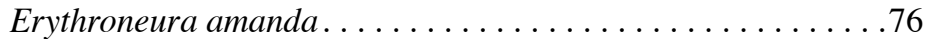

Erythroneura nudata. . . . . . . . . . . . . . . . . . . 76

Erythroneura ortha .......................77

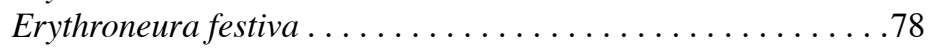

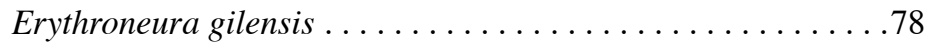

Erythroneura pontifex..........................79

Erythroneura palimpsesta .....................80

Erythroneura beameri......................80

Erythroneura reflecta . . . . . . . . . . . . . . . . .81

Erythroneura integra . . . . . . . . . . . . . . .82

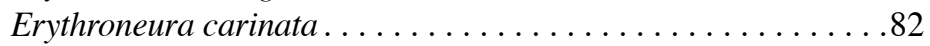

Erythroneura tricincta .................... 83

Erythroneura cymbium .......................884

Erythroneura calycula ......................884

Erythroneura vagabunda ......................85

Erythroneura aza .......................86

Erythroneura glabra ...................... 86

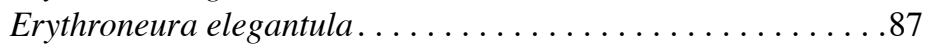

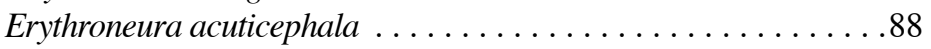

Erythroneura aclys .........................88

Erythroneura bistrata .........................89

Erythroneura prosata .......................90

Erythroneura infuscata .....................90

Erythroneura cancellata ......................91

Erythroneura triapitsyni ..................... 92

Erythroneura bakeri .......................92

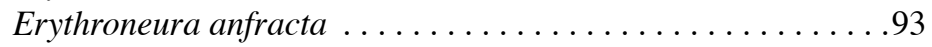

Erythroneura ziczac ........................94

Erythroneura elegans ......................95

Erythroneura delicata........................95

Erythroneura vitifex ......................96

Erythroneura rubra . . . . . . . . . . . . . . . . . . . . . . . . .97 
Erythroneura vitis . . . . . . . . . . . . . . . . .97

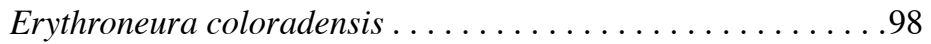

Erythroneura fraxa . . . . . . . . . . . . . . . . . .99

Erythroneura vaga . ........................99

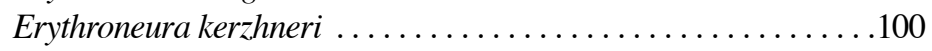

Erythroneura kennedyi .....................100

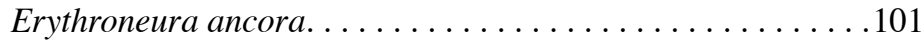

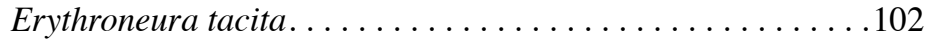

Erythroneura caetra ......................102

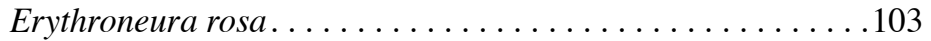

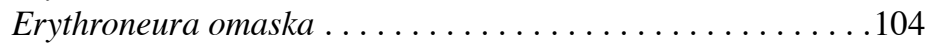

Erythroneura rubrella ............................104

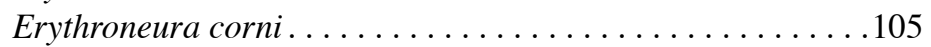

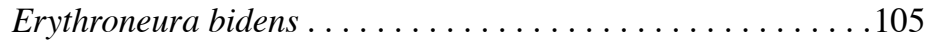

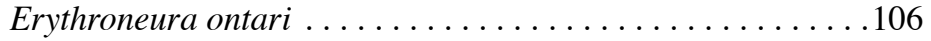

Genus Erasmoneura Young, 1952 . . . . . . . . . . . . . . . . . . . . 107

Key to Species of the Genus Erasmoneura . . . . . . . . . . . . . . . . . . . . . 107

Erasmoneura vulnerata . . . . . . . . . . . . . . . . 108

Erasmoneura fulmina . . . . . . . . . . . . . . . . . . . . 109

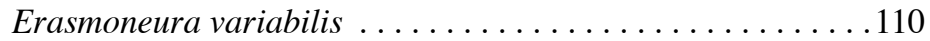

Erasmoneura nigra ......................110

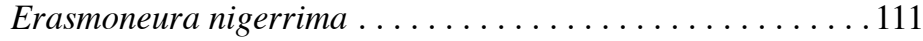

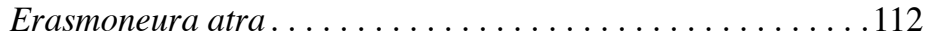

Erasmoneura caerula ......................112

Erasmoneura rubricata. . . . . . . . . . . . . . . . 113

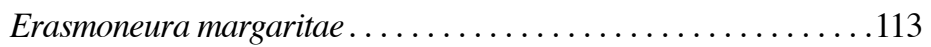

Erasmoneura emeljanovi.............................114

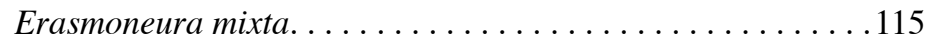

Erasmoneura bipentagona ...................115

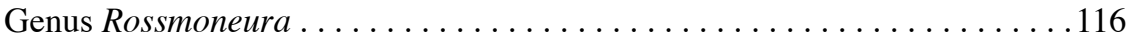

Key to Species of the Genus Rossmoneura . . . . . . . . . . . . . . 116

Rossmoneura carbonata .....................116

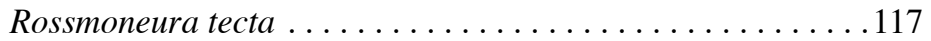

Rossmoneura calva..........................118

Genus Hymetta . . . . . . . . . . . . . . . . . . . . . . . . . . . . . . 118

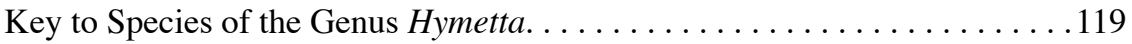

Hymetta kansasensis . . . . . . . . . . . . . . . . . . 119

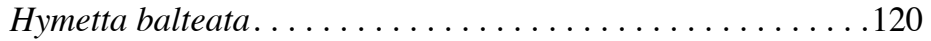

Hymetta anthisma . . . . . . . . . . . . . . . . . .120

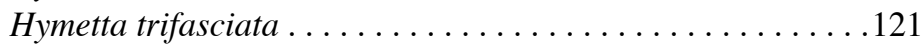

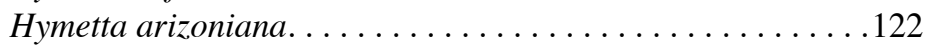

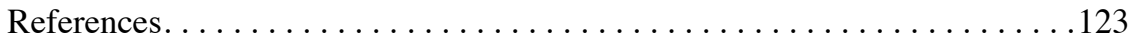

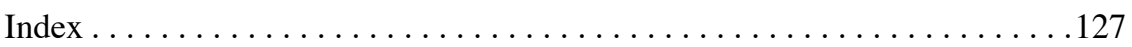





\title{
Review of the Species of New World Erythroneurini (Hemiptera: Cicadellidae: Typhlocybinae). I. Genera Erythroneura, Erasmoneura, Rossmoneura, and Hymetta
}

\author{
Dmitry A. Dmitriev and Christopher H. Dietrich
}

\begin{abstract}
This review provides descriptions, illustrations, keys for identification, and summaries of distributions and host plants for all known species of the genera Erythroneura (54 species), Erasmoneura (12 species), Rossmoneura (3 species), and Hymetta (5 species). Erythroneura browni sp.n., E. ortha sp.n., E. carinata sp.n., E. glabra sp.n., E. bakeri sp.n., E. kerzhneri sp.n. from Central and Eastern USA, E. triapitsyni sp.n. from New Mexico, Erasmoneura margaritae sp.n. from Illinois, and E. emeljanovi sp.n. from South Carolina are described as new. The following new synonyms are recognized: Erythroneura prima Beamer equals E. maritima Hamilton syn. n.; E. diva McAtee equals E. tricincta var. complementa McAtee syn. n.; E. octonotata Walsh equals E. comes var. compta McAtee syn. n., E. cherokee Robinson syn. n., E. compta var. rufomaculata McAtee syn. n., and E. nigroscuta Johnson syn. n.; E. cymbium McAtee equals E. tricincta var. disjuncta McAtee syn. n.; E. calycula McAtee equals E. tricincta var. erasa McAtee syn. n. and E. tricincta var. noncincta Johnson syn. n.; E. ziczac Walsh equals E. ziczac var. walshi Beamer syn. n.; E. delicata McAtee equals E. comes var. accepta McAtee syn. n., E. scripta Robinson syn. n., and $E$. tudella Robinson syn. n.; E. rosa Robinson equals E. repetita McAtee, syn. n.; E. kerzhneri sp.n. equals E. vaga sensu Beamer, 1938 (not Johnson, 1934); Erasmoneura vulnerata Fitch equals $E$. gradata Robinson syn. n.; Erasmoneura fulmina McAtee equals E. bicolorata Beamer syn. n.; Erasmoneura nigra Gillette equals E. vulnerata var. decora McAtee syn. n.; Erasmoneura nigerrima McAtee equals $E$. atrata Johnson syn. n.; Hymetta balteata McAtee equals $H$. trifasciata var. albata McAtee syn. n. and H. balteata var. mediana Fairbairn syn. n.; H. anthisma McAtee equals $H$. distincta Fairbairn syn. n.; Erasmoneura atra Johnson, 1935 is restored and equal to E. nigerrima sensu Beamer, 1946 (not McAtee, 1920). Neotypes are designated for Erythroneura octonotata Walsh, E. tricincta Fitch, and Hymetta trifasciata Say.
\end{abstract}

Keywords: Auchenorrhyncha, Homoptera, leafhopper, morphology, phylogeny, taxonomy, USA. 


\section{Introduction}

The leafhopper tribe Erythroneurini is a diverse group of tiny, delicate leafhoppers that, in the New World, appears to be most diverse in the deciduous forests of temperate North America where species occur on a wide variety of woody host plants. In a recent paper (Dietrich and Dmitriev 2006), we proposed a revised genus-level classification for New World Erythroneurini, recognizing 18 New World genera, including three taxa previously treated as subgenera of Erythroneura (sensu lato). Species belonging to five genera restricted to South America, and the small North American genera Aztegina Dietrich and Dmitriev, Hepzygina Dietrich and Dmitriev, Illinigina Dietrich and Dmitriev, Mexigina Dietrich and Dmitriev, and Nelionidia Dietrich and Dmitriev were treated by Dietrich and Dmitriev (2006). In this and subsequent papers, we provide species-level treatments of the remaining genera of Erythoneurini known to occur in North America. This paper treats the genera Erythroneura, Erasmoneura, Rossmoneura, and Hymetta. Revisions of the genera Erythridula, Eratoneura, and Zyginama are in preparation.

Taxonomic study of New World Erythroneurini began with Fitch (1851), who described the genus Erythroneura based on four species and one variety from New York. Later, Oshanin (1912) designated E. tricincta Fitch as the type species. The genus was first revised by McAtee (1920), who described many additional species and varieties, and organized the species into six informal groups based on wing venation. McAtee (1918, 1919, 1920, 1924a, 1924b, 1924c, 1926) recognized species and varieties based on color pattern, usually selecting females as holotypes. Lawson (1920) and Robinson (1926) were the first to recognize the importance of the male genitalia for diagnosing species of Erythroneura, and provided the first drawings and descriptions of these structures. However, their keys continued to include only characters of the forewing venation and color pattern. Robinson recognized five groups of species within the genus. In a series of publications, Beamer (1927, 1929, 1930a, 1930b, 1931a, 1931b, 1931c, 1931d, 1932a, 1932b, 1932c, 1932d, 1932e, 1932f, 1932g, 1932h, 1932i, 1937, 1938, 1946) revised Erythroneura comprehensively, treating each of four species groups (Beamer 1938) in turn: (Beamer 1930b - obliqua group; Beamer 1931a-1932h

- maculata group; Beamer 1938-comes group; Beamer 1946-vulnerata group). Beamer provided illustrations of the male genitalia for all known species, incorporated these characters into his keys, and associated males with most of the species and varieties that had been described by McAtee based on females. Johnson (1935) independently revised the species of Erythroneura from Ohio and provided a key for their identification. She described many new species in this and subsiquent papers (Knull 1945, 1946, 1951a, 1951b, 1954a, 1954b, 1955). In his generic revision of Western Hemipshere Typhlocybinae, Young (1952) established subgenera for each of Beamer's species groups: Erythridula, Eratoneura, Erythroneura, and Erasmoneura, respectively, and included these in a new tribe, Erythroneurini, along with two other genera: Zygina Fieber and Hymetta McAtee (revised by Fairbairn 1928b). After these revisions, H.H. Ross (with D.M. DeLong) and L.W. Hepner described about 300 additional species of Erythroneura. Dietrich and Dmitriev (2006) elevated the subgenera to the genus level, and transferred three species of Erasmoneura into the new genus Rossmoneura.

Species presently included in the four genera treated here are all apparently native to temperate North America, where they feed and oviposit mainly on woody deciduous hosts. A few species of Erasmoneura and Rossmoneura utilize herbs as hosts for both feeding and oviposition. Adults overwinter in leaf litter. In the spring, they emerge and feed on the new leaves of early emerging deciduous plants before migrating to their "definitive" summer host plants where they mate and lay the eggs (Ross and DeLong 1953). Most species oviposit and undergo nymphal development on a single (or a group of closely related) plant species. In the southern USA, they complete two or more generations per year, but in the North there may be but a single generation. In the fall, adults may again feed on variety host plants prior to seeking out winter shelter. Most New World species of Erythroneurini have no known economic importance, but a few are important pests of grape (McAtee 1920, Robinson 1926, Martinson and Dennehy 1995, Zimmerman et al. 1996, Duso, et al. 2005) and apple (Beamer 1930a). 


\section{Material and Methods}

Few previous workers have specifically targeted Erythroneurini in their collecting, and specimens from trap catches and other general collecting that find their way into curated collections are often in very poor condition. Because of this, and due to time and budget constraints, this study focused only on collections known to contain large numbers of well-curated specimens of Erythroneurini, as well as those housing primary types: Illinois Natural History Survey (INHS), Ohio State University (OSU), University of Kansas Natural History Museum (KSEM), Mississippi State University, Mississippi Entomological Museum (MEM), Canadian National Collection of Insects, Arachnids and Nematodes (CNC), Smithsonian National Museum of Natural History (USNM), Colorado State University (CSUC), California Academy of Sciences (CAS). The numbers of studied specimens from each collection are summarized in Table 1. Future collecting will undoubtedly show that the distributions of most species are much broader than indicated on the maps accompanying individual species treatments. Although these maps show regional biases reflecting the locations and holdings of the studied collections, they are based on vouchered collection records and, thus, accurately reflect current knowledge of species distributions. The type locality is marked with a star on the maps.

Identification of species was mainly based on type material. In some cases, when the type was not located, or the holotype is a female (e.g., most McAtee's species), we followed Beamer's (1927, 1929, 1930a, 1930b, 1931a, 1931b, 1931c, 1931d, 1932a, 1932b, 1932c, 1932d, 1932e, 1932f, 1932g, 1932h, 1932i, 1937, 1938, 1946) interpretation, based on study of dissected male specimens that he labeled "allotype" to indicate that they had been compared to the female primary types of previous workers. Although Beamer's "allotypes" have no official standing in nomenclature, these dissected male specimens facilitate unambiguous interpretation of Beamer's concept of the species.

Morphological terminology follows Dietrich and Dmitriev (2006). Although individual genera, and in many cases species, have a characteristic color pattern, details and intensity may be highly variable both inter- and intraspecifically. Overwintering individuals tend to be more brightly colored than adults of the summer generation of the same species. This has resulted in many species being described multiple times based on different color forms. Species of Erythroneura have the most diverse color patterns. In the descriptions below, the pattern of fully colored individuals is described, although completely or almost completely discolored forms are known for most species. Thus, identification keys are based mainly on male genitalia, with external characters used only for supplemental purposes.

Each species is illustrated by one or more habitus photos taken using a Microptics digital imaging system. Original drawings were prepared only in cases where those available from other sources were deemed inaccurate. Thus, numerous figures are reproduced from other sources, as noted in the figure captions. Inconsistencies (e.g., in line thickness) among line drawings reflect differences in the drawing styles of previous authors. In all cases, figures reproduced from previous publications are either in the public domain or are reproduced with permission.

Line drawings of the male genitalia accompanying each species treatment are labeled as follows:

a-habitus;

b - pygofer or pygofer dorsal appendage,

lateral view;

$\mathrm{c}$ - style apex, broad aspect;

$\mathrm{d}$ - aedeagus, lateral view;

$\mathrm{e}-$ aedeagus, ventral view;

$\mathrm{f}$ - connective.

Nomenclatural, distributional, morphological and host-plant data summarized below were extracted from a relational specimenlevel database of Erythroneurini (Dmitriev \& Dietrich, 2003 onwards), developed using the 3I software package (Dmitriev 2006). The online database provides more detailed information for each species, including a complete list of specimens examined, photos of type specimens, and interactive keys to species and genera.

In the species treatments below, only summer host plants are listed, although most species have also been collected from plants other than their oviposition hosts.

To examine the phylogenetic relationships among species, a matrix of 63 morphological characters was compiled for 73 species 
of Erythroneura, Erasmoneura (excluding $E$. bipentagona Beamer), Rossmoneura, Hymetta, and 13 species from the related genera Erythridula, Eratoneura, Illinigina, and Neoimbecilla. Erythridula was selected as the outgroup based on results of a previous analysis (Dietrich and Dmitriev 2006). Phylogenetic analysis of this matrix was performed using PAUP* 4.0 (Swofford 1998) with 10,000 random addition sequences (nchuck $=5$, chuckscore $=1$ ), and subsequent TBR branch swapping on islands of most parsimonious trees. All multistate characters were treated as non-additive (unordered) except one: Articulation of dorsal pygofer appendage with three ordered states - articulated, not articulated but separated by suture, and fused. Characters were assigned different weights a priori based on their complexity and intraspecific variability. Complex characters that varied little within species were assigned weight $=4$; color pattern characters, which are highly variable within some species, were assigned weight $=1$; all other characters were assigned weight $=2$.

Branch support was measured by calculating the decay index (Bremer 1994) for each consistently resolved node on the most parsimonious trees. This was accomplished using the "enforce topological constraints" option to search for the shortest tree(s) not compatible with each node, using the heuristic search algorithm in PAUP*.

Specimens of newly described taxa are deposited in the insect collections of the Illinois Natural History Survey (Champaign), University of Kansas Natural History Museum (Lawrence), and Mississippi State University (Starkville).

Table 1. Collections and studied material. ${ }^{1}$

\begin{tabular}{|c|c|c|c|c|c|c|c|c|c|}
\hline$\#$ & & & & & & & & & \\
\hline \# & Species & INHS & OSU & KSEM & MEM & CNC & USNM & CSUC & $\mathrm{CAS}$ \\
\hline 1 & Erythroneura kanwakae Robinson & 5 & 19 & 33 & 3 & 23 & & & \\
\hline 2 & E. fiduciaria Knull & 43 & 27 & & 2 & & & & \\
\hline$\overline{3}$ & E. prima Beamer & & & 9 & 1 & 35 & & & \\
\hline 4 & E. diva McAtee & 6 & 76 & 78 & 53 & & 2 & & \\
\hline 5 & E. browni sp.n. & 1 & & & 51 & & & & \\
\hline 6 & E. comes Say & 299 & 321 & 65 & 188 & 147 & & & \\
\hline 7 & E. octonotata Walsh & 943 & 266 & 90 & 525 & & 1 & & \\
\hline 8 & E. amanda McAtee & 12 & 14 & & & & 1 & & \\
\hline 9 & E. nudata McAtee & 115 & 242 & 81 & 417 & 2 & 1 & & \\
\hline 10 & E. ortha sp.n. & 1 & & & 73 & & & & \\
\hline 11 & E. festiva Beamer & 167 & 57 & 158 & 34 & & & & \\
\hline 12 & E. gilensis Beamer & 2 & 46 & 27 & $\frac{8}{8}$ & & & 2 & \\
\hline 13 & E. pontifex McAtee & 126 & 36 & 28 & 7 & & & & \\
\hline 14 & E. palimpsesta McAtee & 21 & 13 & 8 & 6 & & & & \\
\hline 15 & E. beameri Robinson & 123 & 207 & 111 & 82 & 4 & & & \\
\hline 16 & E. reflecta McAtee & 143 & 105 & 25 & 15 & & 1 & & \\
\hline 17 & E. integra McAtee & 11 & 39 & 16 & 62 & 1 & 1 & & \\
\hline 18 & E. carinata sp.n. & 27 & & & 25 & & & & \\
\hline 19 & E. tricincta Fitch & 17 & 162 & 21 & 32 & 94 & & & \\
\hline 20 & E. cymbium McAtee & 35 & 91 & 55 & 198 & & 2 & & \\
\hline 21 & E. calycula McAtee & 54 & 203 & 119 & 292 & & 2 & & \\
\hline 22 & E. vagabunda Knull & 12 & 25 & 1 & 1 & & & & \\
\hline 23 & E. aza Robinson & 16 & 13 & 3 & 17 & & & & \\
\hline 24 & E. glabra sp.n. & 3 & & & & & & & \\
\hline 25 & E. elegantula Osborn & 173 & 16 & 165 & 22 & 4 & & & \\
\hline 26 & E. acuticephala Robinson & 20 & 24 & 42 & 27 & & & & \\
\hline 27 & E. aclys McAtee & 155 & 97 & 67 & 199 & & 1 & 3 & \\
\hline 28 & E. bistrata $\mathrm{McAtee}$ & 130 & 103 & 321 & 431 & & 2 & & \\
\hline 29 & E. prosata Johnson & 64 & 24 & & 7 & & & & \\
\hline 30 & E. infuscata Gillette & 15 & 58 & 68 & 9 & & 1 & 1 & \\
\hline 31 & E. cancellata McAtee & 109 & 40 & 42 & 6 & & 1 & & \\
\hline 32 & E. triapitsyni sp.n. & 19 & & & & & & & \\
\hline
\end{tabular}




\begin{tabular}{|c|c|c|c|c|c|c|c|c|c|}
\hline 33 & E. bakeri sp.n. & 12 & & & 23 & & & & \\
\hline 34 & E. anfracta Beamer & 2 & 108 & 85 & 6 & 15 & & & \\
\hline 35 & E. ziczac Walsh & 911 & 163 & 108 & 44 & 183 & 2 & & \\
\hline 36 & E. elegans McAtee & 217 & 370 & 59 & 2 & 5 & 1 & 7 & \\
\hline 37 & E. delicata McAtee & 212 & 272 & 149 & 38 & 7 & 2 & & \\
\hline 38 & E. vitifex Fitch & 41 & 321 & 52 & 11 & 56 & 1 & 1 & \\
\hline 39 & E. rubra Gillette & 63 & 195 & 103 & 46 & 2 & 1 & 2 & \\
\hline 40 & E. vitis Harris & 932 & 424 & 146 & 287 & 212 & 2 & & \\
\hline 41 & E. coloradensis Gillette & 225 & 52 & 49 & 22 & 8 & 1 & 6 & \\
\hline 42 & E. fraxa Robinson & 49 & 7 & 102 & 54 & & & & \\
\hline 43 & E. vaga Johnson & 41 & 64 & 1 & 79 & & & & \\
\hline 44 & E. kerzhneri sp.n. & & & 70 & 73 & & & & \\
\hline 45 & E. kennedyi Knull & & 16 & & & & & & \\
\hline 46 & E. ancora Beamer & & & 3 & & & & & \\
\hline 47 & E. tacita Beamer & & & 81 & 4 & 1 & & & \\
\hline 48 & E. caetra McAtee & 19 & 4 & 141 & 5 & 14 & 1 & & \\
\hline 49 & E. rosa Robinson & 50 & 109 & 104 & 23 & 66 & & & \\
\hline 50 & E. omaska Robinson & 244 & 22 & 67 & 74 & & & & \\
\hline 51 & E. rubrella McAtee & 987 & 31 & 77 & 26 & 59 & 1 & & \\
\hline 52 & E. corni Robinson & 66 & 60 & 155 & 646 & 23 & & & \\
\hline 53 & E. bidens McAtee & 38 & 29 & 23 & 16 & 2 & 2 & & \\
\hline 54 & E. ontari Robinson & 19 & 110 & 141 & 11 & 84 & & & \\
\hline 55 & Erasmoneura vulnerata Fitch & 805 & 487 & 76 & 809 & 71 & & 5 & \\
\hline 56 & E. fulmina McAtee & 20 & 18 & 19 & 3 & & 2 & & \\
\hline 57 & E. variabilis Beamer & 242 & 227 & 404 & 7 & 178 & & 2 & \\
\hline 58 & E. nigra Gillette & 95 & 60 & 161 & 23 & 16 & 2 & 3 & \\
\hline 59 & E. nigerrima McAtee & & 14 & 105 & & & 1 & & \\
\hline 60 & E. atra Johnson & 46 & 72 & 22 & 25 & & & & \\
\hline 61 & E. caerula Beamer & & 37 & 28 & 1 & & & & \\
\hline 62 & E. rubricata Van Duzee & 24 & 8 & 405 & & & & 1 & 1 \\
\hline 63 & E. margaritae sp.n. & 17 & & & 1 & & & & \\
\hline 64 & E. emeljanovi sp.n. & & & 19 & & & & & \\
\hline 65 & E. mixta Beamer & & 9 & 188 & 1 & & & & \\
\hline 66 & E. bipentagona Beamer & & & 1 & & & & & \\
\hline 67 & Rossmoneura carbonata McAtee & & 3 & 218 & 6 & 132 & & & \\
\hline 68 & R. tecta McAtee & 7 & 37 & 14 & 1 & & 1 & & \\
\hline 69 & R. calva Beamer & & & 42 & 1 & 12 & & & \\
\hline 70 & Hymetta kansasensis Fairbairn & 41 & 3 & 9 & 30 & & & & \\
\hline 71 & H. balteata McAtee & 52 & 164 & 24 & 58 & & 2 & & \\
\hline 72 & H. anthisma McAtee & 27 & 72 & 19 & 1 & & 1 & & \\
\hline 73 & H. trifasciata Say & 37 & 41 & & 37 & & & & \\
\hline 74 & H. arizoniana Fairbairn & & 102 & 17 & & 1 & & & \\
\hline
\end{tabular}

${ }^{1}$ The table shows the number of studied specimens from each collection. See "Material and Methods" for the museum abbreviations.

\section{Results}

The phylogenetic analysis of morphological data with $a$ priori character weighting recovered 2,325 equally parsimonious trees of length 1,119 , rescaled consistency index 0.236 , and retention index 0.725 . The $50 \%$ majority rule tree (Plate 2 ) recovered all included genera as monophyletic, although on some trees Eratoneura was paraphyletic with respect to Erythroneura, and many relationships within Erythroneura were poorly resolved.

Analysis of the same data with all characters having weight $=1$ recovered 484 equally parsimonious trees of length 699. Although these trees were 12 steps shorter than the trees obtained in the analysis based on weighted characters (length calculated based on all weights $=1$ ), we prefer the latter estimate because it requires less homoplasy in the characters considered to be more reliable, and the consensus tree resulting from the analysis of equally weighted characters (not shown) was considerably less well resolved. 


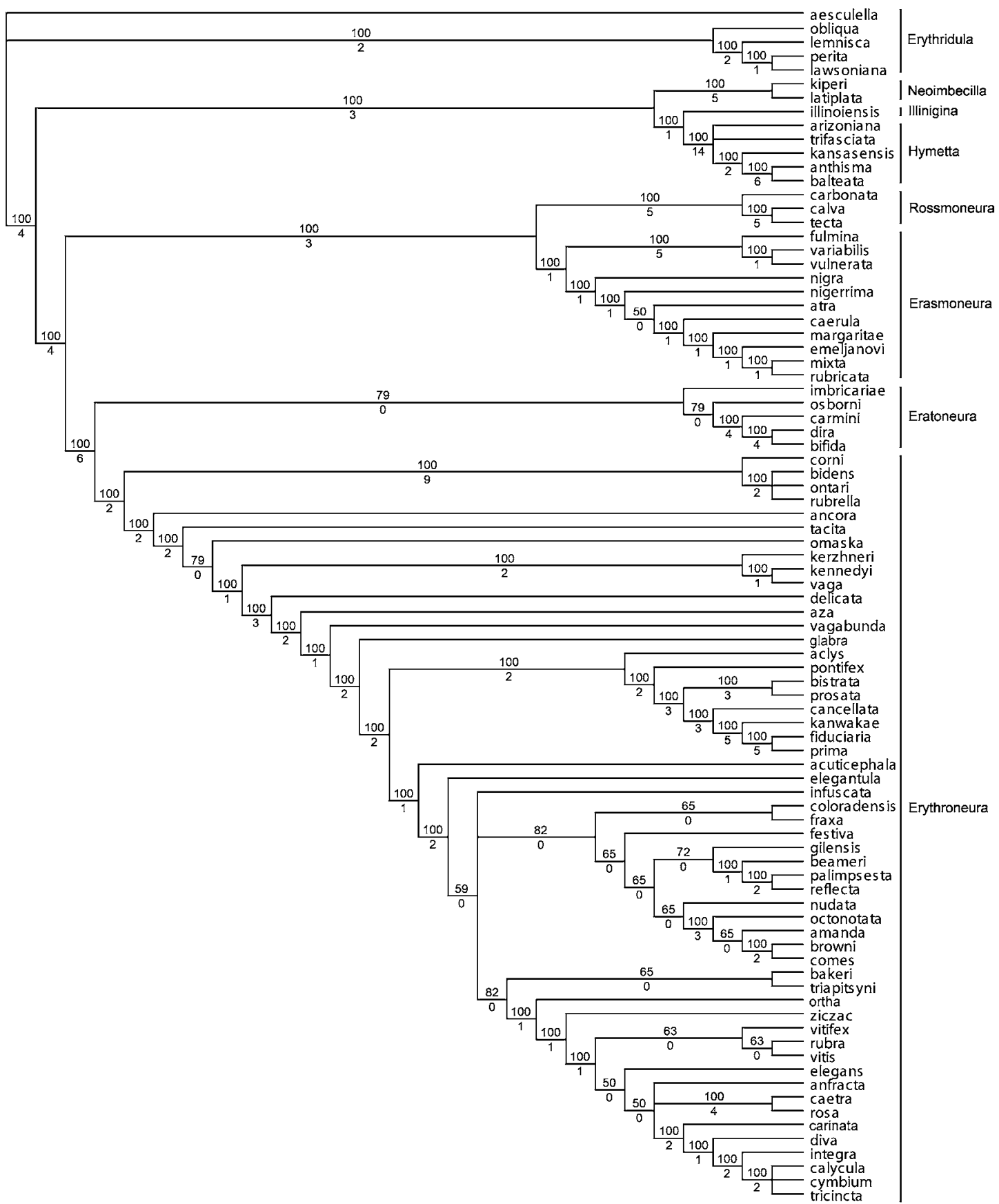

Plate 2. 50\% majority rule tree from phylogenetic analysis. Percentage of the trees supporting the node are given above the branches, and decay indices are given below the branches. 


\section{Taxonomy}

Tribe Erythroneurini Young, 1952

Zyginae Zachvatkin, 1946:152, nom.nud. Erythroneurini Young, 1952:70 (Type: Erythroneura Fitch, 1851)

Bakerini Mahmood, 1967:21 (Type: Bakera Mahmood, 1967)

Genus Erythroneura Fitch, 1851

Erythroneura Fitch, 1851:62

Eurythroneura Rathvon, 1869:551, missp.

Erythroneura Oshanin, 1912:114 (Type:

Erythroneura tricincta Fitch, 1851 designated)

Erthroneura Matsumura, 1932:190, missp.

Erythroueura Lindberg, 1948:161, missp.

Erythroneura (Erythroneura) Young, 1952:79

Description: Length $2.4-3.7 \mathrm{~mm}$, relatively slender. Head narrower than pronotum; crown fore margin strongly produced and angulate medially; ocelli absent or vestigial. Face depressed in profile, less than $45^{\circ}$ from horizontal; anteclypeus narrow in both sexes. Forewing outer apical cell about $2 \mathrm{X}$ as long as wide or longer; second apical cell quadrate (ir crossvein present); third apical cell parallel sided, straight; CuP longer than segment of $\mathrm{CuA}$ between $\mathrm{Cu}$ and MP; basal segment of MP longer than basal segment of $\mathrm{CuA}$; inner apical cell with transverse base; Pcu not visible. Hindwing apex broadly rounded or truncate; submarginal vein not extended to wing apex; RA present; MP and $\mathrm{CuA}$ fused or separated by m-cu crossvein. Front femur AV row with one basal seta distinctly larger than others; PV row without fine basal setae. Pygofer apex not extended to apex of subgenital plate; dorsal emargination extended to base of segment; dorsolateral internal ridge absent; basolateral setae in distinct group, small; distal setae undifferentiated; sparse long fine setae present; apex with rigid setae on internal surface. Pygofer dorsal appendage immovably fused to margin, without basal suture, bifurcate near base, usually C-shaped, branches widely separated; ventral appendages absent. Subgenital plates free, lateral margin with angulate subbasal projection, section basad of medial constriction shorter than distal section; with four basal macrosetae uniseriate along margin; distinct marginal subbasal small rigid setae forming continuous row. Style preapical lobe prominent; apex usually with three points. Aedeagus articulated to con- nective; dorsal apodeme broadly expanded in lateral view, usually triangular in ventral view, without sclerotized connection to anal tube or pygofer appendages. Aedeagus with preatrium short or long; shaft symmetrical, in most cases with ventral and/or distal processes. Connective without median anterior lobe; arms long; stem well developed; depressed. Anal tube without processes.

Coloration highly variable among, and in some cases within, species; usually white or yellow overall with orange, reddish, or brownish oblique vittae forming continuous zigzag pattern or broken into separate flecks; crossbands present in some species; forewing often with dark spot on costal margin, near apex of apical cell II, and at base of inner apical cell. Distribution: Temperate North America; $E$. elegantula Osborn is known from Panama (apparently introduced). Species of Erythroneura described from the Old World were listed as incertae sedis by Dietrich and Dmitriev (2006) and need to be transferred into other genera. Host plants: Deciduous trees, shrubs, and vines; most species recorded from Vitis spp. 


\section{Key to Adult Males of Erythroneura}

1. Pygofer dorsal appendage three-pointed (ventral branch bifurcate) (Fig. 1b) ............................. 2

1'. Pygofer dorsal appendage two-pointed (C-shaped) (Fig. 4b) . ................................................. 4

2(1). Aedeagus ventral processes distally bifurcate (Figs. 2d, 2e).

2 '. Aedeagus ventral processes not bifurcate, strongly sinuate in lateral view (Figs. 1d, 1e).

1. E. kanwakae Robinson

3(2). Lateral branch of aedeagus ventral process longer than medial branch (Fig. 2e).

Anteclypeus pale. Larger (3.3-3.7 mm).

2. E. fiduciaria Knull

3'. Lateral branch of aedeagus ventral process shorter than medial branch (Fig. 3e).

Anteclypeus dark. Smaller (2.7-3 mm).

3. E. prima Beamer

4(1). Aedeagus with ventral processes (Figs. 4d, 4e).

4'. Aedeagus without ventral processes (Figs. 52d, 52e). ..................................................... 52

5(4). Aedeagus ventral processes as long as shaft or longer (Figs. 4d, 4e). .............................. 6

5'. Aedeagus ventral processes shorter than shaft (Fig. 46d). ................................................. 46

6(5). Aedeagus ventral processes bifurcated or with preapical projection (Figs. 6d1, 7d). ............ 7

6'. Aedeagus ventral processes simple (Fig. 10d). .................................................................... 11

7(6). Aedeagus ventral process with short preapical projection (Fig. 6d1). .............................. 8

7'. Aedeagus ventral process with two long branches subequal in length (Fig. 7d). .................. 10

8(7). Third point of style apex shorter than distance between other two points (Fig. 4c).

Forewing with narrow red crossband (Fig. 4a).

4. E. diva McAtee

8'. Third point of style apex longer than distance between other two points (Fig. 6c).

Forewing without crossband.

9(8). Apex of aedeagus extended well beyond bases of distal processes, with distinct spicules

(Fig. 5e).

5. E. browni sp.n

9'. Apex of aedeagus not extended beyond bases of distal processes, without spicules

(Fig. 6e).

6. E. comes Say

10(7). Aedeagus ventral processes bifurcate close to base (Fig. 7d). Clavus with black spot

(Fig. 7a).

7. E. octonotata Walsh

10'. Aedeagus ventral processes bifurcate more distad from base (Fig. 8d). Clavus without

black spot; forewing with broad red crossband (Fig. 8a).

8. E. amanda McAtee

11(6). Third point of style apex elongate, about as long or longer than distance between

other two points (Fig. 16c).

11'. Third point of style apex shorter than distance between other two points (Fig. 19c). ........... 21

12(11). Aedeagus ventral processes nearly parallel to each other (Fig. 9e). ................................ 13

12 '. Aedeagus ventral processes strongly divergent apically (Fig. 16e).

13(12). Aedeagus ventral processes strongly sinuate in lateral view (Fig. 9d).

9. E. nudata McAtee

13'. Aedeagus ventral processes straight or only slightly sinuate in lateral view (Fig. 10d). ....... 14

14(13). Apex of aedeagus extended well beyond bases of distal processes, compressed, with distinct apical spicules. Aedeagus distal processes strongly divergent in ventral view (Fig. 10e).

Anteclypeus pale.

10. E. ortha sp.n.

14'. Apex of aedeagus extended little beyond bases of distal processes, rounded in crossection, without spicules. Aedeagus distal processes parallel in ventral view (Fig. 11e).

Anteclypeus dark.

11. E. festiva Beamer

15(12). Apex of aedeagus extended well beyond bases of distal processes (Fig. 11e). ................ 16

15'. Apex of aedeagus extended little if any beyond bases of distal processes (Fig. 16e). ............ 18

16(15). Shaft of aedeagus denticulate distally (Figs, 5d, 5e).

5. E. browni sp.n

16'. Shaft of aedeagus smooth (Figs. 12d, 12e).

17(16). Aedeagus ventral processes curved dorsad distally in lateral view (Fig. 12d).

Vertex with orange pattern (Fig. 12a).

12. E. gilensis Beamer

17'. Aedeagus ventral processes curved ventrad distally in lateral view (Fig. 13d). Vertex usually black (Fig. 13a).

13. E. pontifex McAtee

18(15). Aedeagus distal processes only slightly divergent distally in ventral view (Fig. 14e); dorsal carina not reaching apex (Fig. 14d).

14. E. palimpsesta McAtee

18'. Aedeagus distal processes strongly divergent distally in ventral view (Fig. 16e); dorsal carina

reaching apex (Fig. 16d). 
19(18). Aedeagus ventral processes abruptly bent laterad $90^{\circ}$ distally in ventral view (Fig. 15e), sinuate distally in lateral view (Fig. 15d); shaft without distal vestiture.

15. E. beameri Robinson

19'. Aedeagus ventral processes evenly curved distally in ventral view (Fig. 16e), straight or curved ventrally in lateral view (Fig. 16d); shaft with distal vestiture. 20

20(19). Aedeagus ventral processes strongly compressed basally (Figs. 16d, 16e). Forewing with oblique vittae forming continuous zigzag pattern (Fig. 16a).

16. E. reflecta McAtee

20 '. Aedeagus ventral processes only slightly compressed (Figs. 17d, 17e). Forewing with broken oblique vittae (Fig. 17a).

21(11). Forewing with narrow crossband (rarely incomplete) near midlength, apex dark, base pale; mesonotum dark (at least lateral triangles) (Figs. 17a, 20a). 6. E. comes Say

21 '. Color pattern not as above. 22

22(21). Ventral branch of pygofer dorsal appendage much longer than dorsal branch (Fig. 17b). 17. E. integra McAtee

22'. Branches of pygofer dorsal appendage of subequal length (Fig. 18b). 23

23(22). Aedeagus with strong dorsal keel, apex extended well beyond bases of distal processes (Figs. 18d, 18e).

18. E. carinata sp.n.

23'. Aedeagus without dorsal keel, apex extended little if any beyond bases of distal processes (Figs. 20d, 20e).

24(23). Aedeagus ventral processes strongly sinuate in lateral view, with apices curved dorsad (Fig. 19d). 19. E. tricincta Fitch

24'. Aedeagus ventral processes straight or with apices curved ventrad (Fig. 20d). 25

25(24). Aedeagus distal processes more slender, their apices more distal in lateral view (Fig. 20d). 20. E. cymbium McAtee

$25^{\prime}$. Aedeagus distal processes broader, their apices more basal in lateral view (Fig. 21d).

21. E. calycula McAtee

26(21). Third point of style apex subequal to or longer than half distance between other two points (Fig. 22c). 27

26'. Third point of style apex shorter than half distance between other two points (Fig. 32c). .... 34

27(26). Aedeagus distal processes slender (Figs. 22d, 22e). ....................................................... 28

$27^{\prime}$. Aedeagus distal processes broad (Figs. 25d, 25e).

28(27). Aedeagus ventral processes evenly divergent (Fig. 22e).

22. E. vagabunda Knull

28 '. Aedeagus ventral processes parallel to each other on ventral side of aedeagus (Fig. 24e). ... 29

29(28). Shaft of aedeagus straight in lateral view, with dorsal distal lobe (Fig. 23d).

29'. Shaft of aedeagus curved dorsally, without dorsal distal lobe (Fig. 24d).

23. E. aza Robinson

30(27). Aedeagus ventral processes parallel or slightly divergent in ventral view

24. E. glabra sp.n.

(Figs. 25e, 26e). Pronotum usually pale with Y-shaped orange vita medially (Fig. 26a). ........ 31

30 '. Aedeagus ventral processes strongly divergent apically in ventral view

(Figs. 27e, 28e). Pronotum mostly dark brown (Figs. 27a, 28a).

31(30). Apex of aedeagus extended beyond bases of distal processes (Fig. 25e). Mesonotum with black basal triangles (Fig. 25a). 25. E. elegantula Osborn

31'. Apex of aedeagus not extended beyond bases of distal processes (Fig. 26e). Mesonotum without black basal triangles (Fig. 26a). 26. E. acuticephala Robinson 32(30). Aedeagus distal processes each with two sharp points, falcate distally in ventral view

(Figs. 27d, 27e). Lateral margins of pronotum pale contrasting with dark brown medial area (Fig. 27a). 27. E. aclys McAtee

32 '. Aedeagus distal processes each with one sharp point, diamond-shaped in ventral view

(Figs. 28d, 28e). Lateral margins of pronotum usually dark, concolorous with medial area

(Figs. 28a, 29a).

33(32). Scutellum pale. Forewing often with crossbands (Fig. 28a).

33'. Scutellum dark. Forewings without crossbands (Fig. 29a).

28. E. bistrata McAtee 34(26). Dorsum almost completely black (Fig. 30a). 
34'. Ground color of dorsum various, but not black.

35(34). Aedeagus ventral processes strongly divergent apically (Fig. 32e)

$35^{\prime}$. Aedeagus ventral processes not or only slightly divergent apically (Fig. 36e).

36(35). Dorsal branch of pygofer dorsal appendage about half length of ventral branch (Fig. 31b).

Aedeagus distal processes rounded in ventral view (Fig. 31e). Forewings with pale diamond-shaped transcommisural marking outlined with dark brown (Fig. 31a).

31. E. cancellata McAtee

36'. Branches of pygofer dorsal appendage subequal in length (Fig. 32b). Aedeagus distal

processes pointed in ventral view (Fig. 32e). Forewings with broken oblique vitae

(Figs. 32a, 33a).

37(36). Aedeagus ventral processes narrowing distally in lateral view (Fig. 32d). Mesonotum with

black lateral triangles (Fig. 32a).

37'. Aedeagus ventral processes of even width in lateral view (Fig. 33d). Mesonotum without

black triangles (Fig. 33a).

33. E. bakeri sp.n.

38(35). Aedeagus apex extended beyond bases of distal processes (Fig. 36e). ........................................ 39

38'. Aedeagus apex not extended beyond bases of aedeagus distal processes (Fig. 40e). ........................ 44

39(38). Aedeagus compressed, with strong dorsal keel (Fig. 34d). ........................................................ 40

39'. Aedeagus rounded in crossection, dorsal carina if present, feebly developed (Fig. 38d). ................. 42

40(39). Aedeagus ventral processes strongly sinuate in lateral view (Fig. 34d). ...... 34. E. anfracta Beamer

40 '. Aedeagus ventral processes straight in lateral view (Fig. 36d).

41(40). Shaft of aedeagus in ventral view extended more than twice its width beyond bases of

distal processes (Fig. 35e). Forewings with continuous zigzag pattern (Fig. 35a). .... 35. E. ziczac Walsh

41'. Shaft of aedeagus in ventral view not extended more than twice its width beyond bases of distal processes (Fig. 36e). Forewings with crossbands interrupted with red longitudinal veins (Fig. 36a).

36. E. elegans McAtee

42(39). Aedeagus with distal processes slender (Fig. 37d); apex of shaft beyond distal processes slightly broadened (Fig. 37e).

37. E. delicata McAtee

42'. Aedeagus with distal processes flattened (Fig. 38d); apex of shaft beyond distal processes not broadened (Fig. 38e).

43(42). Second point of style apex longer than third (Fig. 38c). Aedeagus ventral processes convergent distally (Fig. 38e).

38. E. vitifex Fitch

43'. Second point of style apex shorter than third (Fig. 39c). Aedeagus ventral processes divergent distally (Fig. 39e).

39. E. rubra Gillette

44(38). Second point of style apex longer than third (Fig. 40c). Forewing mostly dark with two pale narrow crossbands, sometimes interrupted with red longitudinal veins (Fig. 40a).

40. E. vitis Harris

44'. Second point of style apex as short or shorter than third (Fig. 42c). Forewing without crossbands (Figs. 41a, 42a).

45(44). Aedeagus distal processes broadened distally in ventral view (Fig. 41e). Mesonotum with black lateral triangles. Forewing with broken oblique vittae (Fig. 41a) 41. E. coloradensis Gillette

45'. Aedeagus distal processes diamond-shaped in ventral view (Fig. 42e). Mesonotum with red lateral triangles. Forewing with continuous zigzag pattern (Fig. 42a).

42. E. fraxa Robinson

46(5). Aedeagus with dorsal processes placed on phallobase or between phallobase and shaft of aedeagus (Figs. 43d, 45d).

46'. Aedeagus without dorsal processes (Fig. 46d).

47(46). Aedeagus with unpaired small dorsal process on phallobase (Fig. 43d).

43. E. vaga Johnson

$47^{\prime}$. Aedeagus with pair of long dorsal processes between aedeagus shaft and phallobase

(Figs. 45d, 45e).

48(47). Third point of style apex longer than distance between other two points (Fig. 44c).

Aedeagus distal processes shorter (Figs. 44d, 44e).

44. E. kerzhneri sp.n.

48'. Third point of style apex shorter than distance between other two points (Fig. 45c). Aedeagus distal processes longer (Figs. 45d, 45e).

45. E. kennedyi Knull

49(46). Aedeagus ventral processes placed close to shaft (Fig. 46d). Dorsal branch of pygofer dorsal appendage subequal to ventral branch (Fig. 46b).

46. E. ancora Beamer 
49'. Aedeagus ventral processes well separated from shaft (Fig. 47d). Dorsal branch of pygofer dorsal appendage much shorter than ventral branch (Fig. 47b).

50(49). Aedeagus ventral processes divergent (Fig. 47e). 47. E. tacita Beamer

50 '. Aedeagus ventral processes parallel to each other (Fig. 48e).

51(50). Branches of pygofer dorsal appendages convergent distally in lateral view, ventral branch distally slightly curved upward (Fig. 48b). Aedeagus in ventral view broadened preapically (Fig. 48e).

48. E. caetra McAtee

51'. Branches of pygofer dorsal appendages strongly divergent in lateral view (Fig. 49b). Aedeagus in ventral view not broadened preapically (Fig. 49e).

49. E. rosa Robinson

52(4). Aedeagus with pair of large distal processes and pair of smaller preapical processes (Figs. 50d, 50e). Pygofer dorsal appendages short (Fig. 50b). 50. E. omaska Robinson

52'. Aedeagus without distal and preapical processes (Figs. 52d, 52e). Pygofer dorsal appendage long (Fig. 52b, 53b).

53(52). Aedeagus broad in ventral view, with strong dorsal keel (Figs. 51d, 51e).

53'. Aedeagus slender in ventral view, without dorsal keel, with dorsal distal lobe

(Figs. 52d, 52e).

51. E. rubrella McAtee

54(53). Dorsal branch of pygofer dorsal appendage subequal to ventral branch (Fig. 52b).

52. E corni Robinson

54'. Dorsal branch of pygofer dorsal appendage much shorter than ventral branch (Fig. 53b). ... 55 55(54). Ventral branch of pygofer dorsal process sinuate in lateral view (Fig. 53b).

Larger (2.8-3.2 mm).

53. E. bidens McAtee

$55^{\prime}$. Ventral branch of pygofer dorsal process evenly curved upward (Fig. 54b). Smaller $(2.5-2.8 \mathrm{~mm})$. 


\section{Erythroneura kanwakae Robinson, 1924 (Fig. 1)}

Erythroneura kanwakae Robinson, 1924c:292

Description. Length 2.9-3.1 mm. 2S abdominal apodemes large, broad, reach $3 \mathrm{~S}$ posterior margin. Pygofer lobe angulate apically; dorsal appendages three-pointed (ventral branch bifurcated), extended beyond pygofer apex. Second point of style apex well developed, third point shorter than second. Aedeagus with preat-

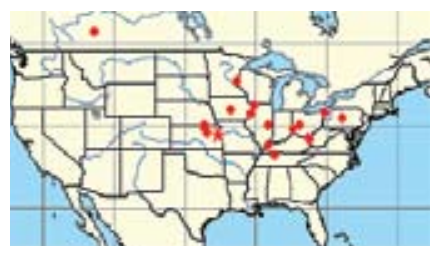
rium longer than shaft; shaft curved dorsally, slender in lateral view, depressed in crossection; apex broadened in ventral view, with distinct apical spicules; ventral processes placed basally, well separated from shaft, longer than shaft, divergent at apex; distal processes apical, flattened, directed dorsad. Dorsum yellow or white, with red or brownish color pattern; vertex with orange parallel submedial lines (often with lateral branch), midline pale; anteclypeus pale, concolorous with rest of face; pronotum with Y-shaped medial vitta; mesonotum entirely pale; thoracic venter with dark mesosternum, remainder pale; forewing with oblique vittae forming continuous zigzag pattern; clavus with separate basal and distal vittae; dark spots at costal margin; apical cell II without distal spot; inner apical cell without brown spot.

Type locality: Holotype $\widehat{o}$, USA, Kansas, Douglas Co., IV 1924, (Robinson), (KSEM).

Distribution: Central and northeastern USA, southern Canada.

Host plants: Ribes hirtellum.
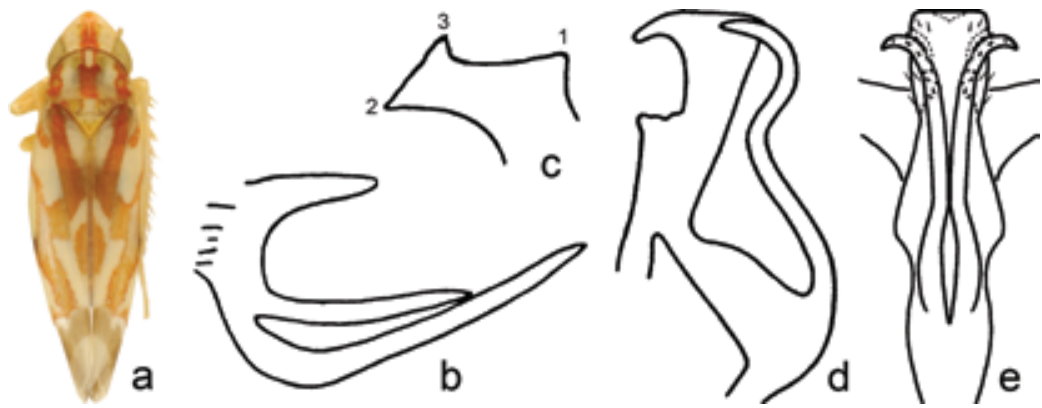

Figure 1. E. kanwakae Robinson. b, d - from Beamer 1938; c - from Hepner, unpublished.

2. Erythroneura fiduciaria Knull, 1951 (Fig. 2)

Erythroneura fiduciaria Knull, 1951a:170

Description: Length $3.3-3.7 \mathrm{~mm}$. $2 \mathrm{~S}$ abdominal apodemes small, narrow, extended dorsomesad. Pygofer lobe angulate; dorsal appendages three-pointed (ventral branch bifurcated), extended beyond pygofer apex. Second point of style apex longer than third, third point very short. Aedeagus with preatrium longer than shaft; shaft curved dorsally, slender in lateral view, round in crossection; with ventral processes placed basally, well separated from shaft, longer than shaft, divergent at apex, bifurcated, with lateral branch longer than medial one; distal

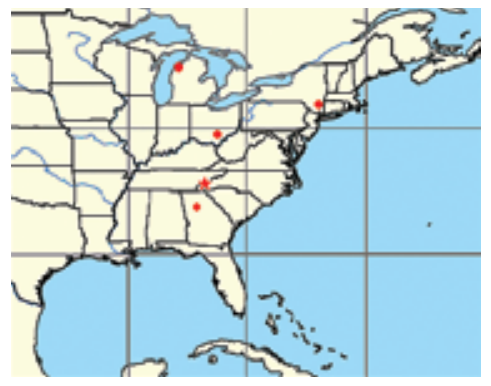
processes apical, triangular. Dorsum yellow or white, with reddish-brown color pattern; vertex with orange parallel submedial lines with lateral branch, midline pale; anteclypeus pale, concolorous with rest of face; pronotum with Y-shaped medial vitta; mesonotum entirely pale; thoracic venter with dark mesosternum, remainder pale; forewing with oblique vittae forming continuous zigzag pattern; clavus with separate basal and distal vittae; dark spot at costal margin; apical cell II without distal spot; inner apical cell without brown spot. Type locality: Holotype + , USA, Tennessee, Sevier Co., Great Smoky Mountain National Park, 21 VI 1942 (Knull), (OSU). 
Distribution: Eastern USA.

Host plants: Hamamelis virginiana, H. macrophylla.
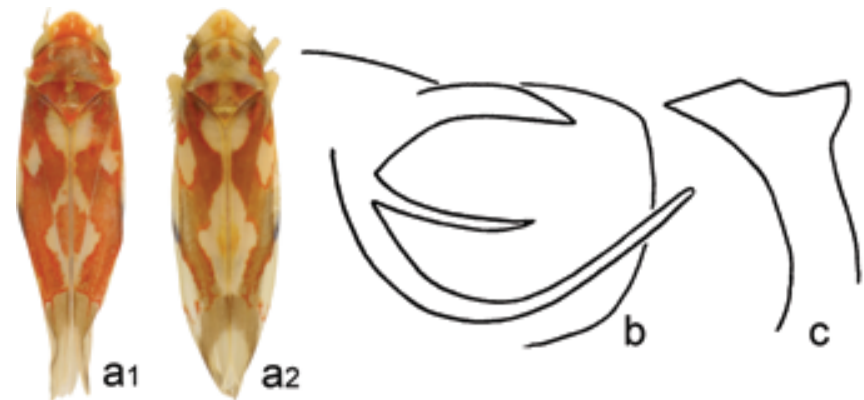

a2
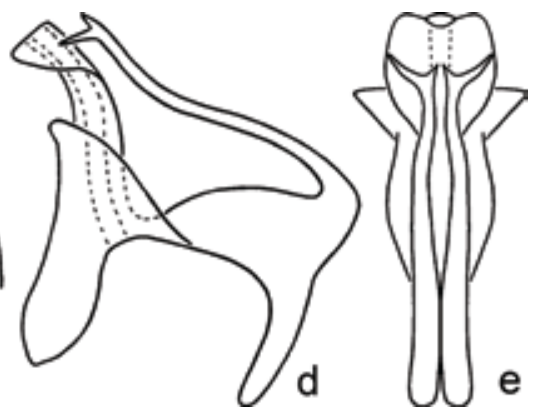

Figure 2. E. fiduciaria Knull. a1 - holotype; a2 - color variation.

\section{Erythroneura prima Beamer, 1938 (Fig. 3)}

Erythroneura prima Beamer, 1938:264

Erythroneura maritima Hamilton, 1987 in Hamilton \& Langor, 1987:679 syn.n.

Description: Length $2.7-3 \mathrm{~mm}$. $2 \mathrm{~S}$ abdominal apodemes small, narrow, extended dorsomesad. Pygofer lobe rounded, dorsal appendages 3 pointed (ventral branch bifurcated), extended beyond pygofer apex. Second point of style apex longer than third; third point very short. Aedeagus with preatrium longer than shaft; shaft curved dorsally, slender in

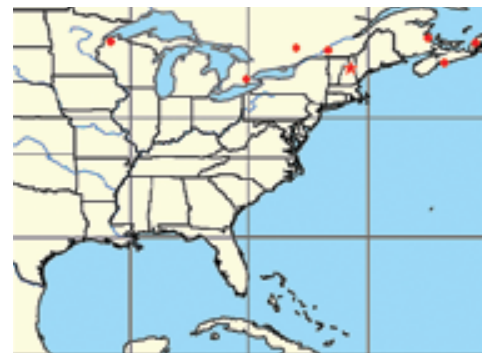
lateral view, round in crossection; ventral processes placed basally, well separated from shaft, longer than shaft, divergent at apex, with small preapical tooth; distal processes apical, triangular. Dorsum yellow or white, with reddish or brownish color pattern; vertex with orange parallel submedial lines (often with lateral branch), midline pale; anteclypeus brown; pronotum almost entirely dark; mesonotum pale, with dark lateral triangles; thoracic venter entirely dark; forewings with oblique vittae forming continuous zigzag pattern; clavus largely or entirely bright red or brownish; dark spot at costal margin; apical cell II without distal spot; inner apical cell without brown spot.

Type locality: Holotype ơ, USA, New Hampshire, Coos Co., Bretton Woods, 31 VIII 1934 (Beamer), (KSEM).

Distribution: North-central and northeastern USA, southeastern Canada.

Host plants: Unknown.
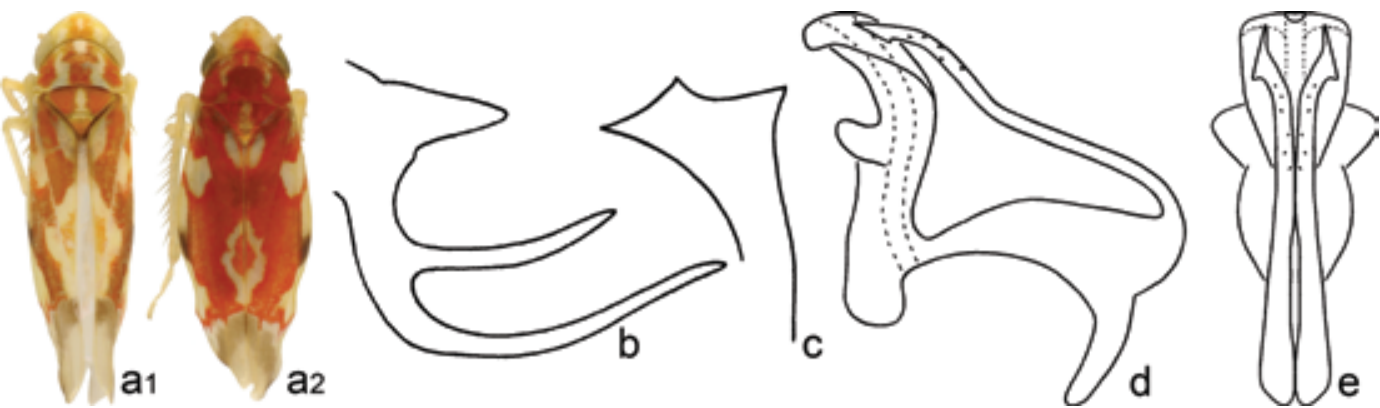

Figure 3. E. prima Beamer. a2 - var. maritima. b - from Beamer 1938. 
4. Erythroneura diva McAtee, 1920 (Fig. 4)

Erythroneura tricincta var. diva McAtee, 1920:308

Erythroneura tricincta var. rubravitta Robinson, 1924b:156

Erythroneura tricincta var. complementa McAtee, 1926:135 syn.n.

Erythroneura diva Beamer, 1938:269

Description: Length 3-3.2 mm. 2S abdominal apodemes small, narrow, extended dorsomesad. Pygofer lobe rounded; dorsal appendage not extended beyond pygofer apex, C-shaped, branches of subequal length. Second point of style apex longer than third;

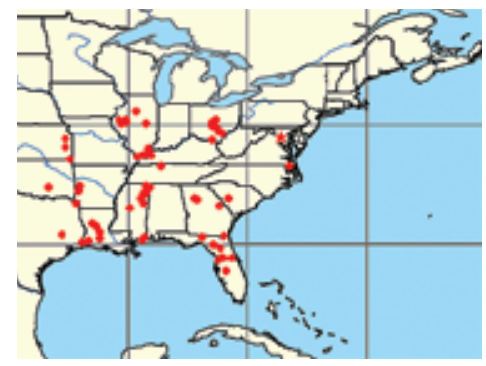
third point short; angle between basal and third points about $90^{\circ}$. Aedeagus with preatrium about as long as shaft; shaft curved dorsally, broad in lateral view, round in crossection, with dorsal carina, and distinct apical spicules; ventral processes placed basally, well separated from shaft, longer than shaft, parallel to each other on ventral side of aedeagus, with small preapical tooth; distal processes subapical, triangular. Dorsum yellow or white; anteclypeus pale, concolorous with rest of face; pronotum almost entirely red; coloration of mesonotum vary from entirely pale to dark, scutellum pale; thoracic venter entirely pale; forewing without (rarely with) oblique vittae, with red narrow crossband near midlength and darkened apex; dark spot at costal margin; apical cell II without distal spot; inner apical cell without brown spot.

Type locality: Holotype $\uparrow$, USA, Maryland, Montgomery Co., Plummers Island, 26 VII 1914 (McAtee), (USNM).

Distribution: Central and eastern USA.

Host plants: Vitis spp.
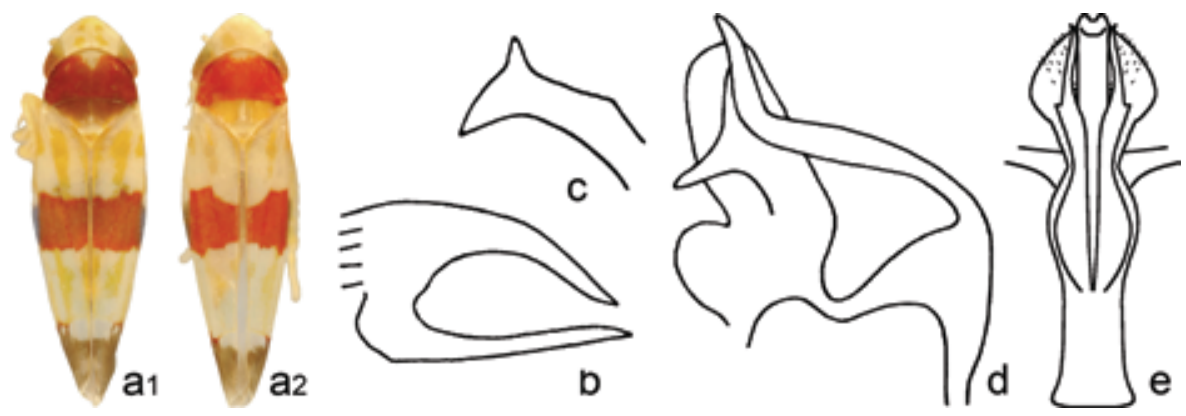

Figure 4. E. diva McAtee. a2 - var. complementa. b-d - from Beamer 1938.

\section{Erythroneura browni Dmitriev \& Dietrich sp.n. (Fig. 5)}

Description: Length $2.7-3 \mathrm{~mm}$. $2 \mathrm{~S}$ abdominal apodemes small, narrow, extended dorsomesad. Pygofer lobe rounded; dorsal appendage not extended beyond pygofer apex, Cshaped, branches subequal in size. Second point of style apex very short, tooth like; third point elongate, longer than distance between other two points; angle between basal and third points less than $90^{\circ}$. Aedeagus with preatrium about as long as shaft; shaft straight and slender in lateral view, denticulate distally, round in crossection, strongly extended beyond bases

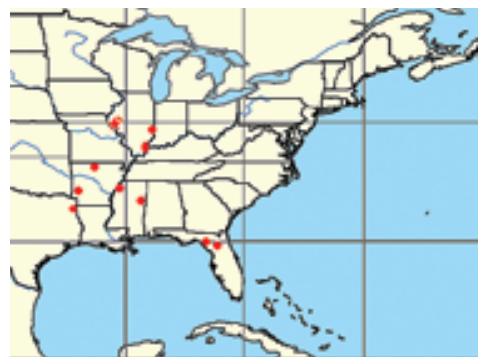
of distal processes, often with distal lobe strongly varying in length; apex truncate in posterior view, with distinct apical spicules; ventral processes placed basally, well separated from shaft, longer than shaft, divergent at apex, often with small tooth near midlength; distal processes long, flattened, triangular. Coloration similar to that of E. comes Say. Dorsum yellow or white with orange color pattern; vertex with orange parallel submedial lines with lateral branch, midline pale; anteclypeus pale, concolorous with rest of face; pronotum with 
Y- shaped medial vitta; mesonotum entirely pale; thoracic venter entirely pale; forewing with broken oblique vittae; clavus with separate basal and distal vittae; dark spot at costal margin; apical cell II with distal spot; inner apical cell with brown spot basally.

Diagnosis: E. browni sp.n. is similar to E. comes Say, but shaft of aedeagus extends well beyond the bases of the distal processes and is denticulate. It is also similar to E. ortha sp.n., but the aedeagus lacks a dorsal keel and has the ventral processes divergent apically.

Type locality: Holotype ${ }^{\uparrow}$, USA, Illinois, Brown Co., Siloam Springs, 19 IV 1960 (Ross \& Cunningham), (INHS).

Studied material: Paratypes: 1 o, Arkansas, Marion Co., Yellville, 23 VIII 1962 (Hepner), (MEM); 4 ô, Florida, Alachua Co., Gainesville, 30 VI-2 X 1970-1972 (Mead); 1 o, Florida, Lafayette Co., on Vitis sp., 1 VIII 1956 (Mead); 5 oे, Illinois, Brown Co., Siloam Springs, (Ross \& Cunningham); 8 ô, Illinois, Brown Co., Siloam Springs, 29 IV 1960 (Ross \& Cunningham); 1 t, Mississippi, Oktibbeha Co., State College, 4 III 1968 (Hepner), (MEM); 1 đ Texas, Marion Co., Jefferson, 3 VII 1962 (Hepner), (MEM); other studied material from Illinois, Arkansas, Mississippi excluded from type series.

Distribution: Central and southeastern USA.

Host plants: Vitis spp.

Note: This species is named in honor of Prof. Richard L. Brown, Director of the Mississippi Entomological Museum, who graciously loaned us the museum's entire Erythroneura collection and provided access to Leon Hepner's unpublished manuscripts, rearing records, notes, and illustrations.
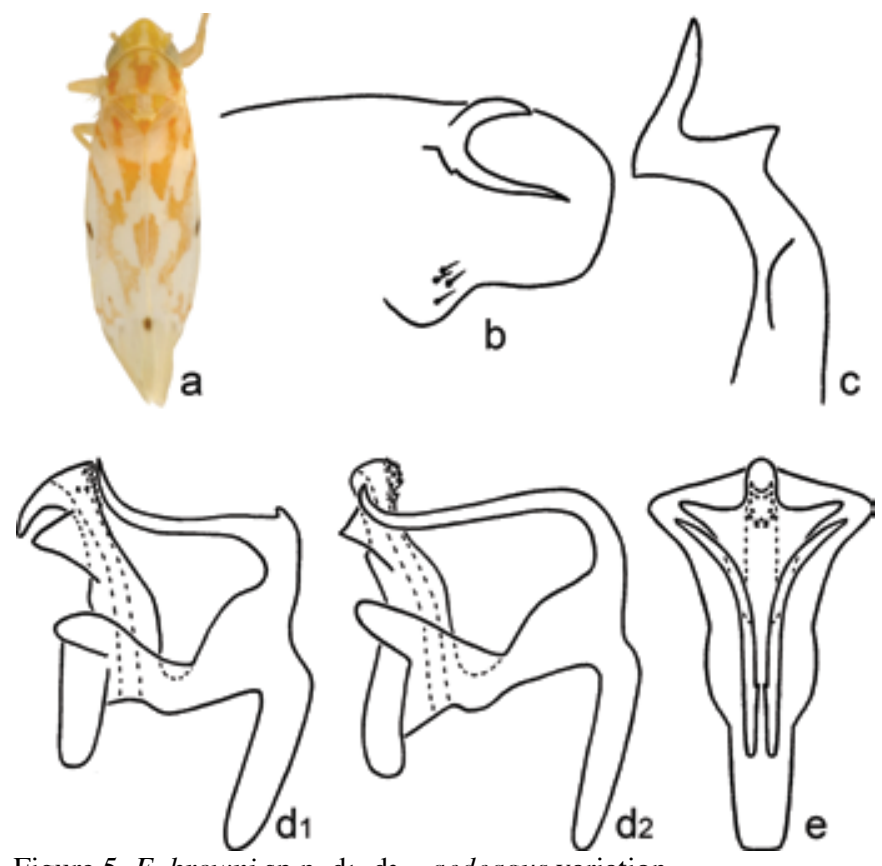

Figure 5. E. browni sp.n. d1, d2 - aedeagus variation. 
6. Erythroneura comes (Say, 1825) (Fig. 6)

Tettigonia comes Say, 1825:343

Erythroneura comes Smith, 1890:447

Typhlocyba comes comes Gillette, 1898:764

Erythroneura comes Beamer, 1938:292, neotype designation

Eastern grape leafhopper

Description: Length $2.7-3 \mathrm{~mm}$. 2S abdominal apodemes large,

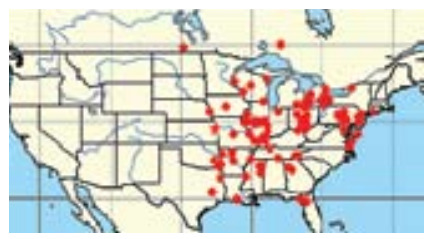

broad, reach $3 \mathrm{~S}$ posterior margin. Pygofer lobe rounded; dorsal appendages not extended beyond pygofer apex, C-shaped, branches of subequal length. Second point of style apex very short, tooth like; third point elongate, longer than distance between other two points; angle between basal and third points less than $90^{\circ}$. Aedeagus with preatrium longer than shaft; shaft curved dorsally, broad in lateral view; round in crossection; with dorsal carina, with distinct apical spicules; ventral processes placed basally, well separated from shaft, longer than shaft; divergent at apex, often with small tooth near midlength; distal processes apical, triangular. Dorsum yellow or white with orange color pattern; vertex with orange parallel submedial lines with lateral branch, midline pale; anteclypeus pale, concolorous with rest of face; pronotum with Y- or V-shaped medial vitta; mesonotum entirely pale; thoracic venter entirely pale; forewing with broken oblique vittae; clavus with separate basal and distal vittae; dark spot at costal margin; apical cell II with distal spot; inner apical cell with brown spot basally.

Type locality: Neotype ${ }^{\star}$, USA, Kansas, Leavenworth Co., 11 IV 1930 (Beamer), (KSEM).

Distribution: Central and eastern USA, southeastern Canada.

Host plants: Vitis spp.
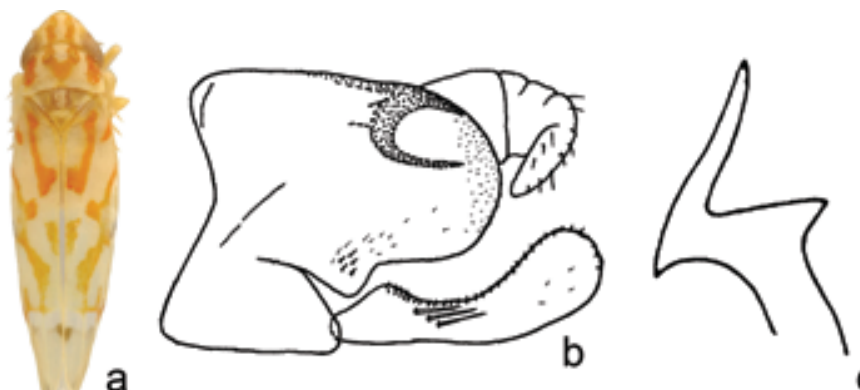

a
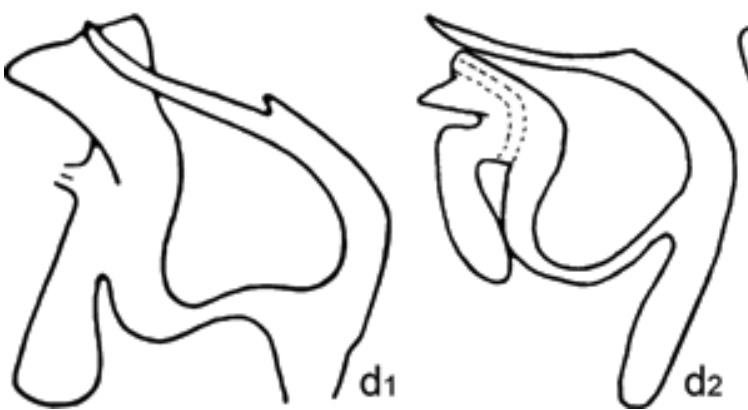

C

Figure 6. E. comes Say. c, d 1 -from Beamer 1938; b - from Dietrich \& Dmitriev 2006; $\mathrm{d}_{2}-$ from Hepner, unpublished. 
7. Erythroneura octonotata Walsh, 1862 (Fig. 7)

Erythroneura octo-notata Walsh, 1862:149

Erythroneura comes var. compta McAtee, 1920:318 syn.n.

Erythroneura octolineata Lawson, 1922:336 missp.

Erythroneura cherokee Robinson, 1924b:154 syn.n.

Erythroneura compta var. rufomaculata McAtee, 1924c:43 syn.n.

Erythroneura nigroscuta Johnson, 1934: 258 syn.n.

Erythroneura rufromaculata Oman, 1949:95 missp.

Description: Length $2.6-2.9 \mathrm{~mm}$. $2 \mathrm{~S}$ abdominal apodemes

large, broad, reach $3 \mathrm{~S}$ posterior margin. Pygofer lobe rounded;

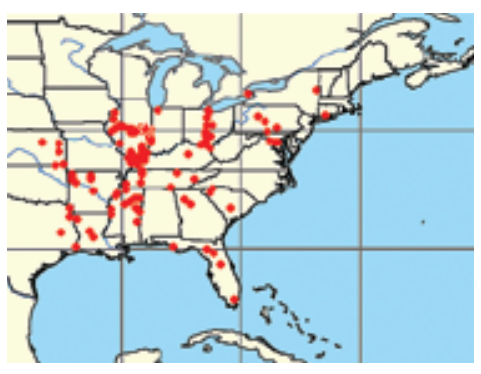
dorsal appendages not extended beyond pygofer apex, Cshaped, branches of subequal length. Second point of style apex very short, tooth like; third point elongate, longer than distance between other two points; angle between basal and third point of style less than $90^{\circ}$. Aedeagus with preatrium longer than shaft; shaft stright and broad in lateral view, round in crossection, with dorsal carina, with distinct apical spicules; ventral processes placed basally, well separated from shaft, longer than shaft, bifurcated close to base; distal processes subapical, triangular. Dorsum yellow or white, with orange color pattern; coloration strongly varies; vertex unicolorous or with orange parallel submedial lines, midline pale; anteclypeus pale, concolorous with rest of face; pronotum with Y- or V-shaped medial vitta; mesonotum pale, usually with dark brown medial spot; thoracic venter entirely pale; forewing without oblique vittae or with broken oblique vittae; clavus with separate basal and distal vittae and dark brown spot near midlength, sometimes basal vitta bright red; dark spot at costal margin; apical cell II with distal spot; inner apical cell with brown spot basally.

Type locality: Neotype $\widehat{\delta}$, USA, Illinois, Champaign Co., St. Joseph, 3 IX 1916, (INHS) - here designated.

Distribution: Central and eastern USA.

Host plants: Vitis spp.

Note: The holotype, along with the rest of Walsh's collection, was destroyed in the Chicago fire of 1871. A neotype is here designated to fix the identity of the species.
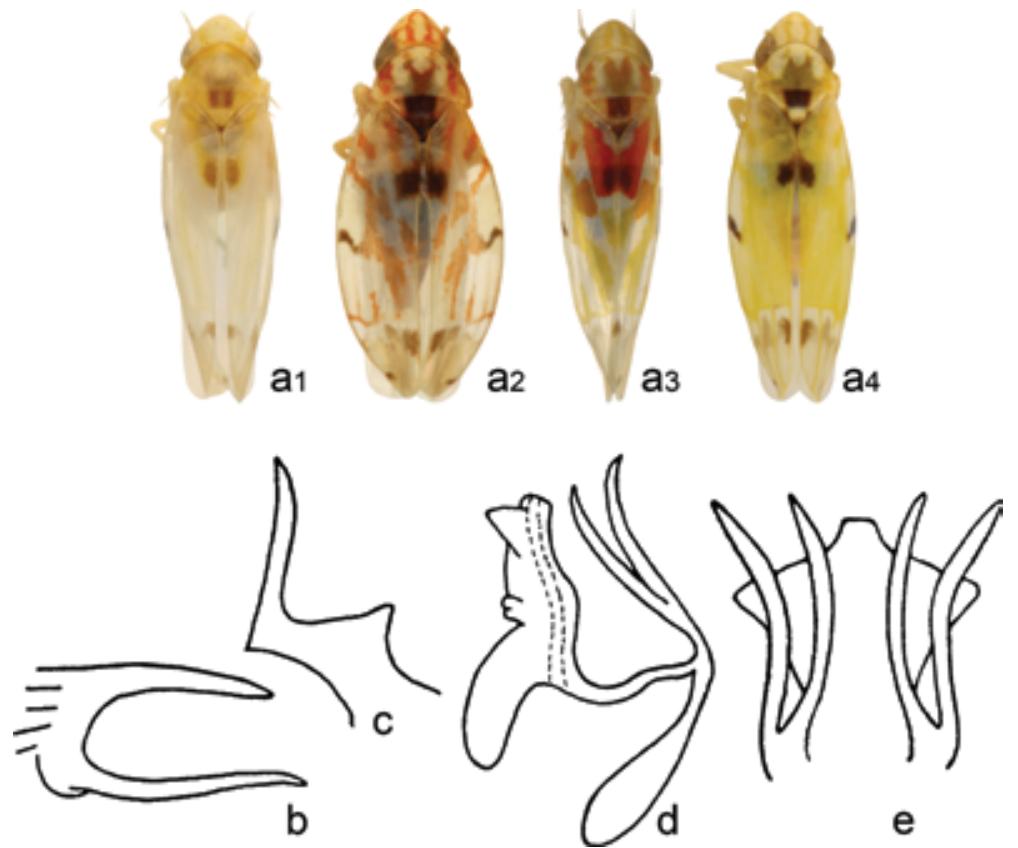

Figure 7. E. octonotata Walsh. a2 - var. compta; a3 - var. rufomaculata; a4 - var. nigroscuta. b, e -from Beamer 1938; c, d - from Hepner, unpublished. 
8. Erythroneura amanda McAtee, 1920 (Fig. 8)

Erythroneura comes var. amanda McAtee, 1920:319

Erythroneura amanda Robinson, 1926:137

Description: Length $2.4-2.6 \mathrm{~mm}$. 2S abdominal apodemes large, broad, reach $3 \mathrm{~S}$ posterior margin. Pygofer lobe rounded; dorsal appendages not extended beyond pygofer apex, C-shaped, branches of subequal length. Second point of style apex very short, tooth like; third point elongate, about as long or longer than distance between other two points; angle between basal and third points less

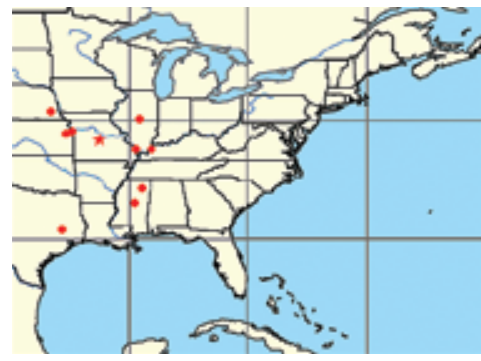
than $90^{\circ}$. Aedeagus with preatrium longer than shaft; shaft straight and broad in lateral view, compressed in crossection, with dorsal carina; ventral processes placed basally, well separated from shaft, longer than shaft, bifurcate near midlength, divergent at apex; distal processes subapical, triangular. Dorsum yellow or white; color pattern red and orange; vertex with orange parallel submedial lines, midline pale; anteclypeus pale, concolorous with rest of face; pronotum with Y-shaped medial vitta; mesonotum almost entirely dark; thoracic venter entirely pale; forewing with broken oblique vittae and wide red crossband at base; dark spot at costal margin; apical cell II with distal spot; inner apical cell with brown spot basally.

Type locality: Holotype $\widehat{0}$, USA, Missouri, VII, on Vitis spp., (USNM).

Distribution: Central and southeastern USA.

Host plants: Vitis spp.

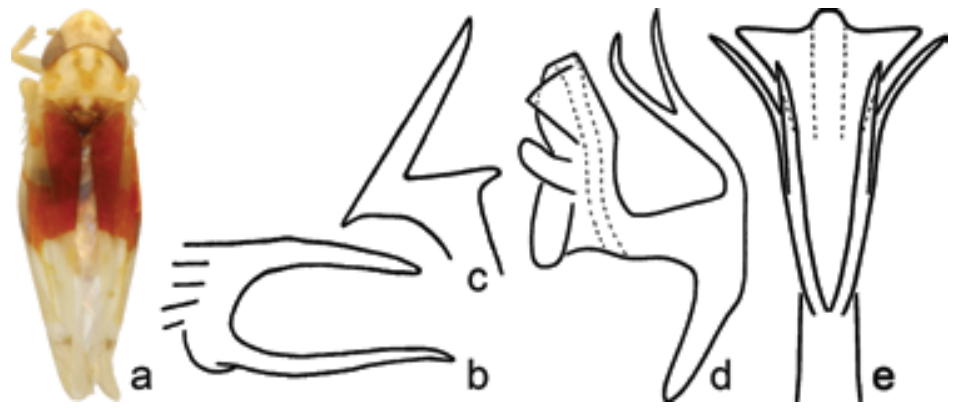

Figure 8. E. amanda McAtee. b, c - from Beamer 1938.

9. Erythroneura nudata McAtee, 1920 (Fig. 9)

Erythroneura comes var. nudata McAtee, 1920:316

Erythroneura attenuata Johnson, 1934:260

Erythroneura nudata Beamer 1938:284

Description: Length $2.8-3.1 \mathrm{~mm}$. $2 \mathrm{~S}$ abdominal apodemes small, narrow, extended dorsomesad. Pygofer lobe rounded; dorsal appendages not extended beyond pygofer apex, Cshaped, branches of subequal length. Second point of style apex very short, tooth like; third point elongate, longer than distance between other two points; angle between basal and third points less than $90^{\circ}$. Aedeagus with preatrium longer than shaft; shaft straight and broad in lateral view, depressed in crossection, with distinct apical spicules; ventral processes placed basally, well separated from shaft, longer than shaft, parallel to each other on ventral side of aedeagus; distal processes apical or subapical, triangular. Coloration similar to that of E. comes Say.

Type locality: Holotype $\widehat{~}$, USA, Maryland, Anne Arundel Co., Odenton, 26 VII 1914 (McAtee), (USNM).

Distribution: Central and eastern USA, southeastern Canada.

Host plants: Vitis spp.

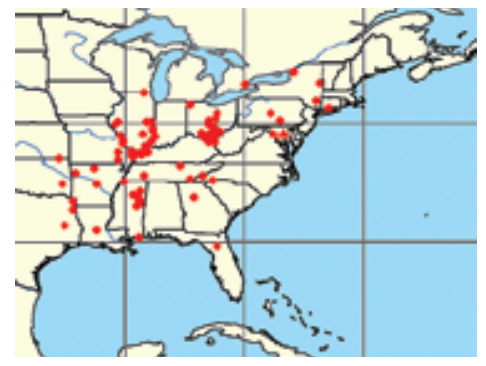




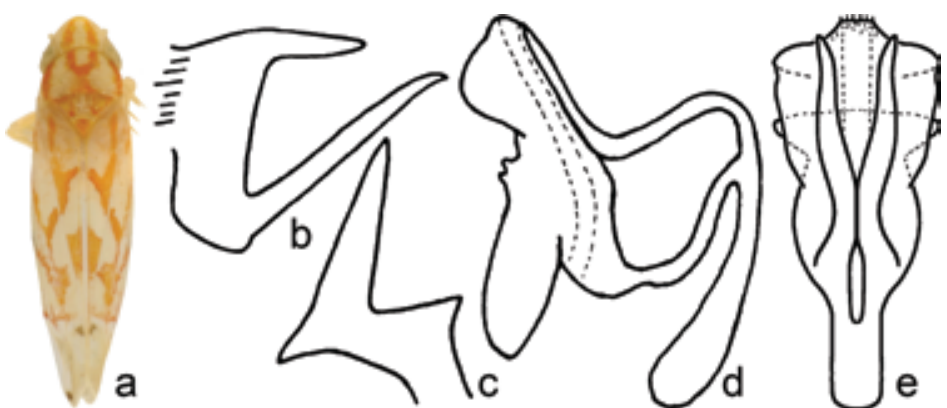

Figure 9. E. nudata McAtee. b, c - from Beamer 1938; d - from Hepner, unpublished.

10. Erythroneura ortha Dmitriev \& Dietrich sp.n. (Fig. 10) Description: Length $2.8-3 \mathrm{~mm}$. $2 \mathrm{~S}$ abdominal apodemes small, narrow, extended dorsomesad. Pygofer lobe rounded; dorsal appendages not extended to pygofer apex, C-shaped, branches of subequal size. Second point of style apex very short, tooth like; third point elongate, longer than distance between other two points; angle between basal and third points less than $90^{\circ}$. Aedeagus with preatrium about as long as shaft; shaft curved dorsally, broad in lateral view, compressed in crossection, with dorsal carina and distinct apical spicules;

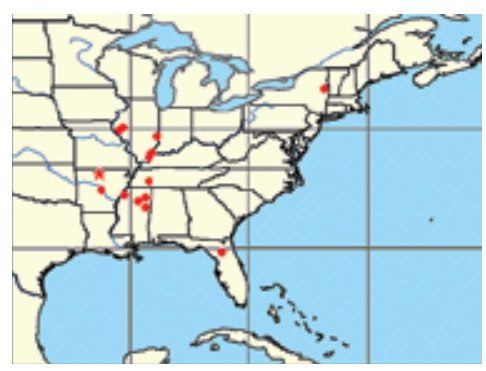
ventral processes placed basally, well separated from shaft, longer than shaft, parallel to each other on ventral side of aedeagus; distal processes subapical, flattened, triangular. Coloration similar to that of E. comes Say; dorsum yellow or white with orange color pattern; vertex with orange parallel submedial lines (often with lateral branch), midline pale; anteclypeus pale, concolorous with rest of face; pronotum with Y- or V-shaped medial vitta; mesonotum entirely pale; thoracic venter entirely pale; forewing with broken oblique vittae; clavus with separate basal and distal vittae; dark spot at costal margin; apical cell II with distal spot; inner apical cell with brown spot basally.

Diagnosis: E. ortha sp.n. is similar to E. comes Say and E. gilensis Beamer, but the shaft of the aedeagus is produced well beyond the bases of the distal processes; and the ventral processes are parallel to each other on the ventral side of the aedeagus. It also differs from E. comes Say in having the shaft of aedeagus compressed with a strong dorsal keel.

Type locality: Holotype ô, USA, Arkansas, Marion Co., Yellville, on Cercis canadensis, 23 VIII 1962 (Hepner), (INHS).

Studied material: Paratypes: 28 ô, Arkansas, Marion Co., Yellville, on Cornus sp., Cercis canadensis, Acer sp., Vitis sp., 23 VIII 1962 (Hepner) (MEM). Other studied material from Florida, Illinois, Mississippi, New York, and Tennessee excluded from type series.

Distribution: Central and eastern USA.

Host plants: Vitis spp.

Note: The species name "ortha," meaning "straight," refers to the straight and parallel ventral processes of the aedeagus.
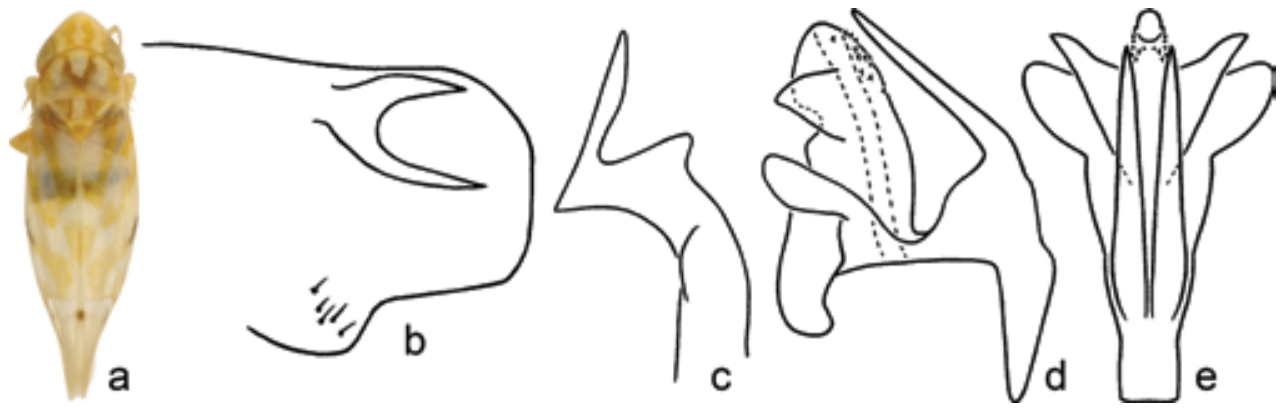

Figure 10. E. ortha sp.n. 
11. Erythroneura festiva Beamer, 1938 (Fig. 11)

Erythroneura festiva Beamer, 1938:290

Description: Length $2.6-2.7 \mathrm{~mm}$. $2 \mathrm{~S}$ abdominal apodemes small, narrow, extended dorsomesad. Pygofer lobe rounded; dorsal appendages not extended beyond pygofer apex, Cshaped, branches of subequal size. Second point of style apex well developed; third point elongate, longer than distance between other two points; angle between basal and third points less than $90^{\circ}$. Aedeagus with preatrium longer than shaft; shaft curved dorsally, broad in lateral view, round in crossec-

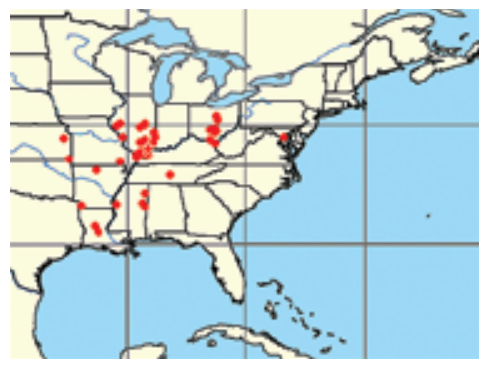
tion, with dorsal carina; ventral processes placed basally, well separated from shaft, longer than shaft, parallel to each other on ventral side of aedeagus; distal processes subapical, triangular. Dorsum yellow or white with orange color pattern; vertex with orange parallel submedial lines with lateral branch, midline pale; anteclypeus brown; pronotum with Y- or V-shaped medial vitta; mesonotum pale, with red lateral triangles; thoracic venter entirely dark; forewing with broken oblique vittae; clavus with separate basal and distal vittae; dark spot at costal margin; apical cell II with distal spot; inner apical cell with brown spot basally.

Type locality: Holotype ô, USA, Illinois, White Co., 31 III 1929 (Beamer), (KSEM).

Distribution: Central and eastern USA.

Host plants: Vitis spp.

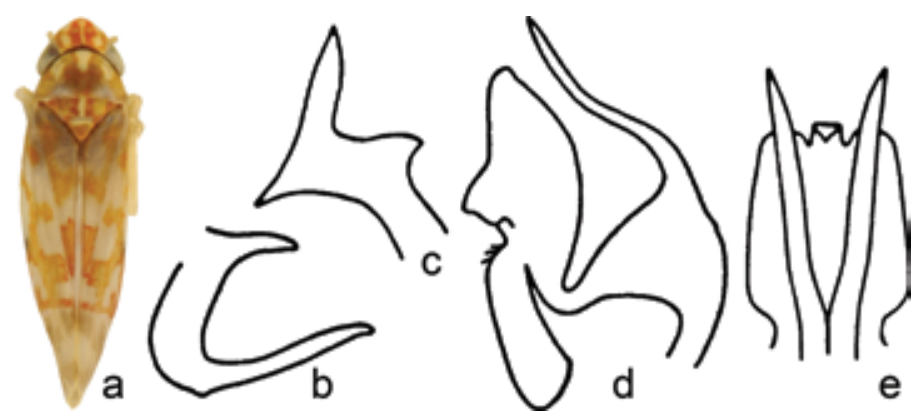

Figure 11. E. festiva Beamer. b-e - from Beamer 1938.

12. Erythroneura gilensis Beamer, 1929 (Fig. 12)

Erythroneura gilensis Beamer, 1929:123

Description: Length $3.2-3.4 \mathrm{~mm}$. 2S abdominal apodemes large, broad, reach $3 \mathrm{~S}$ posterior margin. Pygofer lobe rounded; pygofer dorsal appendages not extended beyond pygofer apex, C-shaped, branches subequal in length. Second point of style apex very short, tooth like; third point elongate, longer than distance between other two points; angle between basal and third points less than $90^{\circ}$. Aedeagus with preatrium longer than shaft; shaft curved dorsally, broad in lateral view,

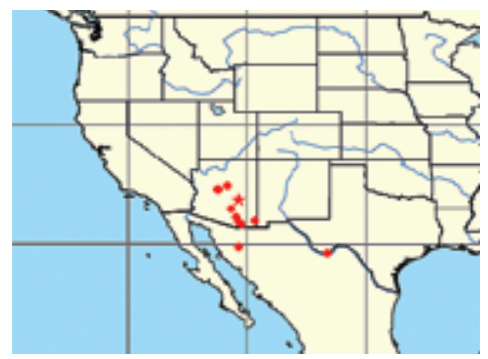
round in crossection, with dorsal carina; ventral processes placed basally, well separated from shaft, longer than shaft, divergent at apex; distal processes subapical, triangular. Coloration similar to that of E. comes Say.

Type locality: Holotype $\delta$, USA, Arizona, Gila Co., 5 VIII 1927 (Beamer), (KSEM).

Distribution: Southwestern USA, northern Mexico.

Host plants: Vitis arizonica. 


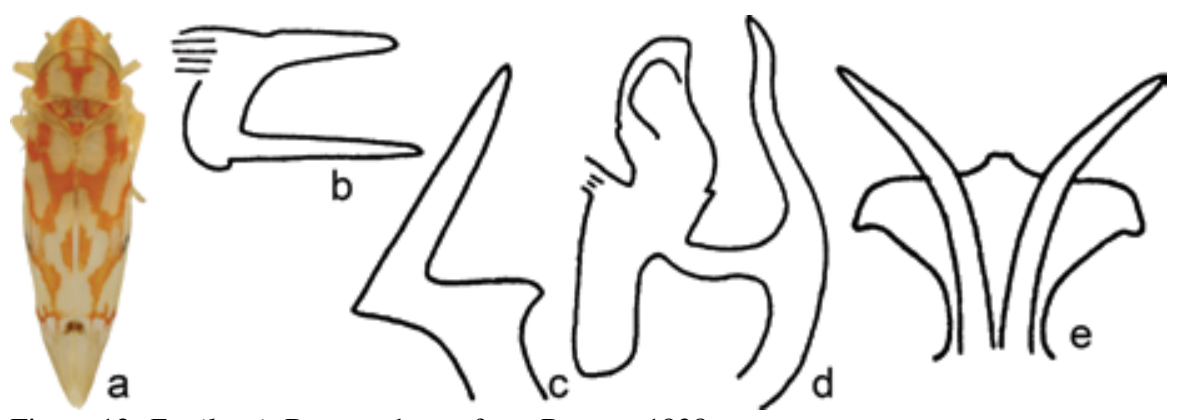

Figure 12. E. gilensis Beamer. b-e - from Beamer 1938.

\section{Erythroneura pontifex McAtee, 1926 (Fig. 13)}

Erythroneura comes var. pontifex McAtee, 1926:136

Erythroneura breakeyi Johnson, 1934:261

Erythroneura pontifex Beamer, 1938:279

Description: Length $2.8-3.1 \mathrm{~mm}$. $2 \mathrm{~S}$ abdominal apodemes small, narrow, extended dorsomesad. Pygofer lobe rounded; pygofer dorsal appendages not extended beyond pygofer apex, C-shaped, with branches subequal in length. Second point of style apex very short, tooth like; third point elongate, longer than distance between other two points; angle between

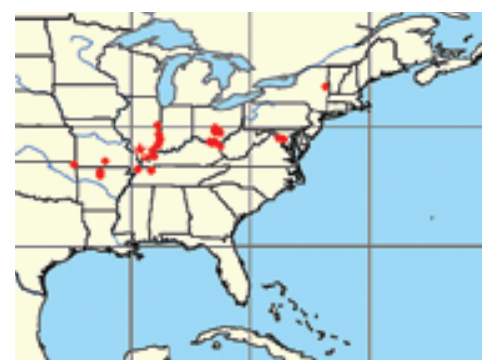
basal and third points less than $90^{\circ}$. Aedeagus with preatrium about as long as shaft; shaft curved dorsally, broad in lateral view, round in crossection; ventral processes placed basally, well separated from shaft, longer than shaft, divergent at apex; distal processes subapical, triangular. Dorsum yellow or white, with reddish or brownish color pattern; vertex with large black area, midline pale; anteclypeus pale, concolorous with rest of face; pronotum with Y- or V-shaped medial vitta; mesonotum pale, with red lateral triangles; thoracic venter with dark mesosternum, remainder pale; forewing with oblique vittae forming continuous zigzag pattern; clavus with separate basal and distal vittae; dark spot at costal margin; apical cell II with distal spot; inner apical cell without brown spot.

Type locality: Holotype + , USA, Illinois, Washington Co., Du Bois, 24 V 1917 (McAtee), (INHS).

Distribution: Central and northeastern USA.

Host plants: Vitis spp.
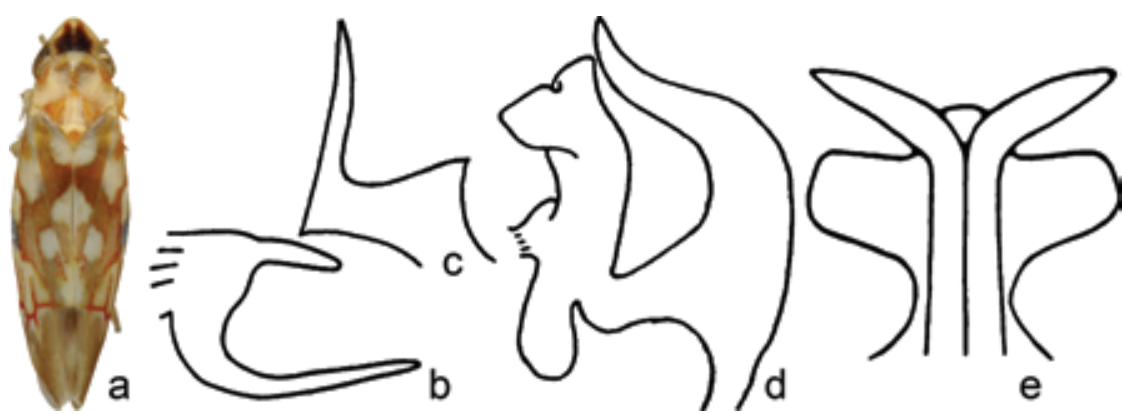

Figure 13. E. pontifex McAtee. b, d, e -from Beamer 1938; c - from Hepner, unpublished. 
14. Erythroneura palimpsesta McAtee, 1924 (Fig. 14, Plate 1a) Erythroneura comes var. palimpsesta McAtee, 1924c:43 Erythroneura palimpsesta Johnson, 1935:107

Description: Length $2.8-3 \mathrm{~mm}$. $2 \mathrm{~S}$ abdominal apodemes large, broad, reach $3 \mathrm{~S}$ posterior margin. Pygofer lobe rounded; dorsal appendages not extended beyond pygofer apex, C-shaped, with branches subequal in length. Second point of style apex very short, tooth like; third point elongate, longer than distance between other two points; angle between basal and third points less than $90^{\circ}$. Aedeagus with preatrium

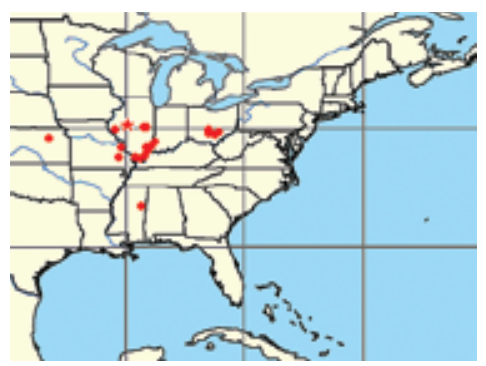
longer than shaft; shaft curved dorsally, broad in lateral view, round in crossection, with dorsal carina not reaching aedeagus apex; ventral processes placed basally, well separated from shaft, longer than shaft, divergent at apex; distal processes apical, triangular. Dorsum yellow or white with reddish brown color pattern; vertex with parallel submedial lines, midline pale; anteclypeus pale, concolorous with rest of face; pronotum with Y- shaped medial vitta; mesonotum pale, with dark lateral triangles; thoracic venter with dark mesosternum, remainder pale; forewing with oblique vittae forming continuous zigzag pattern; clavus with separate basal and distal vittae; dark spot at costal margin; apical cell II with distal spot; inner apical cell with brown spot basally.

Type locality: Holotype to, USA, Illinois, Mason Co., Forest City, 3 IV 1917 (McAtee), (INHS).

Distribution: Central and eastern USA.

Host plants: Parthenocissus quinquefolia.
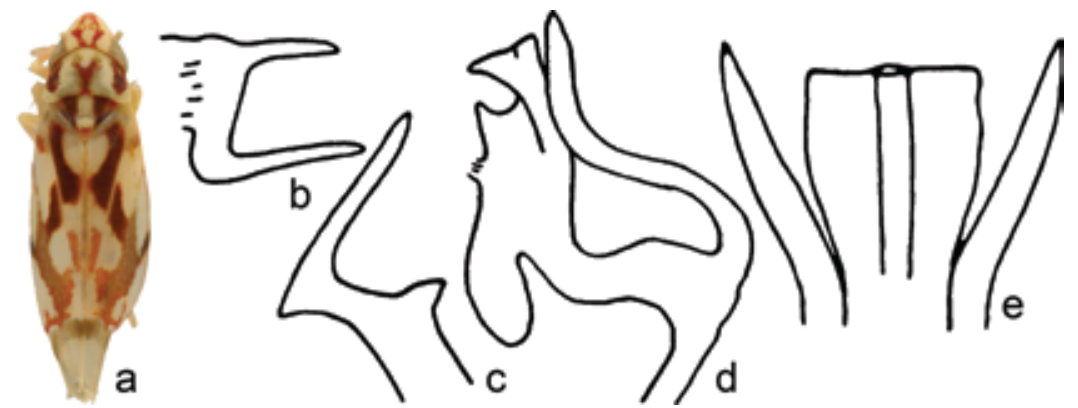

Figure 14. E. palimpsesta McAtee. b-e - from Beamer 1938.

\section{Erythroneura beameri Robinson, 1924 (Fig. 15)}

Erythroneura beameri Robinson, 1924a:61

Description: Length $2.8-3.2 \mathrm{~mm}$. 2S abdominal apodemes large, broad, reach $3 \mathrm{~S}$ posterior margin. Pygofer lobe rounded; dorsal appendages not extended beyond pygofer apex, C-shaped, with branches subequal in length. Second point of style apex very short, tooth like; third point elongate, longer than distance between other two points; angle between basal and third points less than $90^{\circ}$. Aedeagus with preatrium longer than shaft; shaft curved dorsally, broad in lateral view, round in crossection; ventral processes placed basally, well separated from shaft, longer than shaft, divergent at apex; distal processes apical, triangular. Dorsum yellow or white with orange or reddish color pattern; vertex with oblique lateral vittae, midline pale; anteclypeus pale, concolorous with rest of face; pronotum with Y-shaped medial vitta; mesonotum pale, with reddish lateral triangles; thoracic venter entirely pale; forewing with oblique vittae forming zigzag pattern; clavus with separate basal and distal vittae; dark spot at costal margin; apical cell II with distal spot; inner apical cell with brown spot basally.

Type locality: Holotype $\widehat{\delta}$, USA, Kansas, Douglas Co., XI 1923, (Beamer), (KSEM).

Distribution: Central and eastern USA, southeastern Canada.

Host plants: Vitis spp. 

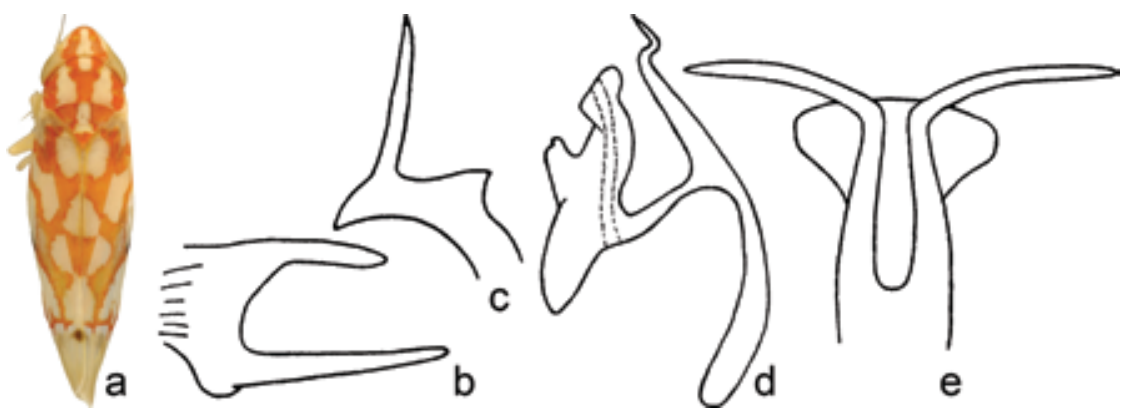

Figure 15. E. beameri Robinson. b, c, e - from Beamer 1938; d - Hepner, unpublished.

16. Erythroneura reflecta McAtee, 1924 (Fig. 16)

Erythroneura comes var. reflecta McAtee, 1924c:43

Erythroneura portea Robinson, 1924b:154

Erythroneura reflecta Beamer, 1938:283

Description: Length 3-3.3 mm. 2S abdominal apodemes small, narrow, extended dorsomesad. Pygofer lobe rounded; pygofer dorsal appendages not extended beyond pygofer apex, C-shaped, with branches subequal in length. Second point of style apex very short, tooth like; third point of style apex elongate, longer than distance between other two points;

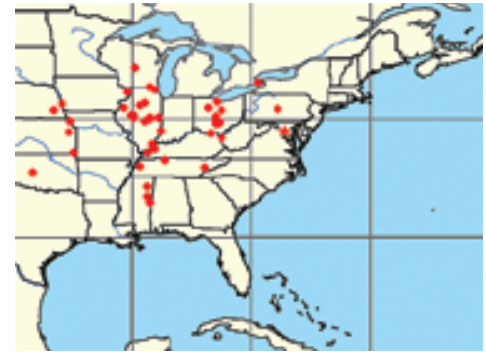
angle between basal and third points less than $90^{\circ}$. Aedeagus with preatrium longer than shaft; shaft curved dorsally, broad in lateral view, round in crossection, with dorsal carina, with distinct apical spicules; ventral processes placed basally, well separated from shaft, longer than shaft, compressed in basal half, divergent at apex; distal processes apical, triangular. Dorsum yellow or white with reddish or brownish color pattern; vertex with orange parallel submedial lines with lateral branch, midline pale; anteclypeus pale, concolorous with rest of face; pronotum with $\mathrm{V}$-shaped medial vitta; mesonotum pale, with dark lateral triangles; thoracic venter with dark mesosternum, remainder pale; forewing with oblique vittae forming continuous zigzag pattern; clavus largely or entirely red or brown; dark spot at costal margin; apical cell II with distal spot; inner apical cell with brown spot basally.

Type locality: Holotype + , USA, Maryland, Montgomery Co., Plummers Island, 14 XII 1913 (McAtee), (USNM).

Distribution: Central and eastern USA, southeastern Canada.

Host plants: Vitis spp.
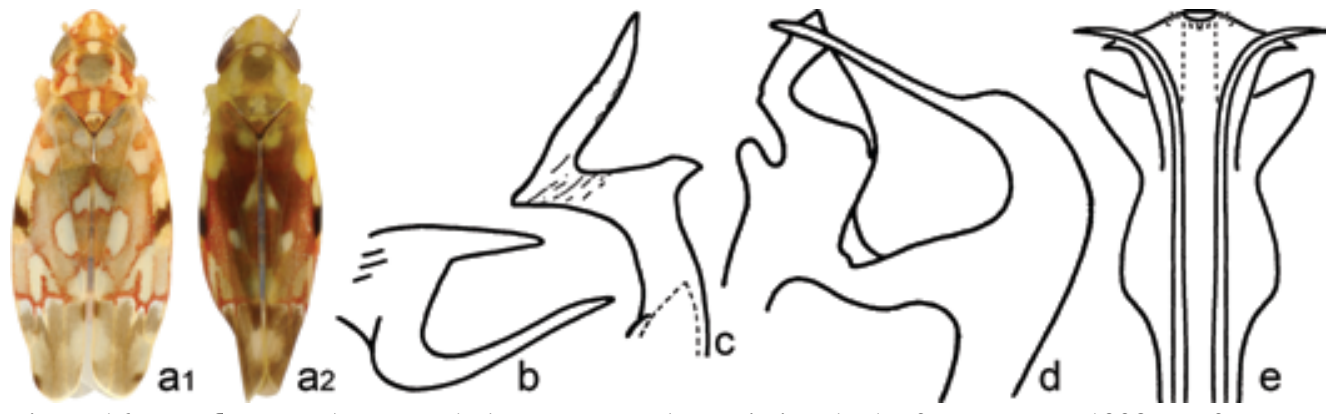

Figure 16. E. reflecta McAtee. a1 - holotype; a2 - color variation. b, d - from Beamer 1938; c - from Young 1952. 


\section{Erythroneura integra McAtee, 1920 (Fig. 17)}

Erythroneura tricincta var. integra McAtee, 1920:309

Erythroneura integra Beamer, 1938:271

Description: Length $2.8-3.2 \mathrm{~mm}$. $2 \mathrm{~S}$ abdominal apodemes large, broad, reach $3 \mathrm{~S}$ posterior margin. Pygofer lobe rounded; dorsal appendages not extended beyond pygofer apex, $\mathrm{C}$-shaped, ventral branch much longer than dorsal. Second point of style apex longer than third; third point short; angle between basal and third points more than $90^{\circ}$. Aedeagus with preatrium about as long as shaft; shaft curved dorsally, broad

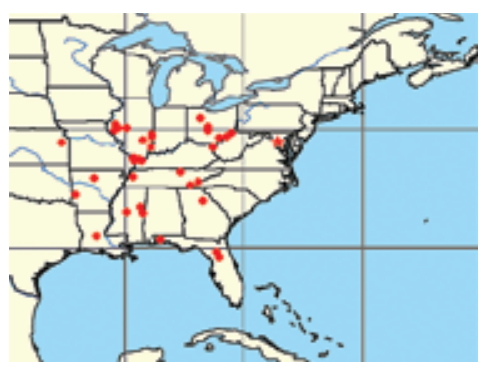
in lateral view, round in crossection, denticulate distally;

ventral processes placed basally, well separated from shaft, longer than shaft, parallel to each other on ventral side of aedeagus; distal processes subapical, triangular. Dorsum yellow or white, with reddish or brown color pattern; vertex with orange parallel submedial lines (often with lateral branch), midline pale; anteclypeus pale, concolorous with rest of face; pronotum almost entirely dark; mesonotum pale, with reddish lateral triangles; thoracic venter entirely pale; forewings with oblique vitae, narrow crossband, and darkened apices; dark spot at costal margin; apical cell II without distal spot; inner apical cell without brown spot.

Type locality: Holotype + , USA, Maryland, Montgomery Co., Plummers Island, 28 III 1915 (McAtee), (USNM).

Distribution: Central and eastern USA.

Host plants: Vitis spp.
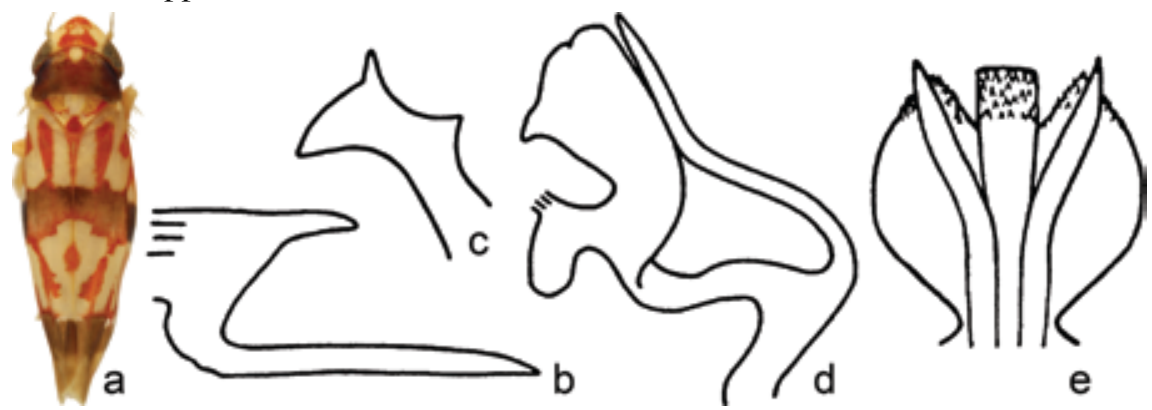

Figure 17. E. integra McAtee. b-e - from Beamer 1938.

18. Erythroneura carinata Dmitriev \& Dietrich sp.n. (Fig. 18) Description: Length 3-3.2 mm. 2S abdominal apodemes small, narrow, extended dorsomesad. Pygofer lobe rounded; dorsal appendages not extended beyond pygofer apex, Cshaped, branches subequal in length. Second point of style apex longer than third; third point short; angle between basal and third points about $90^{\circ}$. Dorsal apodeme broadly expanded in lateral view, triangular in ventral view, without distinct connection to anal tube or pygofer appendages. Aedeagus with preatrium about as long as shaft; shaft curved dorsally, broad

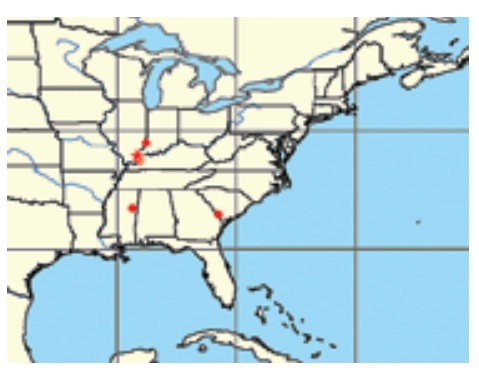
in lateral view, compressed in crossection, with strong dorsal keel, extended far beyond bases of distal processes, with distinct apical spicules; ventral processes placed basally, well separated from shaft, longer than shaft, parallel to each other on ventral side of aedeagus; distal processes long, subapical, flattened, triangular. Dorsum yellow or white, with reddish and brown color pattern; vertex with orange parallel submedial lines (often with lateral branch), midline pale; anteclypeus pale, concolorous with rest of face; pronotum almost entirely dark; mesonotum entirely dark, scutellum pale, contrasting with rest of mesonotum; thoracic venter entirely pale; forewing with oblique vitae, narrow brown crossband, and darkened apices; dark spot at costal margin; apical cell II with distal spot; inner apical cell without brown spot. 
Diagnosis: E. carinata n.sp. is similar to E. diva McAtee and E. cymbium McAtee, but the aedeagus has a strong dorsal keel and its apex extends far beyond the bases of the distal processes. Type locality: Holotype $\widehat{o}$, USA, Illinois, White Co., Gossett, 13 IV 1960 (Ross \& Cunningham), (INHS).

Studied material: Paratypes 23 o, 3 ค , USA, Illinois, White Co., Gossett, 13 IV 1960 (Ross \& Cunningham), (INHS); other studied material from Georgia, Illinois, and Mississippi excluded from type series.

Distribution: Central and southeastern USA.

Host plants: Vitis sp.

Note: The species name "carinata," meaning "keeled," refers to the dorsally keeled aedeagal shaft.

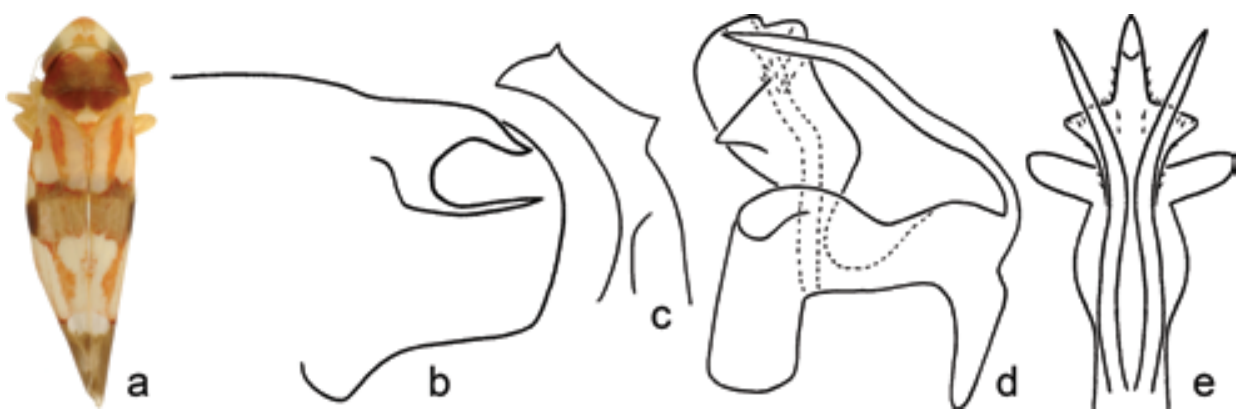

Figure 18. E. carinata sp.n.

19. Erythroneura tricincta Fitch, 1851 (Fig. 19)

Erythroneura tricincta Fitch, 1851:63

Erythroneura tricincta var. $a$ Fitch, 1851:63

Threebanded leafhopper

Description: Length $2.9-3.3 \mathrm{~mm}$. 2S abdominal apodemes small, narrow, extended dorsomesad. Pygofer lobe rounded; dorsal appendages not extended beyond pygofer apex, C-shaped, branches

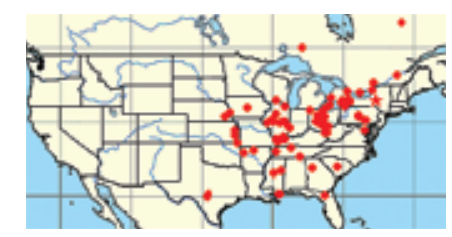
subequal in length. Second point of style apex longer than third; third point shorter than second; angle between basal and third points about $90^{\circ}$. Aedeagus with preatrium about as long as shaft; shaft curved dorsally, broad in lateral view, round in crossection; ventral processes placed basally, well separated from shaft, longer than shaft, parallel to each other on ventral side of aedeagus; distal processes subapical, triangular. Dorsum yellow or white, with reddish and brown color pattern; vertex with orange parallel submedial lines, midline pale; anteclypeus pale, concolorous with rest of face; pronotum mostly dark. Mesonotum dark basally, scutellum pale; thoracic venter entirely pale; forewing with or without oblique vittae, narrow crossband and darkened apices; dark spot at costal margin; apical cell II without distal spot; inner apical cell without brown spot.

Type locality: Neotype ${ }^{\star}$, USA, Kansas, Cherokee Co., 10 IV 1936 (Beamer), (KSEM), here designated

Distribution: Central and eastern USA, southeastern Canada.

Host plants: Vitis spp.

Note: Because Fitch's holotype is lost, we designate a neotype to stabilize the concept of this species, the type of the genus. This concept equals that of the previous revisions (Beamer 1938, Young 1952).

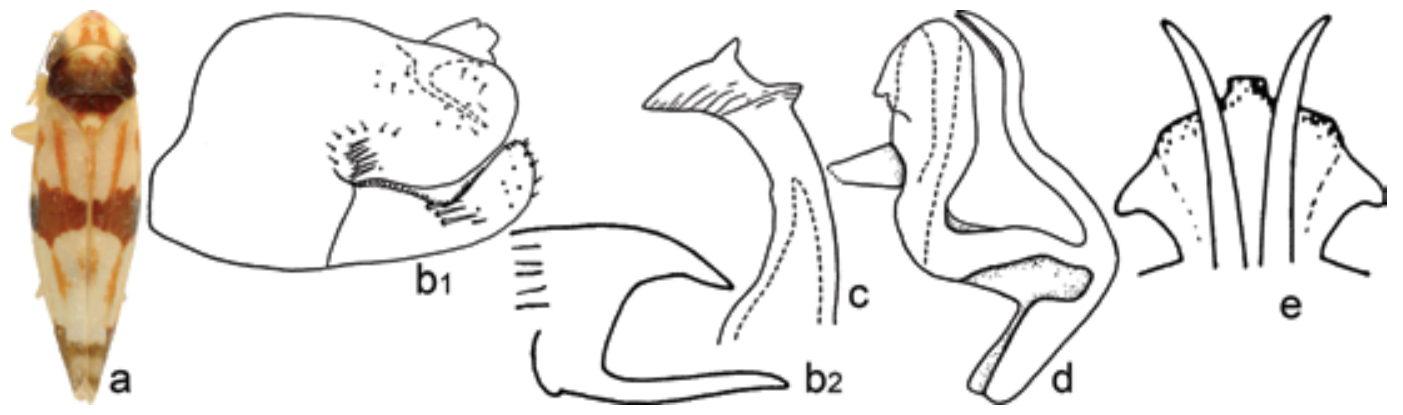

Figure 19. E. tricincta Fitch. b2, e - from Beamer 1938; b1, c, d - from Young 1952. 
20. Erythroneura cymbium McAtee, 1920 (Fig. 20)

Erythroneura tricincta var. cymbium McAtee, 1920:310

Erythroneura tricincta var. disjuncta McAtee, 1920:310, syn.n. Erythroneura cymbium Beamer, 1938:271

Description: Length $2.6-3 \mathrm{~mm}$. Pygofer lobe rounded; dorsal appendages not extended beyond pygofer apex, C-shaped, branches subequal in length. Second point of style apex longer than third;

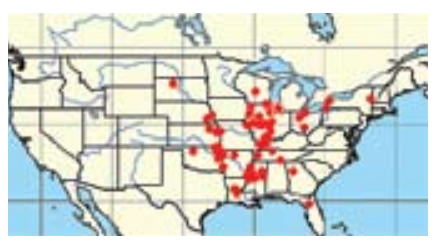
third point short; angle between basal and third points about $90^{\circ}$.

Aedeagus with preatrium about as long as shaft; shaft curved dorsally, broad in lateral view, round in crossection; ventral processes placed basally, well separated from shaft, longer than shaft, parallel to each other on ventral side of aedeagus; distal processes subapical, triangular. Dorsum yellow or white, with reddish and brown color pattern; vertex with orange parallel submedial lines, midline pale; anteclypeus pale, concolorous with rest of face; pronotum with dark posterior half, or at least posterior corners; mesonotum entirely pale; thoracic venter entirely pale; forewings with or without oblique vittae, with narrow crossband, and darkened apices; dark spot at costal margin; apical cell II without distal spot; inner apical cell without brown spot.

Type locality: Holotype + , USA, Michigan, Berrien Co., Benton Harbor, on Vitis sp., 28 V 1912 (Seigler), (USNM).

Distribution: Central and eastern USA, southeastern Canada.

Host plants: Vitis spp.
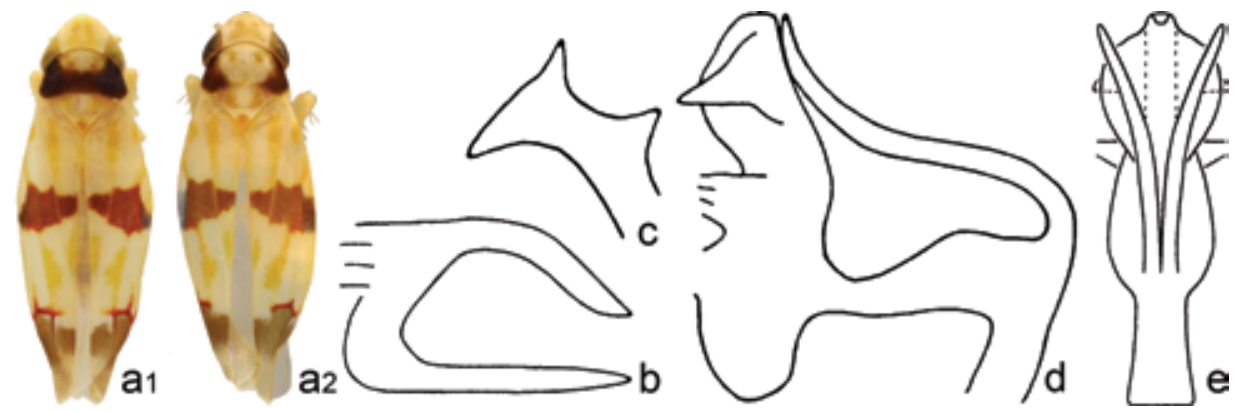

Figure 20. E. cymbium McAtee. a2 - var. disjuncta. b-d - from Beamer 1938.

21. Erythroneura calycula McAtee, 1920 (Fig. 21, Plate1b) Erythroneura tricincta var. calycula McAtee, 1920:308 Erythroneura tricincta var. erasa McAtee, 1920:309, syn.n. Erythroneura calycola Osborn, 1932:515, missp.

Erythroneura tricincta var. noncincta Johnson, 1934:261, syn.n. Erythroneura calycula Beamer, 1938:270

Description: Length $2.6-3 \mathrm{~mm}$. $2 \mathrm{~S}$ abdominal apodemes small, narrow, extended dorsomesad. Pygofer lobe rounded; dorsal appendages not extended beyond pygofer apex, Cshaped, branches subequal in length. Second point of style

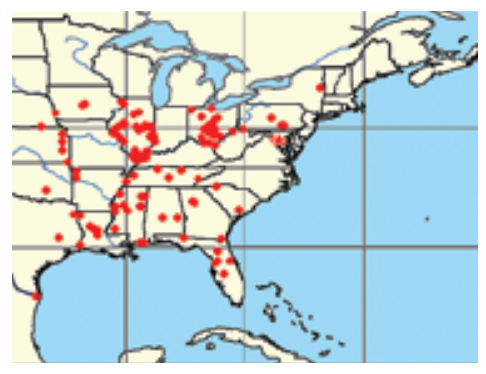
apex longer than third; third point short; angle between basal and third points about $90^{\circ}$. Aedeagus with preatrium about as long as shaft; shaft curved dorsally, slender in lateral view; depressed in crossection; ventral processes placed basally, well separated from shaft, longer than shaft, parallel to each other on ventral side of aedeagus; distal processes apical, triangular. Dorsum yellow or white, with reddish and brown color pattern; vertex with orange parallel submedial lines, midline pale; anteclypeus pale, concolorous with rest of face; pronotum with dark posterior corners; mesonotum with dark lateral triangles, or base entirely dark, scutellum pale; thoracic venter entirely pale; forewings with or without oblique vittae, with narrow crossband, and darkened apices; dark spot at costal margin; apical cell II without distal spot; inner apical cell without brown spot. 
Type locality: Holotype đ̊, USA, Maryland, Montgomery Co., Plummers Island, 14 XII 1913 (McAtee), (USNM).

Distribution: Central and eastern USA.

Host plants: Vitis spp.
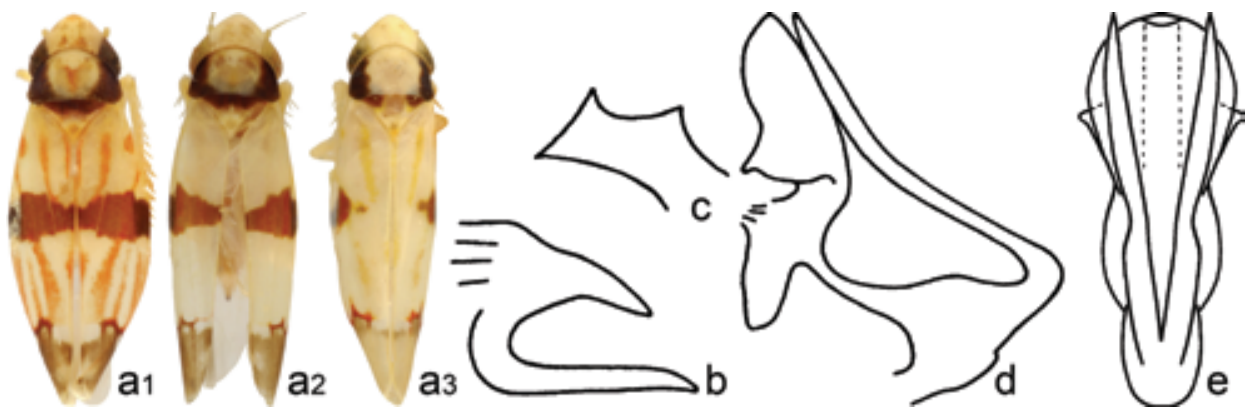

Figure 21. E. calycula McAtee. a2 - var. erasa; a3 - var. noncincta. b, d - from Beamer 1938; c - from Hepner, unpublished.

\section{Erythroneura vagabunda Knull, 1945 (Fig. 22)}

Erythroneura vagabunda Knull, 1945:109

Description: Length $2.9-3.1 \mathrm{~mm}$. 2S abdominal apodemes large, broad, reach $3 \mathrm{~S}$ posterior margin. Pygofer lobe rounded; dorsal appendages not extended beyond pygofer apex, $\mathrm{C}$-shaped, branches subequal in length. Second point of style apex well developed; third point elongate, longer than half distance between other two points; angle between basal and third points less than $90^{\circ}$. Aedeagus with preatrium about as long as shaft; shaft curved dorsally, slender in lateral view,

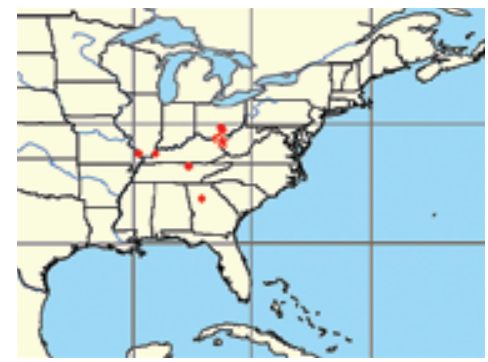
denticulate distally, round in crossection; ventral processes placed basally, well separated from shaft, longer than shaft, evenly divergent; distal processes long, subapical, slender. Dorsum yellow or white with orange color pattern; vertex with orange parallel submedial lines, midline pale; anteclypeus pale, concolorous with rest of face; pronotum with Y-shaped medial vitta; mesonotum pale, with orange lateral triangles; thoracic venter with dark mesosternum, remainder pale; forewing with broken oblique vittae; clavus with separate basal and distal vittae and dark brown spot near midlength; dark spot at costal margin; apical cell II with distal spot; inner apical cell with brown spot basally.

Type locality: Holotype $\widehat{o}$, USA, Ohio, Lawrence Co., 29 IV 1934 (Caldwell), (OSU).

Distribution: Central and eastern USA.

Host plants: Unknown.
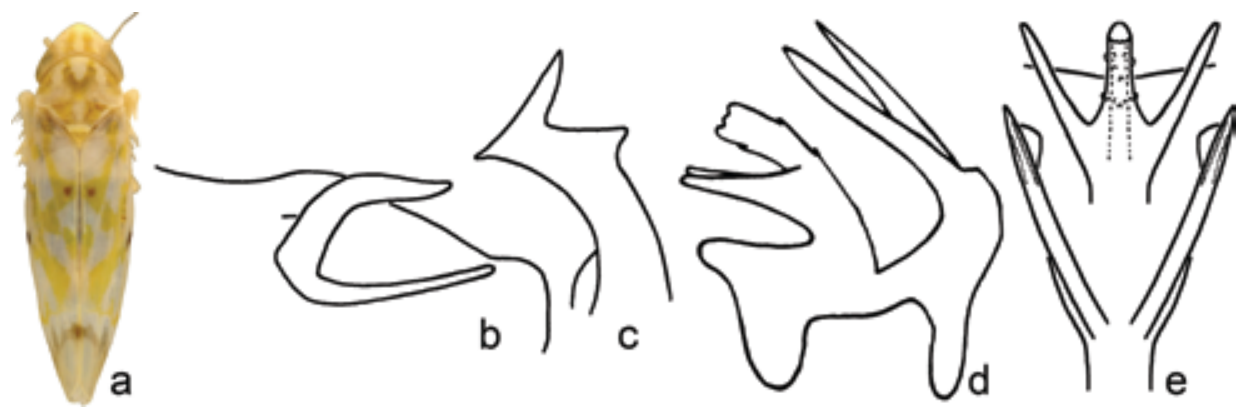

Figure 22. E. vagabunda Knull. d - from Knull 1945. 
23. Erythroneura aza Robinson, 1924 (Fig. 23) Erythroneura aza Robinson, 1924c:291

Description: Length 2.9-3.1 mm. Abdomen. 2S abdominal apodemes large, broad, reach $3 \mathrm{~S}$ posterior margin. Pygofer lobe rounded; dorsal appendages not extended beyond pygofer apex, C-shaped, branches subequal in length. Second point of style apex well developed; third point elongate, longer than half distance between other two points; angle between basal and third points less than $90^{\circ}$. Aedeagus with preatrium longer than shaft; shaft straight and slender in lateral view,

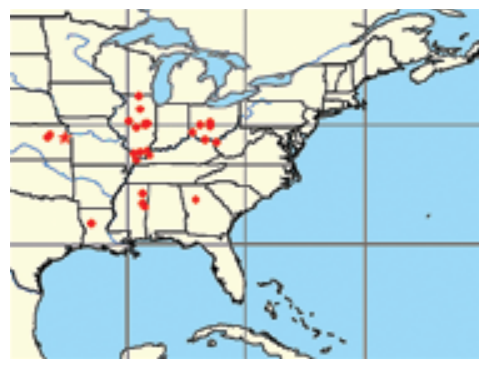
round in crossection; apex slightly broadened in ventral view; ventral processes placed basally, well separated from shaft, longer than shaft, parallel to each other on ventral side of aedeagus; distal processes long, subapical, slender. Dorsum yellow or white, with orange or reddish color pattern; vertex with parallel submedial lines, midline pale; anteclypeus pale, concolorous with rest of face; pronotum with Y-shaped medial vitta; mesonotum pale, with orange lateral triangles; thoracic venter entirely pale or with dark mesosternum; forewing with oblique vittae forming zigzag pattern; clavus with separate basal and distal vittae; dark spot at costal margin; apical cell II with distal spot; inner apical cell with brown spot basally.

Type locality: Holotype $\delta$, USA, Kansas, Douglas Co., Lawrence, 15 XII 1923 (Robinson), (KSEM).

Distribution: Central and eastern USA.

Host plants: Vitis spp.
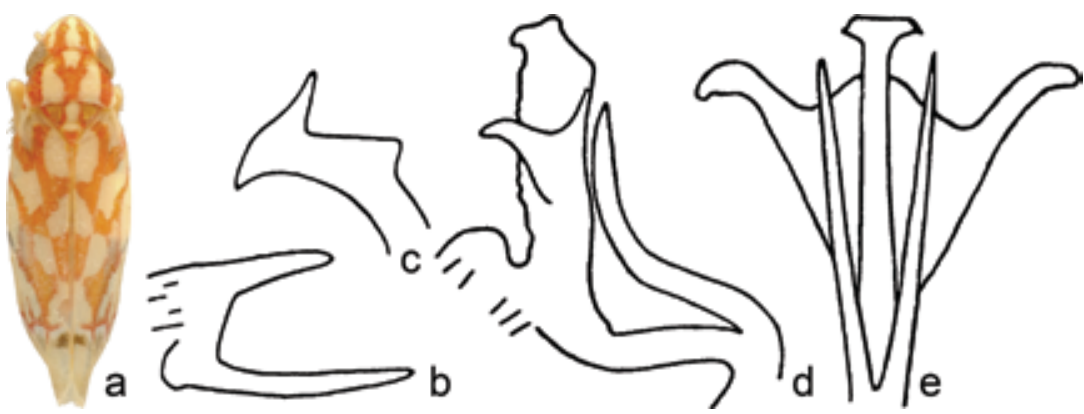

Figure 23. E. aza Robinson. b-e - from Beamer 1938.

24. Erythroneura glabra Dmitriev \& Dietrich sp.n. (Fig. 24) Description: Length $2.8-3 \mathrm{~mm}$. $2 \mathrm{~S}$ abdominal apodemes small, narrow, extended dorsomesad. Pygofer lobe rounded; dorsal appendages not extended beyond pygofer apex, Cshaped, branches subequal in length. Second point of style apex well developed; third point longer than half distance between other two points; angle between basal and third points less than $90^{\circ}$. Aedeagus with preatrium about as long as shaft; shaft symmetrical, curved dorsally, broad in lateral view, round in crossection; apex truncate in posterior view; ventral processes placed basally, well separated from shaft, longer

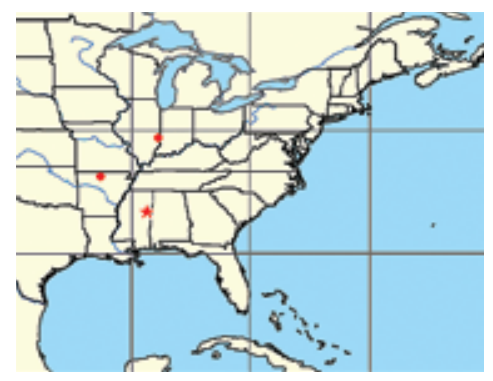
than shaft, parallel to each other on ventral side of aedeagus; distal processes long, subapical, slender. Coloration similar to that of E. comes Say: dorsum yellow or white with orange color pattern; vertex with orange parallel submedial lines (often with lateral branch), midline pale; anteclypeus pale, concolorous with rest of face; pronotum with Y- or $\mathrm{V}$-shaped medial vitta; mesonotum pale, with orange lateral triangles; thoracic venter entirely pale; forewings with broken oblique vittae; clavus with separate basal and distal vittae; dark spot at costal margin; apical cell II with distal spot; inner apical cell with brown spot basally.

Diagnosis: The coloration of new species similar to that of $E$. comes Say, and the male genitalia resemble those of E. vagabunda Knull, but the aedeagus shaft lacks distal denticuli and the ventral processes are parallel to each other. 
Type locality: Holotype ô, USA, Mississippi, Oktibbeha Co., State College, 4 I 1962 (Hepner), (INHS).

Studied material: Paratypes, 1 ô, USA, Arkansas, Marion Co., Yellville, on Cornus sp., 23 VIII 1962 (Hepner), (MEM); 1 ô, Illinois, Clark Co., Rocky Branch, 25 VII 1954 (Cunningham), (INHS).

Distribution: Central and southeastern USA.

Host plants: Unknown.

Note: The species name "glabra," meaning "bare," refers to the lack of denticuli on the apex of the aedeagal shaft.

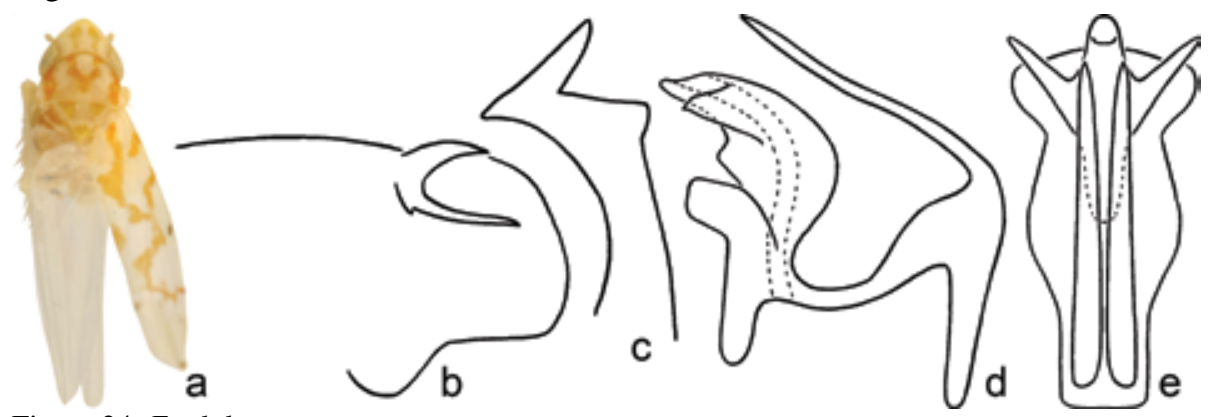

Figure 24. E. glabra sp.n.

\section{Erythroneura elegantula Osborn, 1928 (Fig. 25)}

Erythroneura elegantula Osborn, 1928a:289

Western grape leafhopper

Description: Length $2.8-3 \mathrm{~mm}$. 2S abdominal apodemes small, narrow, extended dorsomesad. Pygofer lobe rounded; dorsal appendages not extended beyond pygofer apex, Cshaped, branches subequal in length. Second point of style apex longer than third; third point elongate, longer than half distance between other two points; angle between basal and third points less than $90^{\circ}$. Aedeagus with preatrium longer than shaft; shaft

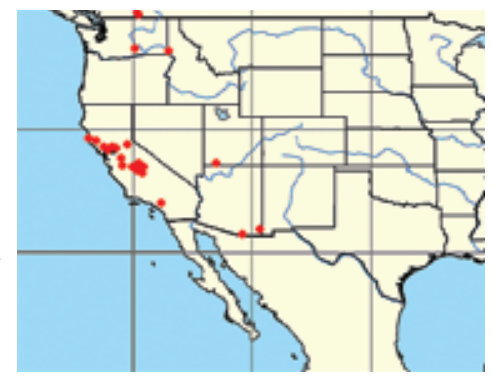
curved dorsally, broad in lateral view, compressed in crossection, with dorsal carina; ventral processes placed basally, well separated from shaft, longer than shaft, parallel to each other on ventral side of aedeagus; distal processes, triangular. Dorsum yellow or white, with orange color pattern; vertex with orange parallel submedial lines, midline pale; anteclypeus pale, concolor-

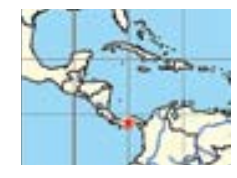
ous with rest of face; pronotum with Y-shaped medial vitta; mesonotum pale, with black lateral triangles; thoracic venter entirely pale or with dark mesosternum; forewing with broken oblique vittae; clavus with separate basal and distal vittae; dark spot at costal margin; apical cell II with distal spot; inner apical cell with brown spot basally.

Type locality: Holotype $q$, Panama, Canal Zone (CMNH). Type was not studied.

Distribution: Western USA, southwestern Canada, Panama (apparently introduced).

Host plants: Vitis spp.
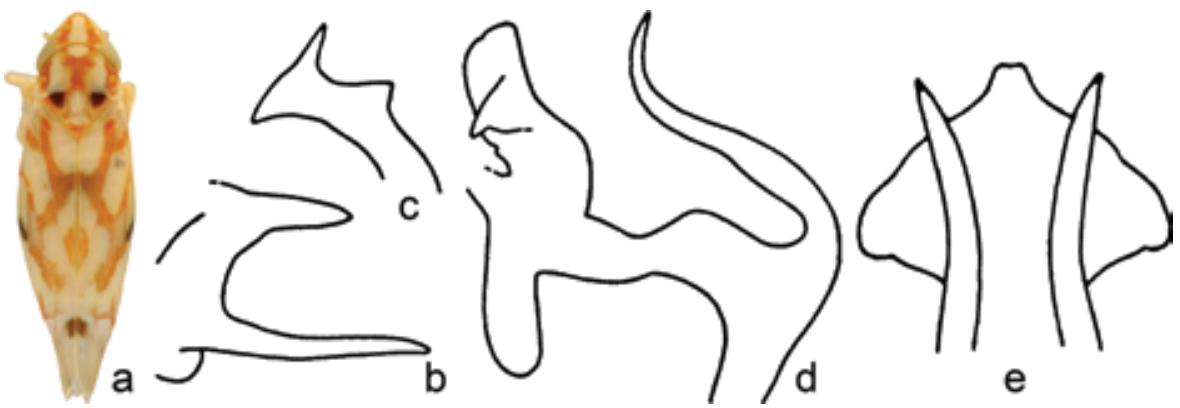

Figure 25. E. elegantula Osborn. b-e - from Beamer 1938. 
26. Erythroneura acuticephala Robinson, 1924 (Fig. 26, Plate 1c) Erythroneura acuticephala Robinson, 1924a:61

Description: Length 2.6-2.9 mm. Abomen. 2S abdominal apodemes large, broad, reach $3 \mathrm{~S}$ posterior margin. Pygofer lobe rounded; dorsal appendages not extended beyond pygofer apex, C-shaped, branches subequal in length. Second point of style apex well developed; third point elongate, longer than half distance between other two points; angle between basal and third points less than $90^{\circ}$. Aedeagus with preatrium about as long as shaft; shaft curved dorsally, broad in lateral view;

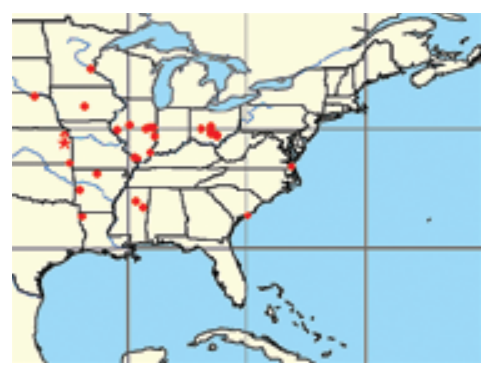
compressed in crossection; ventral processes placed basally, well separated from shaft, longer than shaft, parallel to each other on ventral side of aedeagus; distal processes apical, triangular. Dorsum yellow or white, with reddish or orange color pattern; vertex with parallel submedial lines, midline pale; anteclypeus pale, concolorous with rest of face; pronotum with Y-shaped medial vitta; mesonotum pale, with orange lateral triangles; thoracic venter entirely pale; forewing with oblique vittae forming continuous zigzag pattern; clavus with separate basal and distal vittae; dark spot at costal margin; apical cell II with distal spot; inner apical cell with brown spot basally.

Type locality: Holotype đิ, USA, Kansas, Douglas Co., XII 1923, (Robinson), (KSEM).

Distribution: Central and eastern USA.

Host plants: Vitis spp.

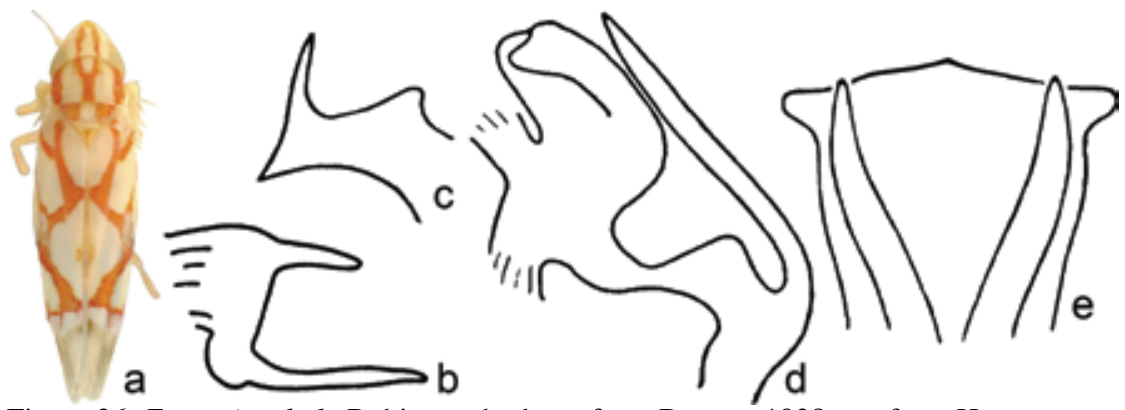

Figure 26. E. acuticephala Robinson. b, d, e - from Beamer 1938; c - from Hepner, unpublished.

27. Erythroneura aclys McAtee, 1920 (Fig. 27)

Erythroneura aclys McAtee, 1920:290

Description: Length $2.7-3.1 \mathrm{~mm}$. 2S abdominal apodemes large, broad, reach $3 \mathrm{~S}$ posterior margin. Pygofer lobe rounded; dorsal appendages not extended beyond pygofer apex, $\mathrm{C}$-shaped, branches subequal in length. Second point of style apex well developed; third point longer than half distance between other two points; angle between basal and third points less than $90^{\circ}$. Aedeagus with preatrium about as long as shaft; shaft curved dorsally, broad in lateral view, round in cros-

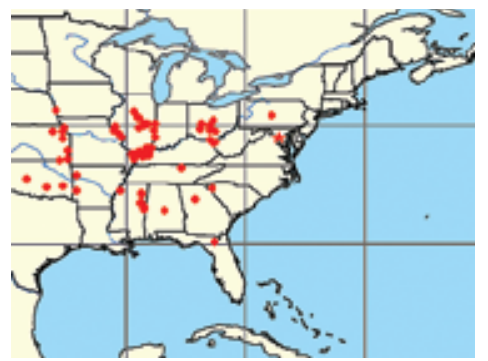
section; ventral processes placed basally, well separated from shaft, longer than shaft, divergent at apex; distal processes subapical, triangular. Dorsum yellow or white, with brown color pattern; vertex with large basal dark area, often extended onto thorax, midline dark; anteclypeus pale, concolorous with rest of face; pronotum dark with pale lateral margins; mesonotum entirely dark; thoracic venter entirely pale; forewings with oblique vittae forming continuous zigzag pattern; clavus largely brown; dark spot at costal margin; apical cell II without distal spot; inner apical cell without brown spot.

Type locality: Holotype $\hat{o}$, USA, Maryland, Montgomery Co., Plummers Island, 21 XII 1913

(McAtee), (USNM). Type was not studied.

Distribution: Central and eastern USA.

Host plants: Cercis canadensis. 


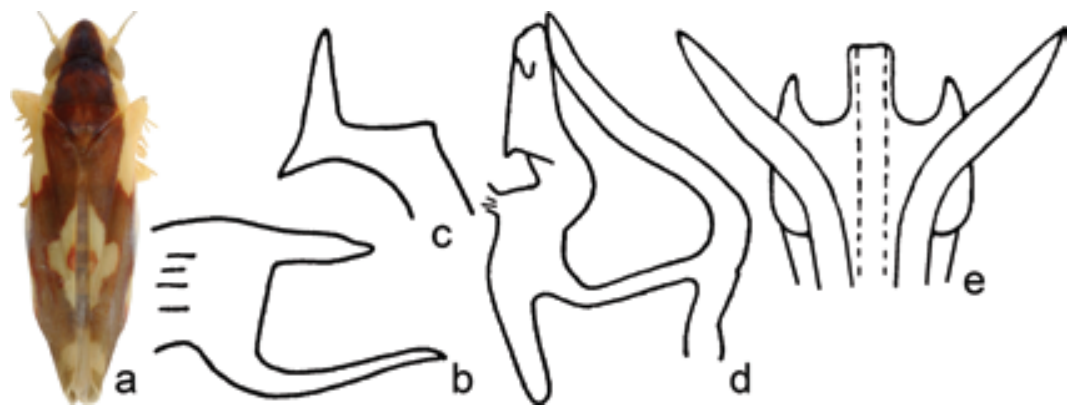

Figure 27. E. aclys McAtee. b-e - from Beamer 1938; a - original.

28. Erythroneura bistrata McAtee, 1920 (Fig. 28)

Erythroneura vitis var. bistrata McAtee, 1920:305

Erythroneura vitis var. stricta McAtee, 1920:306

Erythroneura rubranotum Robinson, 1924a:60

Erythroneura bistrata Johnson, 1934:262

Erythroneura vitis var. fusco-clava Beamer, 1927:31

Description: Body. Size 2.9-3.2 mm. 2S abdominal apodemes small, narrow, extended dorsomesad. Pygofer lobe rounded; dorsal appendages not extended beyond pygofer apex, C-shaped, branches subequal in length. Second point of style apex well developed; third point elongate, longer than half distance between other two points; angle between basal and third points less than $90^{\circ}$. Aedeagus with preatrium longer than shaft; shaft curved dorsally, slender in lateral view, round in crossection, with distinct apical spicules; ventral processes placed basally, well separated from shaft, longer than shaft, divergent at apex; distal processes subapical, triangular. Dorsum yellow or white with reddish brownish color pattern, which strongly vary; vertex unicolorous pale or darkened posteriorly, midline pale; anteclypeus pale, concolorous with rest of face; pronotum almost entirely dark; mesonotum dark, with pale scutellum; thoracic venter entirely pale; forewing mostly dark with small pale spots or with two narrow pale crossbands; dark spot at costal margin; apical cell II without distal spot; inner apical cell without brown spot.

Type locality: Holotype ô, Maryland, Montgomery Co., Plummers Island, 28 III 1915 (McAtee), (USNM).

Distribution: Central and eastern USA.

Host plants: Cercis canadensis.
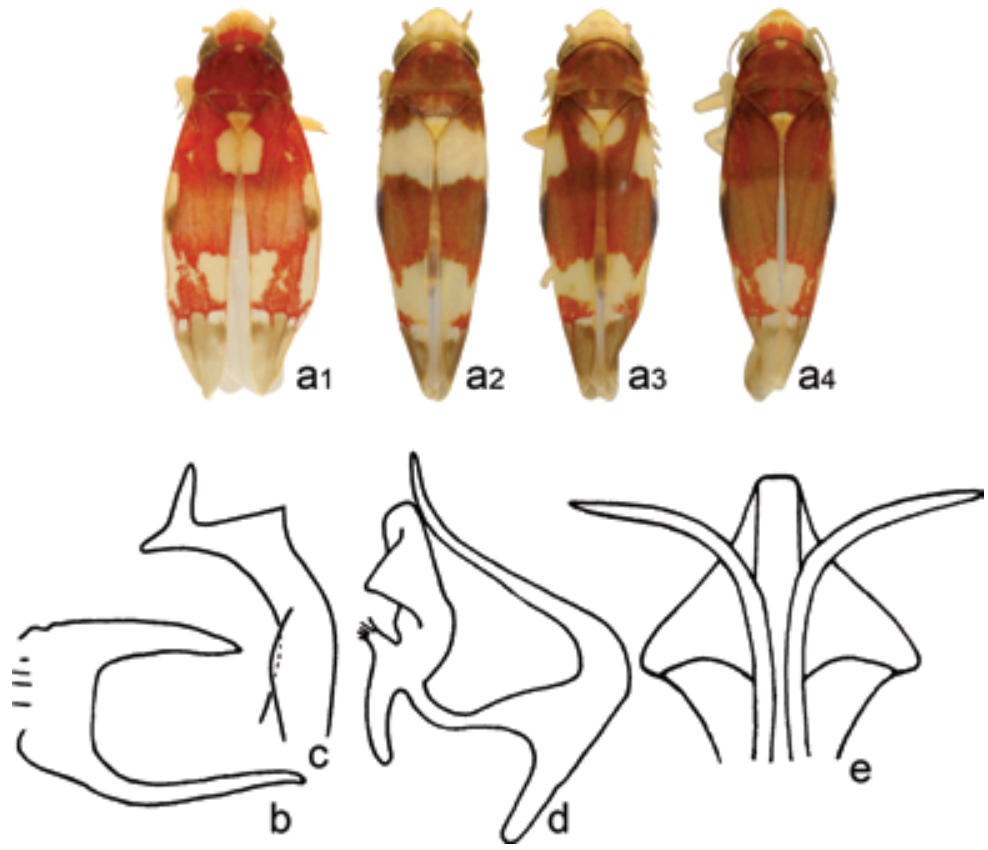

Figure 28. E. bistrata McAtee. a1 - holotype, a2 - var. stricta, a3 - var. rubranota, a4 - color variation. b, d, e - from Beamer 1938. 
29. Erythroneura prosata Johnson, 1935 (Fig. 29)

Erythroneura infuscata var. prosata Johnson, 1935:108

Erythroneura prosata DeLong \& Caldwell, 1937:81

Description: Length $2.8-3 \mathrm{~mm}$. $2 \mathrm{~S}$ abdominal apodemes small, narrow, extended dorsomesad. Pygofer lobe rounded; dorsal appendages not extended beyond pygofer apex, Cshaped, branches subequal in length. Second point of style apex well developed; third point elongate, longer than half distance between other two points; angle between basal and third points less than $90^{\circ}$. Aedeagus with preatrium longer than shaft; shaft

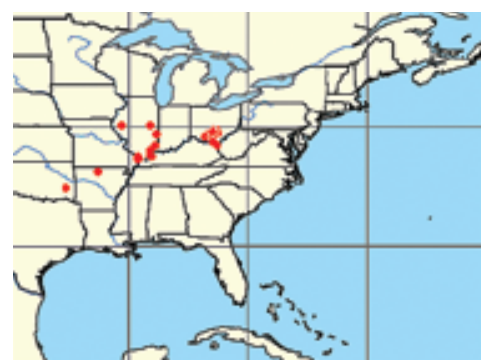
curved dorsally, slender in lateral view, round in crossection, with dorsal carina, with distinct apical spicules; ventral processes placed basally, well separated from shaft, longer than shaft, divergent at apex; distal processes subapical, triangular. Dorsum yellow or white, with reddish brown color pattern; vertex mostly dark, midline dark; anteclypeus pale, concolorous with rest of face; pronotum almost entirely dark; mesonotum with dark lateral triangles and dark apex of scutellum; thoracic venter with dark mesosternum, remainder pale; forewings mostly dark with small pale spots; dark spot at costal margin; apical cell II with distal spot; inner apical cell without brown spot.

Type locality: Holotype $\hat{o}$, USA, Ohio, Pickaway Co., 31 III 1934 (Caldwell), (OSU).

Distribution: Central USA.

Host plants: Rubus spp. (?).

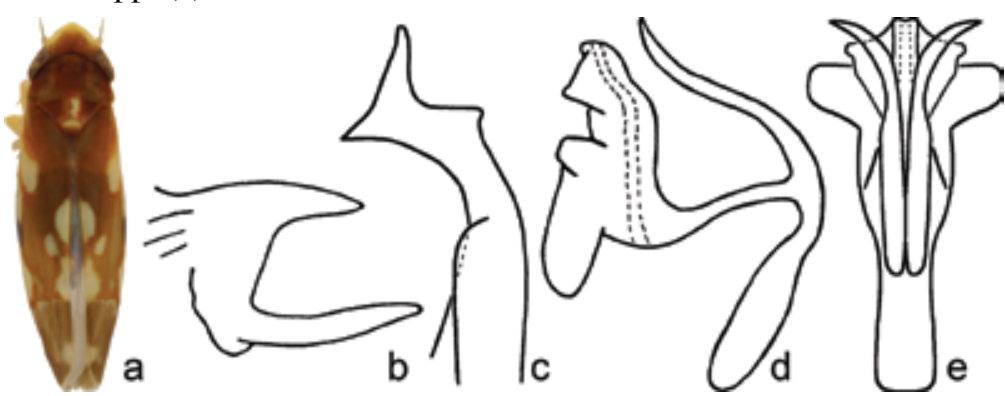

Figure 29. E. prosata Johnson. b -from Beamer 1938; d - from Hepner, unpublished.

30. Erythroneura infuscata (Gillette, 1898) (Fig. 30, Plate 1d) Typhlocyba comes var. infuscata Gillette, 1898:764

Erythroneura comes var. infuscata Van Duzee, 1916:77

Erythroneura infuscata McAtee, 1920:302

Description: Length $2.8-3 \mathrm{~mm}$. 2S abdominal apodemes large, broad, reach $3 \mathrm{~S}$ posterior margin. Pygofer lobe rounded; dorsal appendages not extended beyond pygofer apex, C-shaped, branches subequal in length. Second point of style apex well developed; third point elongate, not longer than half distance between other two points; angle between basal and third points

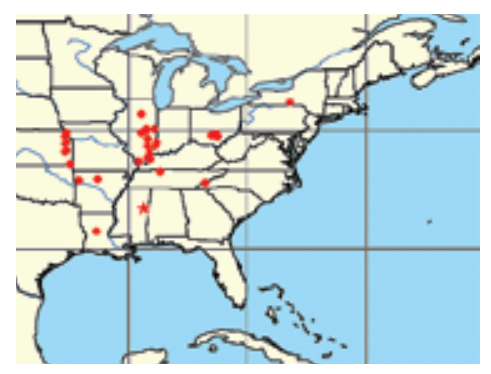
less than $90^{\circ}$. Aedeagus with preatrium longer than shaft; shaft curved dorsally, broad in lateral view, compressed in crossection, with strong dorsal keel; ventral processes placed basally, well separated from shaft, longer than shaft, divergent at apex; distal processes subapical, triangular. Dorsum mostly black, with small pale spots at middle of mesonotum and at costal margin of wings; anteclypeus pale, concolorous with rest of face; thoracic venter entirely dark.

Type locality: Holotype + , USA, Mississippi, Oktibbeha Co., Agriculture College (MSU), (USNM).

Distribution: Central and eastern USA.

Host plants: Unknown. 


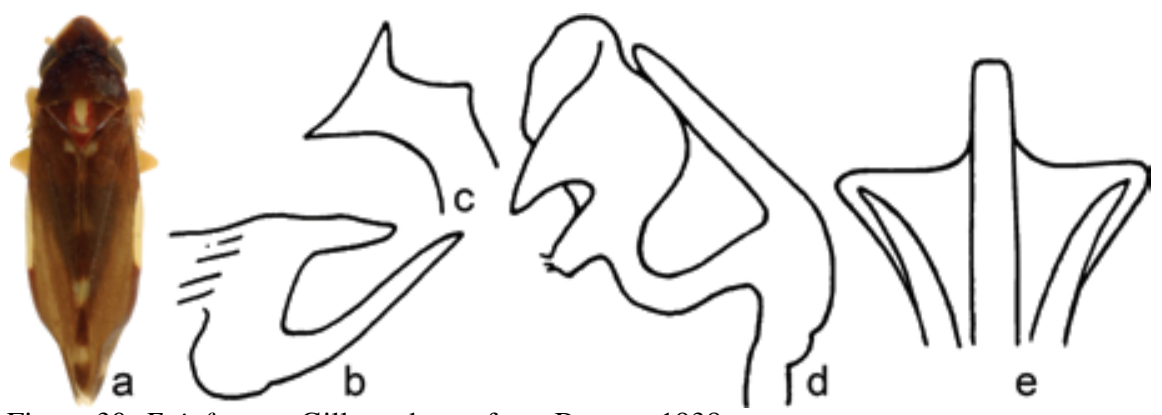

Figure 30. E. infuscata Gillette. b-e - from Beamer 1938.

\section{Erythroneura cancellata McAtee, 1920 (Fig. 31)}

Erythroneura comes var. cancellata McAtee, 1920:320

Erythroneura cancellata Robinson, 1926:141

Description: Length 3.2-3.4 mm. 2S abdominal apodemes small, narrow, extended dorsomesad. Pygofer lobe rounded; dorsal appendages not extended beyond pygofer apex, Cshaped, ventral branch about twice as long as dorsal branch. Second point of style apex well developed; third point subequal in size with second; angle between basal and third points about $90^{\circ}$. Aedeagus with preatrium longer than shaft;

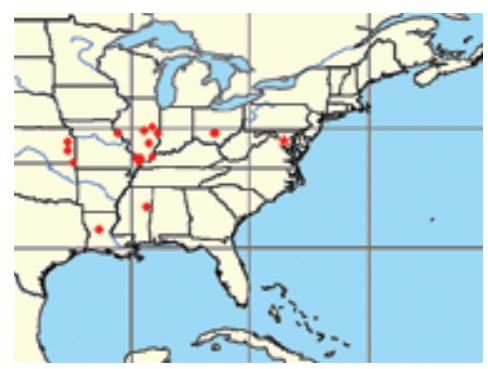
shaft curved dorsally, slender in lateral view, round in crossection, with dorsal carina; ventral processes placed basally, well separated from shaft, longer than shaft, divergent only at apex; distal processes subapical, triangular. Dorsum yellow or white, with orange and brown color pattern; vertex with large basal dark area, often extended onto thorax, midline dark; anteclypeus pale, concolorous with rest of face; pronotum with Y-shaped medial vitta or almost entirely dark; mesonotum pale, with brown lateral triangles; thoracic venter with dark mesosternum, remainder pale; forewings with pale diamond-shaped transcommisural marking outlined with dark brown, with oblique vittae forming zigzag pattern; clavus with separate basal and distal vittae; dark spot at costal margin; apical cell II with distal spot; inner apical cell with brown spot basally.

Type locality: Holotype + , USA, Maryland, Montgomery Co., Plummers Island, 30 XI 1913 (McAtee), (USNM).

Distribution: Central and eastern USA.

Host plants: Cercis canadensis.
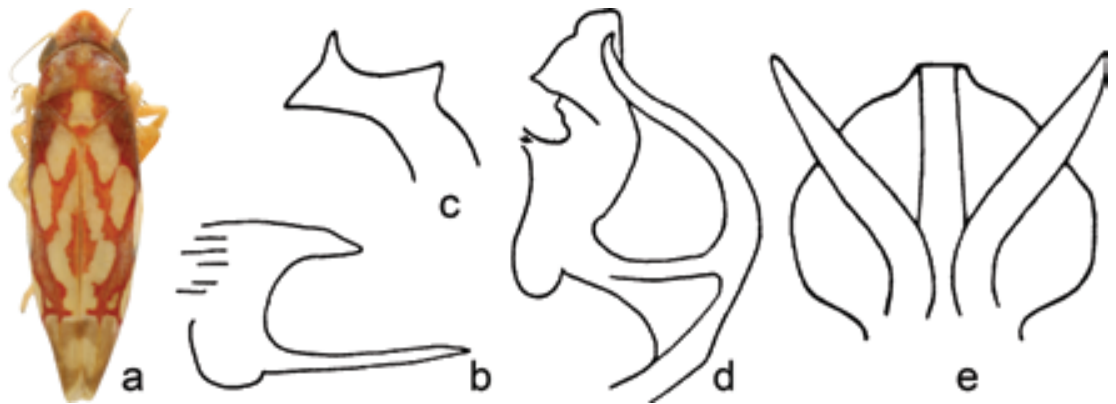

Figure 31. E. cancellata McAtee. b-e - from Beamer 1938. 
32. Erythroneura triapitsyni Dmitriev \& Dietrich sp.n. (Fig. 32) Description: Length $2.7-2.9 \mathrm{~mm}$. $2 \mathrm{~S}$ abdominal apodemes large, broad, reach $3 \mathrm{~S}$ posterior margin. Pygofer lobe rounded; dorsal appendages not extended beyond pygofer apex, Cshaped, branches subequal in length. Second point of style apex longer than third; third point elongate, not longer than half distance between other two points; angle between basal and third points less than $90^{\circ}$. Aedeagus with preatrium about as long as shaft; shaft symmetrical, curved dorsally, broad in lateral view, smooth, round in crossection, with dorsal carina; apex truncate

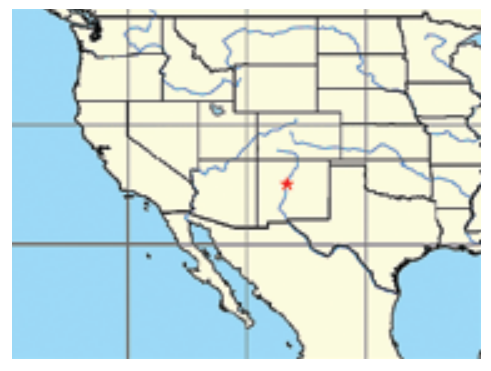
in posterior view; ventral processes placed basally, well separated from shaft, longer than shaft, divergent at apex; distal processes long, subapical, flattened, triangular. Coloration similar to that of E. elegantula Osborn: dorsum yellow or white, with orange color pattern; vertex with orange parallel submedial lines (often with lateral branch), midline pale; anteclypeus pale, concolorous with rest of face; pronotum with V-shaped medial vitta; mesonotum pale, with black lateral triangles; thoracic venter entirely pale; forewing with broken oblique vittae; clavus with separate basal and distal vittae; dark spot at costal margin; apical cell II with distal spot; inner apical cell with brown spot basally.

Diagnosis: The coloration of E. triapitsyni sp.n. is similar to that of E. elegantula Osborn. The male genitalia are similar to those of E. bakeri sp.n. but the aedeagus is round in crossection. Type locality: Holotype $\widehat{\sigma}$, USA, New Mexico, Bernalillo Co., Albuquerque, Los Ranchos de

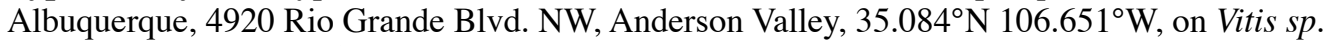
(cultivated), 26 IX 2005 (Triapitsyn), (INHS).

Studied material: Paratypes: 7 ô, 11 으, same locality as holotype, 26-28 IX 2005 (Triapitsyn), (INHS).

Distribution: New Mexico.

Host plants: Vitis spp.

Note: The species is named for Dr. Serguei Triapitsyn (University of California, Riverside), who collected the type series.

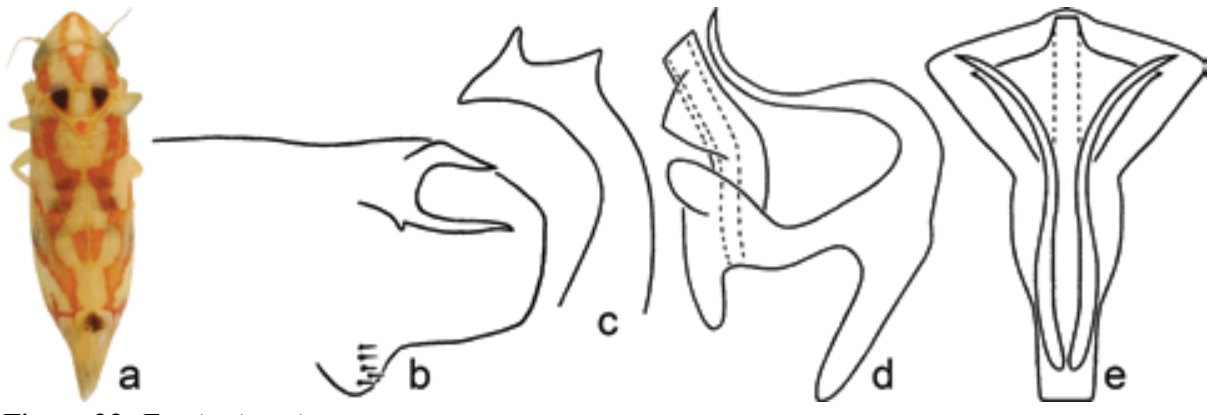

Figure 32. E. triapitsyni sp.n.

33. Erythroneura bakeri Dmitriev \& Dietrich sp.n. (Fig. 33)

Description: Length $2.7-2.8 \mathrm{~mm}$. 2S abdominal apodemes large, broad, reach $3 \mathrm{~S}$ posterior margin. Pygofer lobe rounded; dorsal appendages not extended beyond pygofer apex, C-shaped, branches subequal in length. Second point of style apex well developed; third point elongate, not longer than half distance between other two points; angle between basal and third points less than $90^{\circ}$. Aedeagus with preatrium about as long as shaft; shaft symmetrical, curved dorsally, broad in lateral view, smooth, compressed in crossection, with dor-

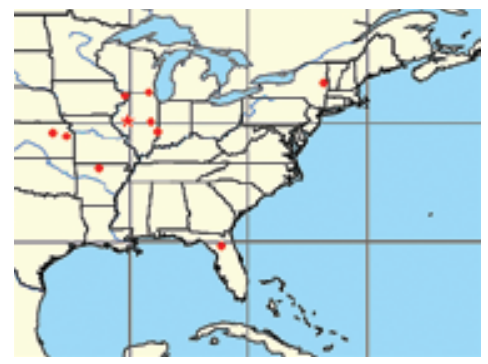
sal carina; apex truncate in posterior view; ventral processes 
placed basally, well separated from shaft, longer than shaft, divergent at apex; distal processes long, subapical, flattened, triangular. Dorsum yellow or white, with red or orange color pattern; vertex with parallel submedial lines (often with lateral branch), midline pale; anteclypeus pale, concolorous with rest of face; pronotum with Y-shaped medial vitta; mesonotum entirely pale; thoracic venter with dark mesosternum, remainder pale; forewing with broken oblique vittae; clavus with separate basal and distal vittae; dark spot at costal margin; apical cell II with distal spot; inner apical cell with brown spot basally.

Diagnosis: E. bakeri sp.n. is similar to E. triapitsyni sp.n., but the aedeagus has a stronger dorsal carina, and the mesonotum lacks black lateral triangles.

Type locality: Holotype $\widehat{\delta}$, USA, Illinois, Fulton Co., Anderson Lake State Conservation Area, 8 IX 1954 (Ross), (INHS).

Studied material: Paratypes, 2 o, Illinois, Clark Co., Darwin, on Quercus lyrata, 15 IX 1953 (Ross), (INHS); 6 ô, Illinois, Fulton Co., Anderson Lake State Conservation Area, 8 IX 1954 (Ross), (INHS), 2 ô, Illinois, Jo Daviess Co., Blanding, on Prunus virginiana, 28 IV 1954 (Ross), (INHS); other studied material from Wisconsin, Kansas, Arkansas, Illinois, New York, and Florida excluded from type series.

Distribution: Central and eastern USA.

Host plants: Vitis spp.

Note: This species is named in memory of C.F. Baker (1872-1927), a pioneer in the study of Auchenorrhyncha.

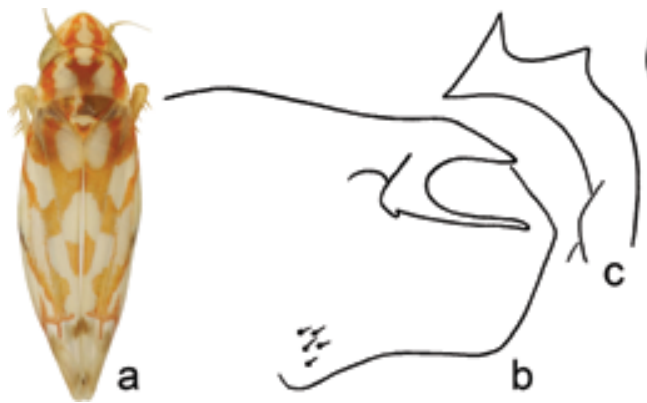

Figure 33. E. bakeri sp.n. a - holotype.

34. Erythroneura anfracta Beamer, 1929 (Fig. 34)

Erythroneura anfracta Beamer, 1929:123

Description: Length $3.1-3.3 \mathrm{~mm}$. 2S abdominal apodemes large, broad, reach $3 \mathrm{~S}$ posterior margin. Pygofer lobe angulate; dorsal appendages not extended beyond pygofer apex, C-shaped, branches subequal in length. Second point of style apex longer than third; third point short; angle between basal and third points about $90^{\circ}$. Aedeagus with preatrium about as long as shaft; shaft curved dorsally, broad in lateral view; compressed in crossection, with strong dorsal keel; ventral

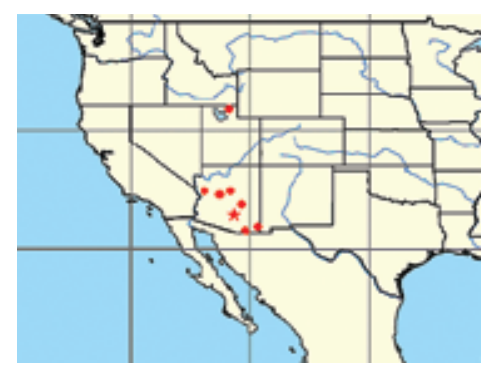
processes placed basally, well separated from shaft, longer than shaft, parallel to each other on ventral side; distal processes subapical, triangular. Dorsum yellow or white, with orange, reddish, or brownish color pattern; vertex with parallel submedial lines, midline pale; anteclypeus pale, concolorous with rest of face; pronotum with Y-shaped medial vitta; mesonotum pale, with dark lateral triangles; scutellum pale; thoracic venter with dark mesosternum, remainder pale; forewings with oblique vittae forming continuous zigzag pattern or interrupted with pale crossband; clavus with separate basal and distal vittae; dark spot at costal margin; apical cell II with distal spot; inner apical cell with brown spot basally. 
Type locality: Holotype đ̊, USA, Arizona, Pinal Co., 6 VIII 1927 (Beamer), (KSEM).

Distribution: Arizona, Utah.

Host plants: Vitis arizonica.
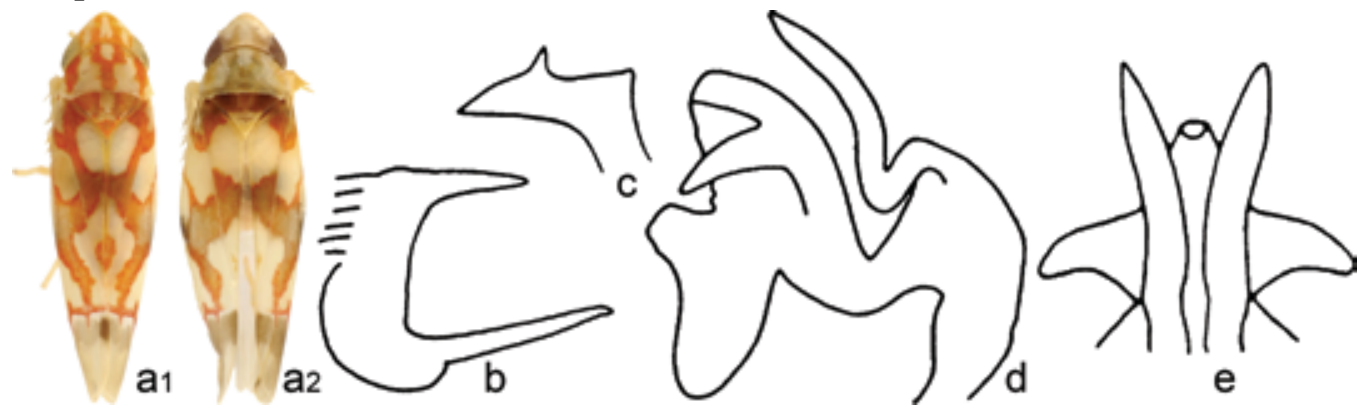

Figure 34. E. anfracta Beamer. a2 - color variation. b-e - from Beamer 1938.

35. Erythroneura ziczac Walsh, 1862 (Fig. 35)

Erythroneura ziczac Walsh, 1862:149

Typhlocyba zigzag Wirtner, 1904:227, missp.

Erythroneura ziczac Beamer, 1938:276, neotype designation

Erythroneura ziczac var. walshi Beamer, 1938:276, syn.n.

Erythroneura zizac Kaloostian, 1952:20, missp.

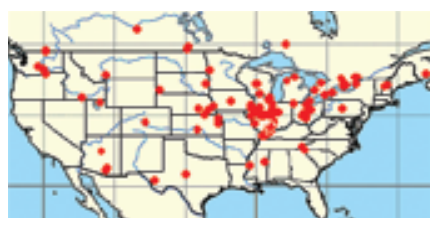

Virginiacreeper leafhopper

Description: Length $2.8-3.1 \mathrm{~mm}$. 2S abdominal apodemes large, broad, reach $3 \mathrm{~S}$ posterior margin. Pygofer lobe angulate; dorsal appendages not extended beyond pygofer apex, C-shaped, branches subequal in length. Second point of style apex well developed; third point elongate, not longer than half distance between other two points; angle between basal and third points less than $90^{\circ}$. Aedeagus with preatrium about as long as shaft; shaft curved dorsally, broad in lateral view, compressed in crossection, with strong dorsal keel, with distinct apical spicules; ventral processes placed basally, well separated from shaft, longer than shaft, parallel to each other on ventral side of aedeagus; distal processes subapical, triangular. Dorsum yellow or white with reddish brown color pattern; vertex with parallel submedial lines, midline pale; anteclypeus pale, concolorous with rest of face; pronotum with Y- or V-shaped medial vitta or almost entirely dark; mesonotum pale, with dark lateral triangles; thoracic venter with dark mesosternum, remainder pale; forewings with oblique vittae forming continuous zigzag pattern; clavus with separate basal and distal vittae; dark spot at costal margin; apical cell II with distal spot; inner apical cell with brown spot basally.

Type locality: Neotype $\widehat{\delta}$, USA, Illinois, Wabash Co., 31 III 1929 (Beamer), (KSEM).

Distribution: USA, southern Canada.

Host plants: Vitis spp.
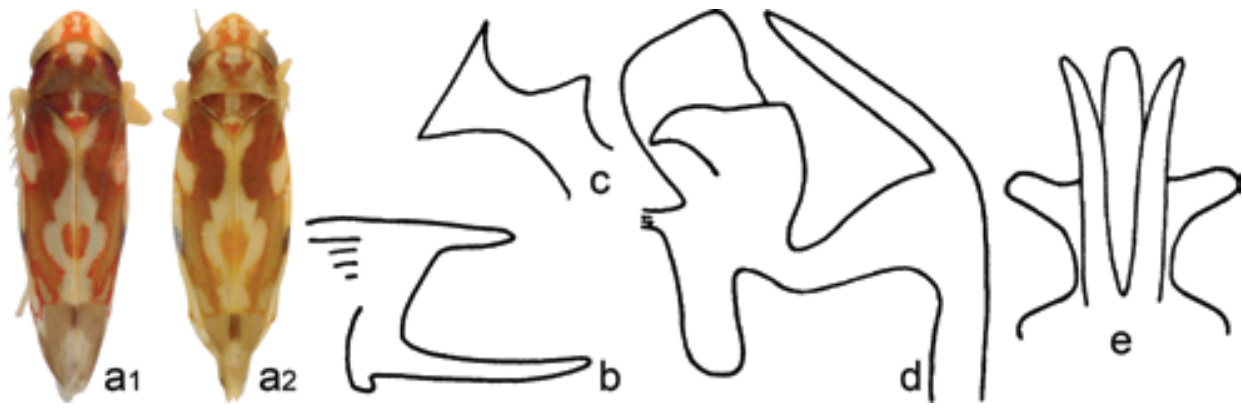

Figure 35. E. ziczac Walsh. a2 - var. walshi. b, d, e - from Beamer 1938; c - from Hepner, unpublished. 
36. Erythroneura elegans McAtee, 1920 (Fig. 36)

Erythroneura comes var. elegans McAtee, 1920:315

Erythroneura elegans Robinson, 1926:137

Description: Length 2.7-2.9 mm. 2S abdominal apodemes small, narrow, extended dorsomesad. Pygofer lobe angulate; dorsal appendages not extended beyond pygofer apex, C-shaped, branches

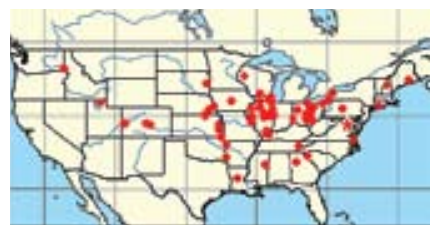
subequal in length. Second point of style apex longer than third; third point short; angle between basal and third points less than $90^{\circ}$. Aedeagus with preatrium about as long as shaft; shaft curved dorsally, broad in lateral view, compressed in crossection, with strong dorsal keel, with distinct apical spicules; ventral processes placed basally, well separated from shaft, longer than shaft, parallel to each other on ventral side of aedeagus; distal processes subapical, triangular. Dorsum yellow or white, with reddish brown color pattern; vertex with orange parallel submedial lines, midline pale; anteclypeus pale, concolorous with rest of face; pronotum with Y-shaped medial vitta; mesonotum pale, with dark lateral triangles; thoracic venter with dark mesosternum, remainder pale; forewings with oblique vittae forming zigzag pattern, pale narrow crossband at middle interrupted with red longitudinal veins; dark spot at costal margin; apical cell II with distal spot; inner apical cell with brown spot basally.

Type locality: Holotype ô, USA, Maryland, Montgomery Co., Plummers Island, 11 I 1914 (McAtee), (USNM).

Distribution: USA, southern Canada.

Host plants: Vitis spp.

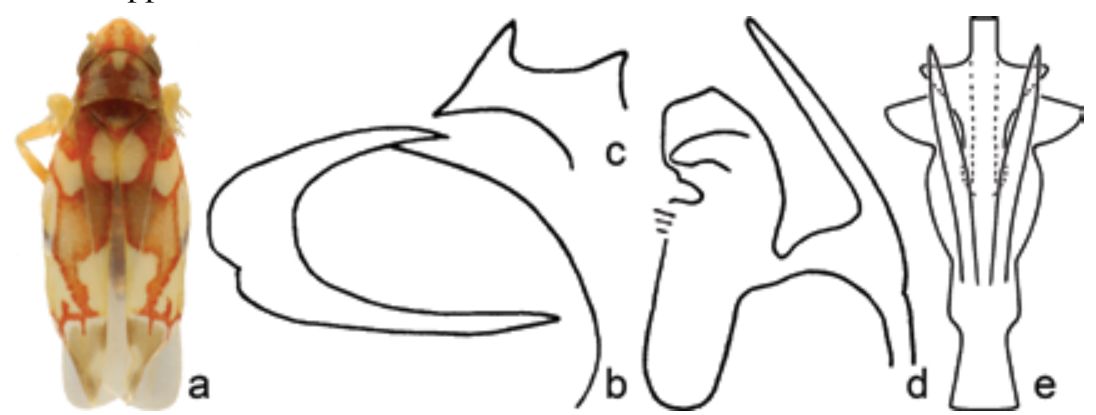

Figure 36. E. elegans McAtee. a - holotype. d-from Beamer 1938; b, c-from Hepner, unpublished.

37. Erythroneura delicata McAtee, 1920 (Fig. 37)

Erythroneura comes var. delicata McAtee, 1920:317

Erythroneura comes var. accepta McAtee, 1920:317, syn.n.

Erythroneura lacta Robinson, 1924a:62

Erythroneura scripta Robinson, 1924c:290, syn.n.

Erythroneura tudella Robinson, 1924c:291, syn.n.

Erythroneura delicata Johnson, 1935:110

Erythroneura delictata Young, 1952:80, missp.

Description: Length 2.9-3.2 mm. 2S abdominal apodemes large, broad, reach $3 \mathrm{~S}$ posterior margin. Pygofer lobe rounded; dorsal appendages not extended beyond pygofer apex, C-shaped, branches subequal in length. Second point of style apex well developed; third point subequal in size with second; angle between basal and third points about $90^{\circ}$. Aedeagus with preatrium longer than shaft; shaft curved dorsally, slender in lateral view, round in crossection; apex usually broadened in ventral view; ventral processes placed basally, well separated from shaft, longer than shaft, parallel to each other on ventral side of aedeagus; distal processes subapical, slender. Dorsum yellow or white, with orange color pattern; vertex with orange parallel submedial lines, midline pale; anteclypeus pale, concolorous with rest of face; pronotum with Y-shaped medial vitta; mesonotum pale, with orange lateral triangles; thoracic venter with dark mesosternum, remainder pale; forewing with broken oblique vittae; clavus with separate basal and distal vittae, in some cases with 
dark brown spot at middle; dark spot at costal margin; apical cell II with distal spot; inner apical cell with brown spot basally.

Type locality: Holotype + , USA, Maryland, Montgomery Co., Plummers Island, 26 VII 1914 (McAtee), (USNM).

Distribution: Central and northeastern USA, southeastern Canada.

Host plants: Vitis spp.
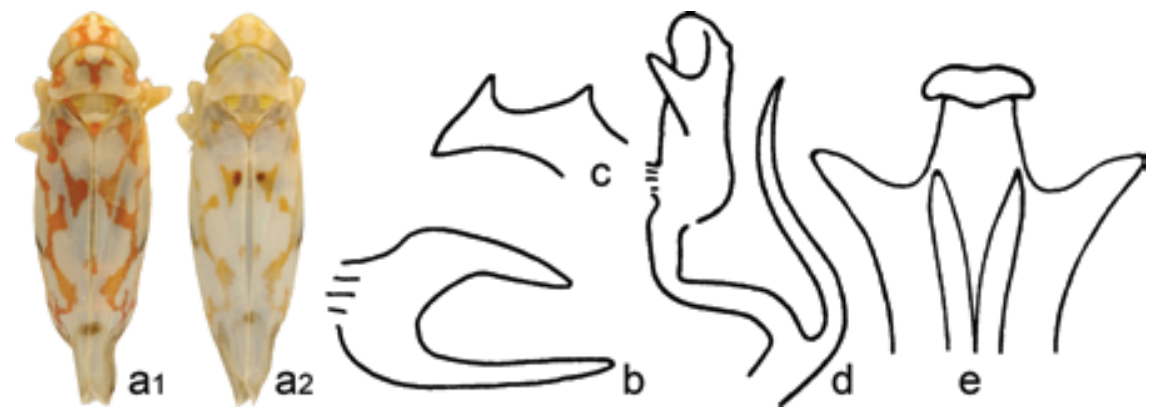

Figure 37. E. delicata McAtee. a2 - var. accepta. b, d, e - from Beamer 1938; c - from Hepner, unpublished.

38. Erythroneura vitifex Fitch, 1856 (Fig. 38)

Erythroneura vitifex Fitch, 1856:392

Erythroneura vitifex Beamer, 1938:281, neotype designation Erythroneura vitifix Padley, 1941:395, missp.

Description: Length $2.7-3 \mathrm{~mm}$. Abdomen. $2 \mathrm{~S}$ abdominal apodemes large, broad, reach $3 \mathrm{~S}$ posterior margin. Pygofer lobe

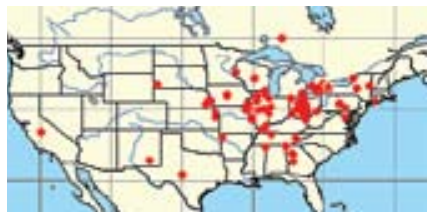
angulate; dorsal appendages not extended beyond pygofer apex, C-shaped, branches subequal in length. Second point of style apex longer than third; third point short; angle between basal and third points less than $90^{\circ}$. Aedeagus with preatrium longer than shaft; shaft curved dorsally, broad in lateral view, round in crossection, with dorsal carina; ventral processes placed basally, well separated from shaft, longer than shaft, parallel to each other on ventral side of aedeagus; distal processes subapical, triangular. Dorsum yellow or white, with red or orange color pattern; vertex with orange parallel submedial lines, midline pale; anteclypeus pale, concolorous with rest of face; pronotum with Y-shaped medial vitta; mesonotum pale, with reddish lateral triangles; thoracic venter with dark mesosternum, remainder pale; forewing with oblique vittae forming continuous zigzag pattern; clavus with separate basal and distal vittae; dark spot at costal margin; apical cell II with distal spot; inner apical cell with brown spot basally.

Type locality: Neotype ơ, Canada, Ontario, Vineland, VIII 1922, (Robinson), (KSEM).

Distribution: USA, southern Canada.

Host plants: Vitis spp.
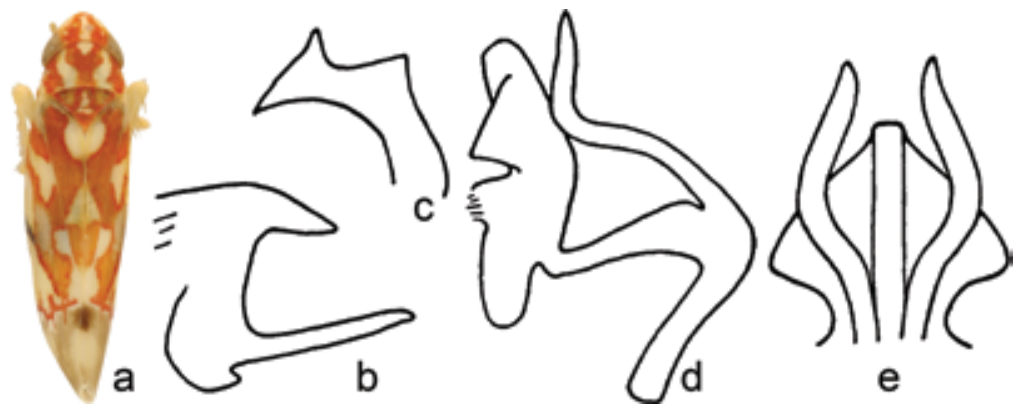

Figure 38. E. vitifex Fitch. b-e - from Beamer 1938. 
39. Erythroneura rubra (Gillette, 1898) (Fig. 39)

Typhlocyba comes var. rubra Gillette, 1898:764

Erythroneura comes var. rubra Van Duzee, 1916:77

Erythroneura irrorata Robinson, 1924b:154

Erythroneura rubra Robinson, 1926:135

Description: Length 2.9-3.1 mm. 2S abdominal apodemes large, broad, reach $3 \mathrm{~S}$ posterior margin. Pygofer lobe angulate; dorsal appendages not extended beyond pygofer apex, $\mathrm{C}$-shaped, branches subequal in length. Second point of style apex well developed; third point subequal in size with second;

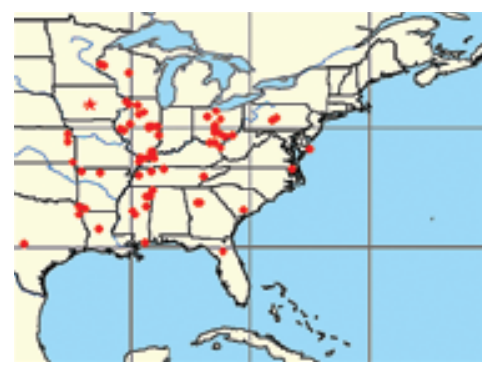
angle between basal and third points about $90^{\circ}$. Aedeagus

with preatrium longer than shaft; shaft curved dorsally, broad in lateral view, round in crossection, with dorsal carina, with distinct apical spicules; ventral processes placed basally, well separated from shaft, longer than shaft, parallel to each other on ventral side of aedeagus; distal processes subapical, triangular. Dorsum yellow or white, with strongly developed reddish color pattern; vertex with orange parallel submedial lines, midline pale; anteclypeus pale, concolorous with rest of face; pronotum with Y- or V-shaped medial vitta; mesonotum entirely red; thoracic venter entirely dark; forewings with oblique vittae forming zigzag pattern; clavus with separate basal and distal vittae; dark spot at costal margin; apical cell II with distal spot; inner apical cell without brown spot.

Type locality: Holotype $\uparrow$, USA, Iowa, (Baker), (USNM).

Distribution: Central and eastern USA.

Host plants: Vitis spp.
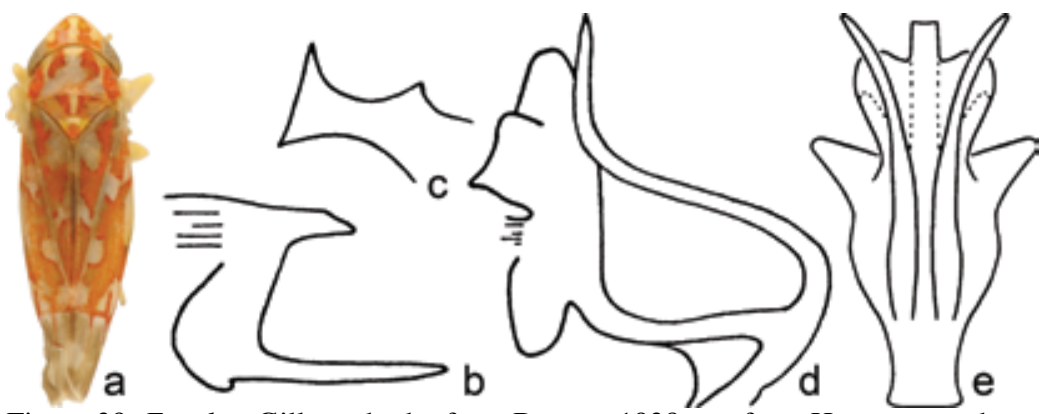

Figure 39. E. rubra Gillette. b, d - from Beamer 1938; c - from Hepner, unpublished

40. Erythroneura vitis (Harris, 1831) (Fig. 40)

Tettigonia vitis Harris, 1831:43

Erythroneura vitis Fitch, 1851:63

Erythroneura vitis var. corona McAtee, 1920:304, syn.n.

Erythroneura comes var. venusta McAtee, 1920:319

Erythroneura vitis var. flava Robinson, 1924a:62

Grapevine leafhopper

Description: Length $2.8-3.1 \mathrm{~mm}$. $2 \mathrm{~S}$ abdominal apodemes large, broad, reach $3 \mathrm{~S}$ posterior margin. Second point of style apex longer than third; third point shorter than second; angle between basal and third points less than $90^{\circ}$. Aedeagus with preatrium about as long as shaft; shaft curved dorsally, broad in lateral view, round in crossection, with dorsal carina, with distinct apical spicules; ventral processes placed basally, well separated from shaft, longer than shaft, parallel to each other on ventral side of aedeagus; distal processes apical, triangular. Coloration strongly varies; dorsum yellow or white, with reddish brown color pattern; vertex unicolorous pale or with orange parallel submedial lines, midline pale; anteclypeus pale, concolorous with rest of face; pronotum with Y- or V-shaped medial vitta or almost entirely dark; mesonotum entirely dark; thoracic venter with dark mesosternum, remainder pale; forewing with two pale crossbands of various width; dark 
spot at costal margin; apical cell II without distal spot; inner apical cell without brown spot.

Type locality: Holotype [sex unknown], USA, New York, (Harris), (BSNH). Type was not studied.

Distribution: Eastern and southwestern USA, southeastern Canada.

Host plant: Vitis spp.
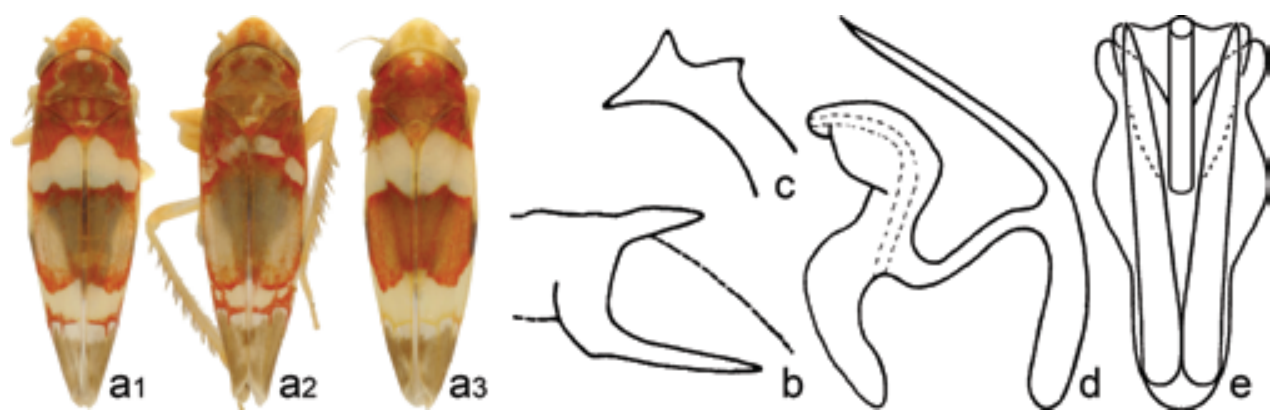

Figure 40. E. vitis Harris. a2 - var. corona; a3 - var. flava; b, c - from Beamer 1938; d - from Hepner, unpublished.

41. Erythroneura coloradensis (Gillette, 1892) (Fig. 41)

Typhlocyba vitifex var. coloradoensis Gillette, 1892:16

Typhlocyba vitifex var. coloradensis Gillette \& Baker, 1895:113, emend.

Erythroneura comes var. coloradensis Van Duzee, 1914:57

Typhlocyba celoradensis Merrill, 1915:21, missp.

Typhlocyba colorado Gillette \& List, 1921:20, missp.

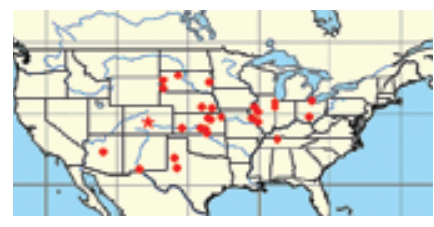

Erythroneura coloradensis Robinson, 1926:134

Erythroneura coloradensis Beamer, 1938:278, lectotype designation

Description: Length $2.8-3.2 \mathrm{~mm}$. 2S abdominal apodemes small, narrow, extended dorsomesad. Pygofer lobe rounded; dorsal appendages not extended beyond pygofer apex, C-shaped, branches subequal in length. Second point of style apex well developed; third point of style apex not longer than half distance between other two points; angle between basal and third points less than $90^{\circ}$. Aedeagus with preatrium longer than shaft; shaft curved dorsally, broad in lateral view, round in crossection, with dorsal carina, with distinct apical spicules; ventral processes placed basally, well separated from shaft, longer than shaft, parallel to each other on ventral side of aedeagus; distal processes apical, triangular. Dorsum yellow or white, with reddish or orange color pattern; vertex with orange parallel submedial lines, midline pale; anteclypeus pale, concolorous with rest of face; pronotum with Y- or V-shaped medial vitta; mesonotum pale, with black lateral triangles; thoracic venter with dark mesosternum, remainder pale; forewing with broken oblique vittae; clavus with separate basal and distal vittae; dark spot at costal margin; apical cell II with distal spot; inner apical cell with brown spot basally.

Type locality: Lectotype $\widehat{\delta}$, USA, Colorado, (Gillette), (USNM).

Distribution: Central and southwestern USA, southeastern Canada.

Host plants: Vitis spp.

42. Erythroneura fraxa Robinson, 1924 (Fig. 42)
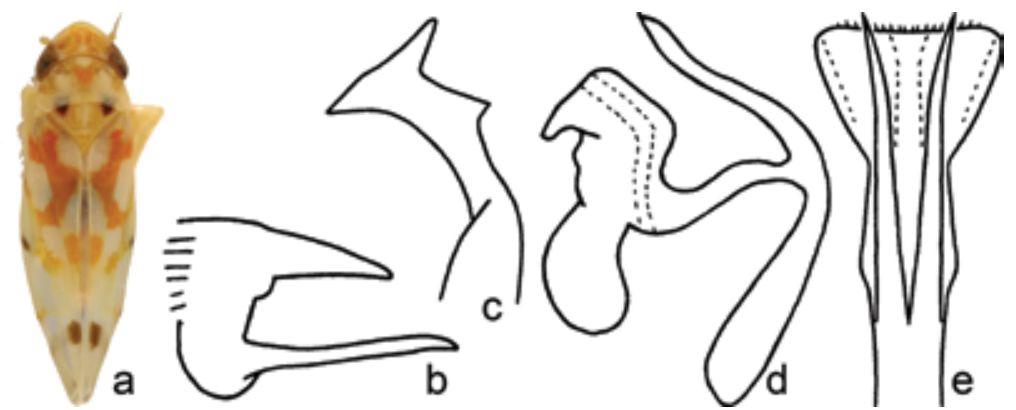

Figure 41. E. coloradensis Gillette. b- from Beamer 1938; d - from Hepner, unpublished. 
Erythroneura fraxa Robinson, 1924c:292

Description: Length 2.9-3.2 mm. 2S abdominal apodemes large, broad, reach $3 \mathrm{~S}$ posterior margin. Pygofer lobe rounded; dorsal appendages not extended beyond pygofer apex, C-shaped, branches subequal in length. Second point of style apex well developed; third point not longer than half distance between other two points; angle between basal and third points less than $90^{\circ}$. Aedeagus with preat-

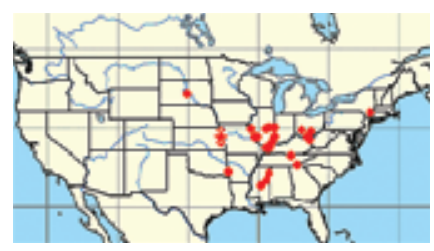
rium longer than shaft; shaft straight in lateral view, slender in lateral view, round in crossection, with distinct apical spicules; ventral processes placed basally, well separated from shaft, longer than shaft, parallel to each other on ventral side of aedeagus; distal processes apical, triangular. Dorsum yellow or white, with orange or red color pattern; vertex with orange parallel submedial lines, midline pale; anteclypeus pale, concolorous with rest of face; pronotum with Y-shaped medial vitta; mesonotum pale, with reddish lateral triangles; thoracic venter with dark mesosternum, remainder pale; forewing with oblique vittae usully forming continuous zigzag pattern; clavus with separate basal and distal vittae; dark spot at costal margin; apical cell II with distal spot; inner apical cell with brown spot basally.

Type locality: Holotype $q$, USA, Kansas, Douglas Co., XII 1923, (Robinson), (KSEM).

Distribution: Central and eastern USA.

Host plants: Cercis canadensis.
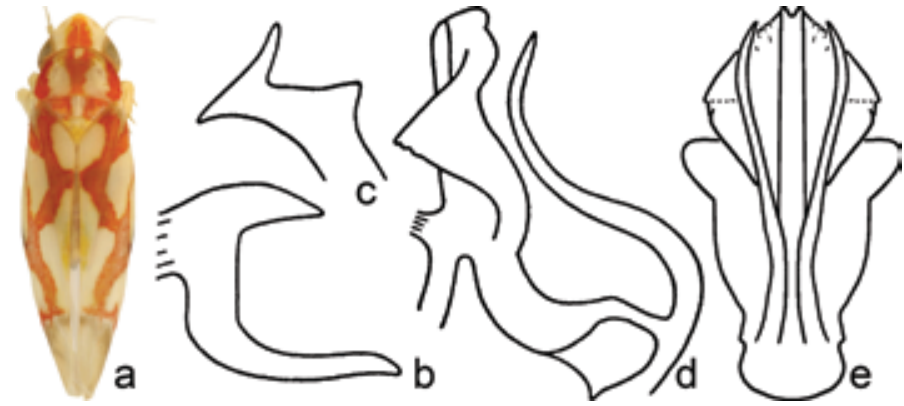

Figure 42. E. fraxa Robinson. b-d - from Beamer 1938.

\section{Erythroneura vaga Johnson, 1934 (Fig. 43)}

Erythroneura vaga Johnson, 1934:260

Description: Length $2.9-3.1 \mathrm{~mm}$. $2 \mathrm{~S}$ abdominal apodemes small, narrow, extended dorsomesad. Pygofer lobe rounded; dorsal appendages not extended beyond pygofer apex, Cshaped, branches subequal in length. Second point of style apex well developed; third point elongate, longer than distance between other two points; angle between basal and third points less than $90^{\circ}$. Aedeagus with preatrium shorter than shaft; shaft curved dorsally, slender in lateral view, round in crossection,

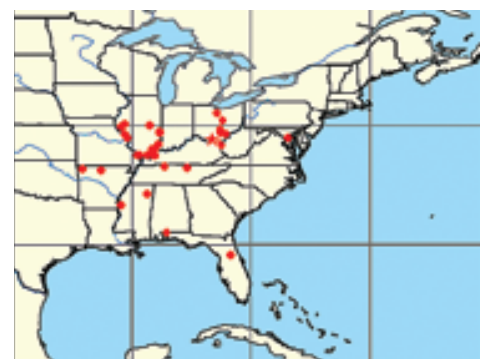
with unpaired process on dorsal apodeme; ventral processes placed basally, close to shaft, shorter than shaft, parallel to each other on ventral side of aedeagus; distal processes apical, slender. Coloration similar to E. comes Say.

Type locality: Holotype $\widehat{\jmath}$, USA, Ohio, Adams Co., Mineral Springs, 31 VIII 1931 (Osborn), (OSU). Distribution: Central and eastern USA.

Host plants: Cercis canadensis.

Note: E. vaga sensu Beamer, 1938a equals E. kerzhneri sp.n.
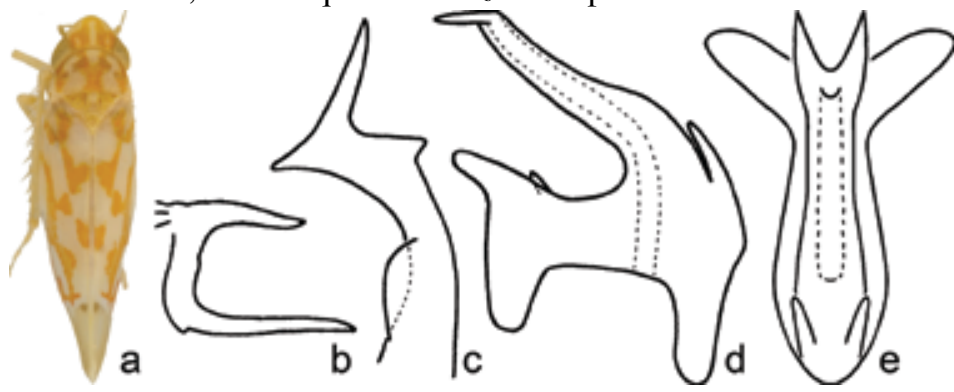

Figure 43. E. vaga Johnson. b - from Beamer 1938. 
44. Erythroneura kerzhneri Dmitriev \& Dietrich sp.n. (Fig. 44)

Erythroneura vaga Beamer, 1938:285 not Johnson, 1934, misid.

Description: Length $2.8-3.1 \mathrm{~mm}$. 2S abdominal apodemes small, narrow, extended dorsomesad. Pygofer lobe rounded; dorsal appendages not extended beyond pygofer apex, Cshaped, branches subequal in length. Second point of style apex well developed; third point elongate, about as long as distance between other two points; angle between basal and third points less than $90^{\circ}$. Aedeagus with preatrium shorter

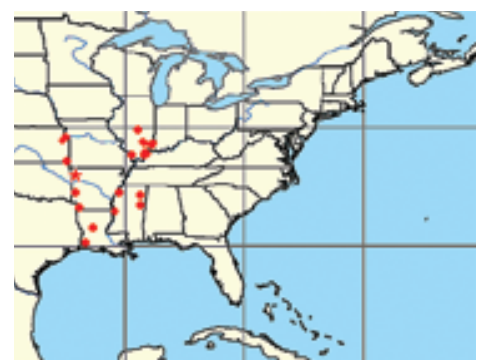
than shaft; shaft symmetrical, curved ventrally, slender in lateral view, smooth or denticulate distally, round in crossection; with pair of long dorsal processes between shaft and dorsal apodeme; apex of aedeagus broadened in ventral view; ventral processes placed basally, well separated from shaft, shorter than shaft, parallel to each other on ventral side of aedeagus, simple or bifurcated at apex; distal processes short, apical. Coloration similar to that of E. kennedyi Knull; dorsum yellow or white, with reddish or orange color pattern; vertex with orange parallel submedial lines (often with lateral branch), midline pale; anteclypeus pale, concolorous with rest of face; pronotum with Y-shaped medial vitta; mesonotum pale, with reddish lateral triangles; thoracic venter entirely pale; forewing with broken oblique vittae; clavus with separate basal and distal vittae; dark spot at costal margin; apical cell II with distal spot; inner apical cell with brown spot basally.

Diagnosis: E. kerzhneri sp.n. is similar to E. kennedyi Knull, but has the dorsal and distal processes of the aedeagus much shorter, the basal processes longer, and the third point of the style longer, about as long as distance between other points.

Type locality: Holotype $\widehat{\delta}$, USA, Arkansas, Washington Co., 30 VI 1940 (Sanderson), (KSEM). Studied material: Paratypes: USA, 2 ô, Arkansas, Miller Co., Fouke, 21 XII 1931 (Beamer), (KSEM); 2 §, Arkansas, Polk Co., 21 VIII 1928 (Beamer), (KSEM); 2 §, Illinois, Clay Co., 31 III 1929 (Oman), (KSEM); 1 ô, Illinois, Clay Co., 31 III 1929 (Beamer), (KSEM); 8 ô, Illinois, Clay Co., Flora, 31 III 1929 (Beamer), (KSEM). Other studied material from Illinois, Kansas, Louisiana, and Mississippi excluded from paratypes.

Distribution: Central and southeastern USA.

Host plants: Ilex decidua, Ulmus alata.

Note: The species named in honor of Prof. Izyaslav Kerzhner (Zoological Institute, Russian Academy of Sciences, St. Petersburg), Russian specialist on Heteroptera.
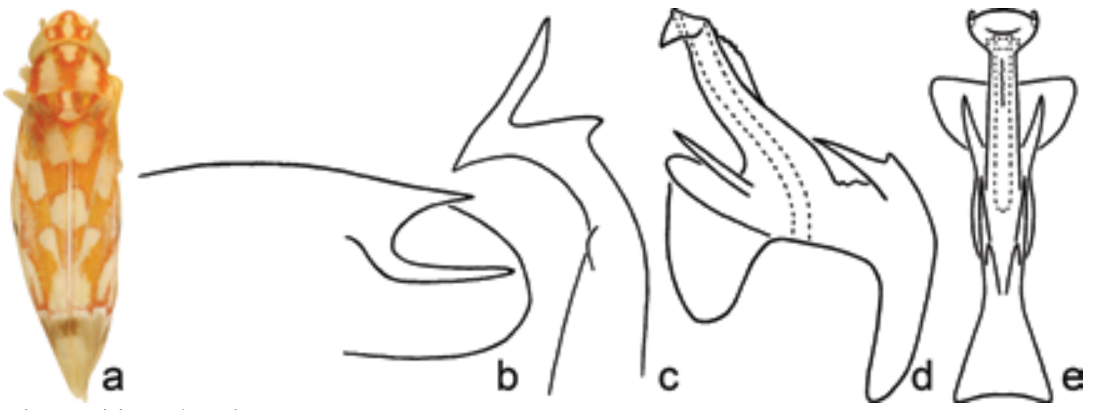

Figure 44. E. kerzhneri sp.n.

\section{Erythroneura kennedyi Knull, 1945 (Fig. 45)}

Erythroneura kennedyi Knull, 1945:109

Description: Length $2.9-3.1 \mathrm{~mm}$. 2S abdominal apodemes small, narrow, extended dorsomesad. Pygofer lobe rounded; dorsal appendages not extended beyond pygofer apex, Cshaped, branches subequal in length. Second point of style apex longer than third; third point not longer than half distance between other two points; angle between basal and third points less than $90^{\circ}$. Aedeagus with preatrium shorter than

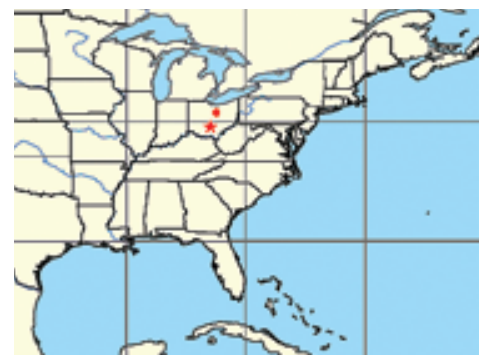


shaft of aedeagus; shaft straight and slender in lateral view, round in crossection; with long dorsal processes between shaft and dorsal apodeme; ventral processes placed basally, close to shaft, shorter than shaft, parallel to each other on ventral side; aedeagus distal processes apical, slender. Dorsum yellow or white, with reddish or orange color pattern; vertex with parallel submedial lines, midline pale; anteclypeus pale, concolorous with rest of face; pronotum with Y-shaped medial vitta; mesonotum pale, with reddish lateral triangles; thoracic venter entirely pale; forewing with broken oblique vittae; clavus with separate basal and distal vittae; dark spot at costal margin; apical cell II with distal spot; inner apical cell with brown spot basally.

Type locality: Holotype $\hat{o}$, USA, Ohio, Pickaway Co., 20 II 1934 (Caldwell), (OSU).

Distribution: Known only from type locality in Ohio.

Host plants: Unknown.

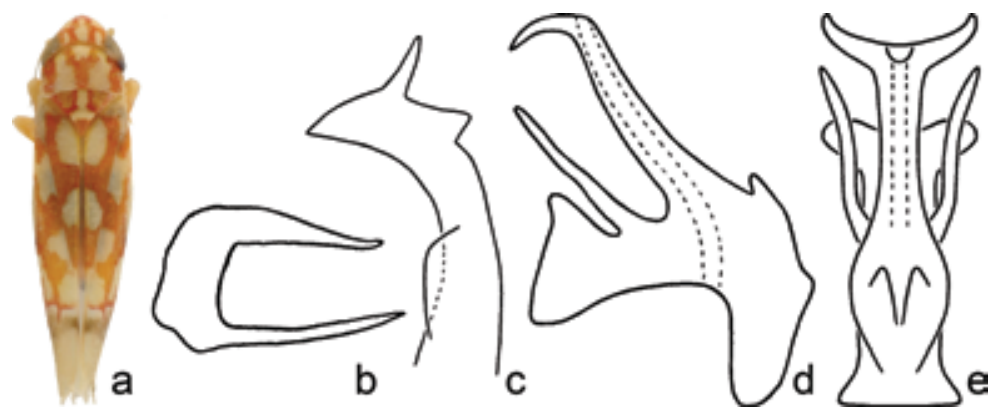

Figure 45. E. kennedyi Knull. b - from Knull 1945.

46. Erythroneura ancora Beamer, 1929 (Fig. 46)

Erythroneura ancora Beamer, 1929:122

Description: Length 3.1-3.2 mm. Male genitalia. Pygofer lobe rounded; dorsal appendages not extended beyond pygofer apex, C-shaped, branches subequal in length. Second point of style apex longer than third; third point short; angle between basal and third points about $90^{\circ}$. Aedeagus with preatrium shorter than shaft; shaft curved dorsally, slender in lateral view, with small dorsal distal lobe; ventral processes placed basally, close to shaft, shorter than shaft; distal

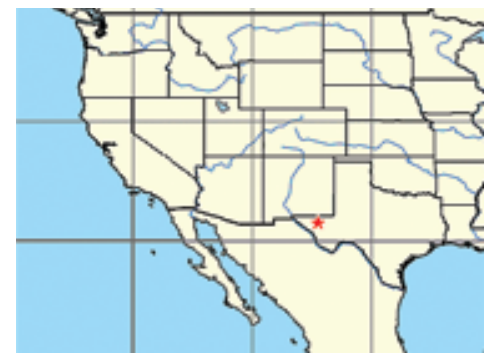
processes absent. Dorsum yellow, with orange color pattern; vertex with orange parallel submedial lines, midline pale; anteclypeus pale, concolorous with rest of face; pronotum with Y-shaped medial vitta; mesonotum pale, with dark lateral triangles; thoracic venter entirely pale; forewings with oblique vittae usully forming zigzag pattern; clavus with separate basal and distal vittae; dark spot at costal margin; apical cell II with distal spot; inner apical cell with brown spot basally.

Type locality: Holotype, ô, USA, Texas, Culberson Co., 10 VII 1927 (Beamer), (KSEM).

Distribution: Known only from type locality in Texas.

Host plants: Unknown.

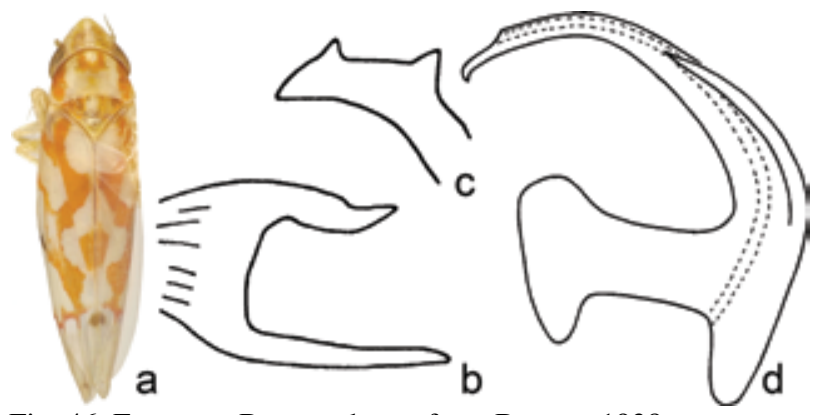

Fig. 46. E. ancora Beamer. b, c- from Beamer 1938. 
47. Erythroneura tacita Beamer, 1938 (Fig. 47)

Erythroneura tacita Beamer, 1938:293

Description: Length 3.1-3.5 mm. 2S abdominal apodemes small, narrow, extended dorsomesad. Pygofer lobe rounded; dorsal appendages not extended beyond pygofer apex, C-shaped, dorsal branch strongly reduced, ventral branch much longer. Second

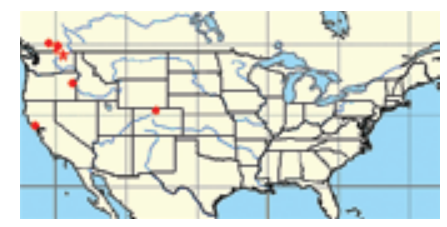
point of style apex longer than third; third point very short; angle between basal and third points about $90^{\circ}$. Aedeagus with preatrium about as long as shaft; shaft curved dorsally, slender in lateral view, round in crossection; ventral processes placed basally, well separated from shaft, shorter than shaft, evenly divergent; distal processes long, slender. Dorsum yellow or white, with reddish or orange color pattern; vertex with orange parallel submedial lines, midline pale; anteclypeus pale, concolorous with rest of face; pronotum with Y-shaped medial vitta; mesonotum entirely pale; thoracic venter entirely pale; forewing with broken oblique vittae; clavus with separate basal and distal vittae; dark spot at costal margin; apical cell II with distal spot; inner apical cell with brown spot basally.

Type locality: Holotype $\widehat{0}$, USA, Washington, Ferry Co., Republic, 6 VIII 1931 (Beamer), (KSEM).

Distribution: Western USA, southwestern Canada.

Host plants: Unknown.
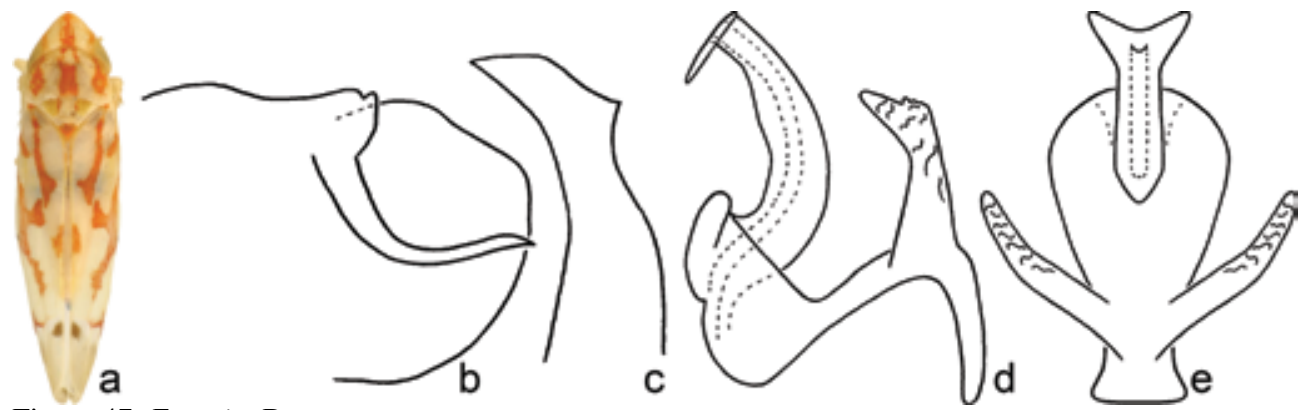

Figure 47. E. tacita Beamer.

48. Erythroneura caetra McAtee, 1924 (Fig. 48)

Erythroneura ligata var. caetra McAtee, 1924b:130

Erythroneura ligata var. caestra DeLong \& Caldwell, 1937:79, missp.

Erythroneura caetra Beamer, 1938:281

Description: Length $2.9-3.3 \mathrm{~mm}$. $2 \mathrm{~S}$ abdominal apodemes

large, broad, reach $3 \mathrm{~S}$ posterior margin. Pygofer lobe angulate;

dorsal appendages extended beyond pygofer apex, C-shaped, ventral branch much longer than dorsal. Second point of style apex longer than third; third point of style apex very short or absent. Aedeagus with preatrium shorter than shaft; shaft curved dorsally, broad in lateral view, compressed in crossection, with subapical dorsal lobe, with distinct apical spicules; ventral processes placed basally, well separated from shaft, shorter than shaft, parallel to each other on ventral side of aedeagus; distal processes apical, small, toothlike. Dorsum yellow or white with reddish brown color; vertex with parallel submedial lines, midline pale; anteclypeus dark; pronotum dark with pale lateral margins; mesonotum pale, with black lateral triangles; thoracic venter with dark mesosternum, remainder pale; forewings with oblique vittae forming continuous zigzag pattern; clavus with continuous vitta parallel to suture; dark spot at costal margin; apical cell II with distal spot; inner apical cell with brown spot basally.

Type locality: Holotype + , USA, California, Monterey Co., Salinas, 26 IV 1908 (Ball), (USNM). Distribution: Western USA, southwestern Canada.

Host plants: Salix exigua. 

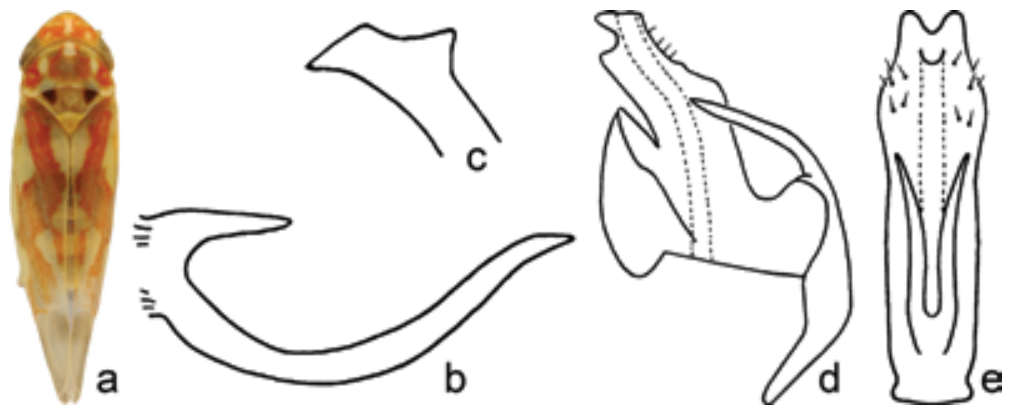

Figure 48. E. caetra McAtee. b, c - from Beamer 1938.

49. Erythroneura rosa Robinson, 1924 (Fig. 49)

Erythroneura rosa Robinson, 1924a:58

Erythroneura mallochi McAtee, 1924c:41

Erythroneura repetita McAtee, 1926:131, syn.n.

Description: Length $2.8-3.2 \mathrm{~mm}$. 2S abdominal apodemes large, broad, reach $3 \mathrm{~S}$ posterior margin. Pygofer lobe angulate;

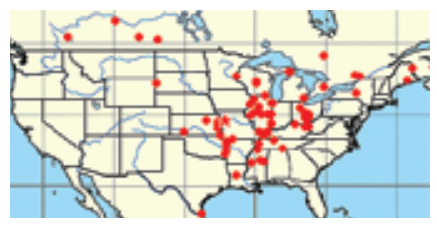
dorsal appendages extended beyond pygofer apex, C-shaped, ventral branch much longer than dorsal, branches strongly divergent. Second point of style apex longer than third; third point very short or absent. Aedeagus with preatrium shorter than shaft; shaft curved dorsally, broad in lateral view, compressed in crossection, with subapical dorsal lobe, with distinct apical spicules; ventral processes placed basally, well separated from shaft, shorter than shaft, parallel to each other on ventral side of aedeagus; distal processes apical, small toothlike. Dorsum yellow or white, with reddish or brownish color pattern; vertex with orange parallel submedial lines, midline pale; anteclypeus dark; pronotum dark with pale lateral margins or pale with two longitudinal strips; mesonotum pale, with dark lateral triangles; thoracic venter with dark mesosternum, remainder pale; forewings with oblique vittae forming zigzag pattern or dark with two narrow crossbands; dark spot at costal margin; apical cell II with distal spot; inner apical cell with brown spot basally.

Type locality: Holotype ô, USA, Missouri, Jackson Co., Atherton, 19 V 1922 (Adams), (KSEM). Distribution: Central and eastern USA, southern Canada.

Host plants: Salix myricoides, S. babylonica, S. cordata, S. bebbiana, S. petiolaris, S. caprea, S. humilis, S. interior.
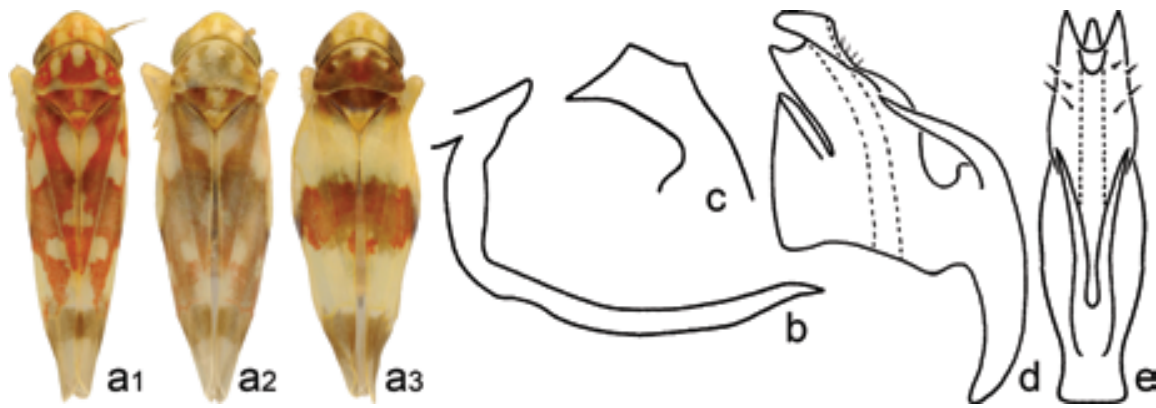

Figure 49. E. rosa Robinson. a2 - var. mallochi; a3 - var. repetita; b, c - from Beamer 1938. 
50. Erythroneura omaska Robinson, 1924 (Fig.50)

Erythroneura omaska Robinson, 1924a:62

Description: Length 3-3.2 mm. 2S abdominal apodemes small, narrow, extended dorsomesad. Pygofer lobe rounded; dorsal appendages not extended beyond pygofer apex, Cshaped, branches subequal in length. Second point of style apex longer than third; third point short; angle between basal and third points about $90^{\circ}$. Aedeagus with preatrium shorter than shaft; shaft curved dorsally, slender in lateral view, denticulate distally, depressed in crossection. Aedeagus with

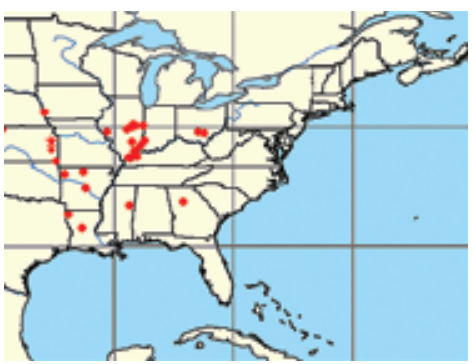
two dorsal processes arising near midlength of shaft; ventral processes absent; distal processes apical, slender. Dorsum yellow or white, with reddish or orange color pattern; vertex with parallel submedial lines, midline pale; anteclypeus pale, concolorous with rest of face; pronotum with Yor V-shaped medial vitta; mesonotum pale, with orange lateral triangles; thoracic venter with dark mesosternum, remainder pale; forewing with broken oblique vittae; clavus with separate basal and distal vittae; dark spot at costal margin; apical cell II with distal spot; inner apical cell with brown spot basally.

Type locality: Holotype $\widehat{o}$, USA, Kansas, Douglas Co., X 1923, (Robinson), (KSEM).

Distribution: Central and eastern USA.

Host plants: Unknown. Recorded from Rubus sp., Vitis sp., Ilex decidua.

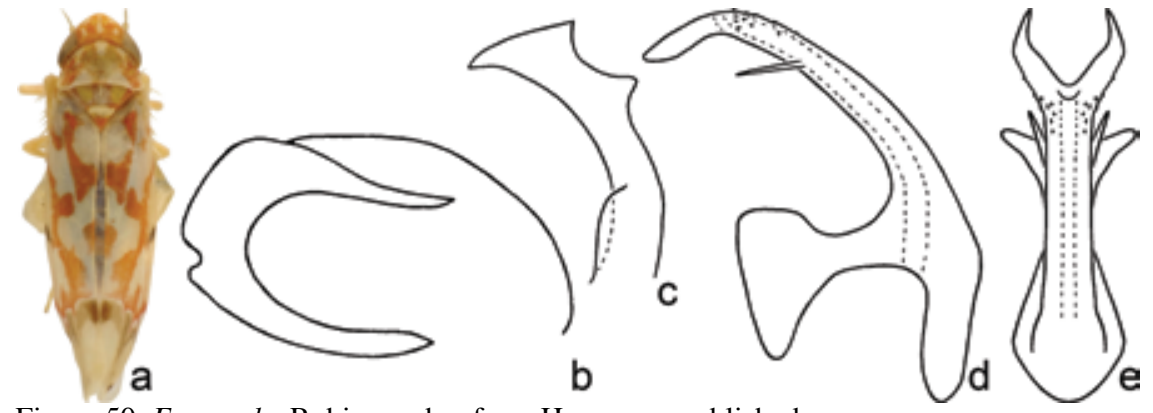

Figure 50. E. omaska Robinson. b - from Hepner, unpublished.

51. Erythroneura rubrella McAtee, 1920 (Fig. 51)

Erythroneura comes var. rubrella McAtee, 1920:316

Erythroneura rubrella Johnson, 1935:109

Description: Length $2.7-3 \mathrm{~mm}$. 2S abdominal apodemes small, narrow, extended dorsomesad. Pygofer lobe angulate; dorsal appendages extended beyond pygofer apex, $\mathrm{C}$-shaped, ventral branch much longer than dorsal. Second point of style apex very short, tooth like; third point of style apex subequal in size with second; angle between basal and third points about $90^{\circ}$. Aedeagus with preatrium shorter than shaft; shaft straight and broad in lateral view, compressed in crossection, with dorsal keel; apex of aedeagus acuminate in ventral view, with distinct apical spicules; ventral processes absent; distal processes absent. Dorsum yellow or white, with reddish color pattern; vertex with orange parallel submedial lines, midline red; anteclypeus dark; pronotum dark with pale lateral margins or pale with two longitudinal strips; mesonotum pale, with reddish lateral triangles; thoracic venter entirely dark; forewing with broken oblique vittae; clavus with separate basal and distal vittae; dark spot at costal margin; apical cell II without distal spot; inner apical cell without brown spot.

Type locality: Holotype ơ, USA, Maryland, Montgomery Co., Plummers Island, 30 XI 1913

(McAtee), (USNM).

Distribution: Northwestern, central, and eastern USA, southern Canada.

Host plants: Cornus pumila, C. stolonifera. 

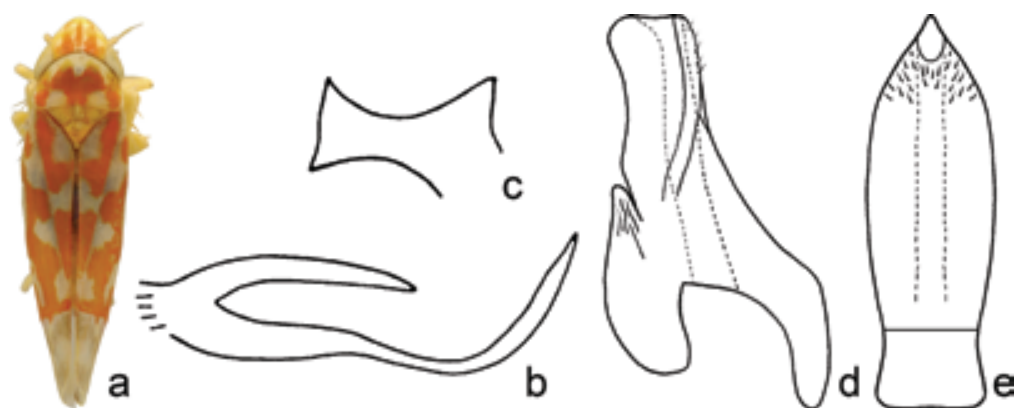

Figure 51. E. rubrella McAtee. b - from Beamer 1938; c - from Hepner, unpublished.

52. Erythroneura corni Robinson, 1924 (Fig. 52)

Erythroneura corni Robinson, 1924a:60

Erythroneura ornata Osborn, 1928b:364

Description: Length $2.6-3 \mathrm{~mm}$. $2 \mathrm{~S}$ abdominal apodemes large, broad, reach $3 \mathrm{~S}$ posterior margin. Pygofer lobe rounded; dorsal appendages extended beyond pygofer apex, C-shaped, branches very long of subequal length. Second point of style apex very short, tooth like; third point not longer than half dis-

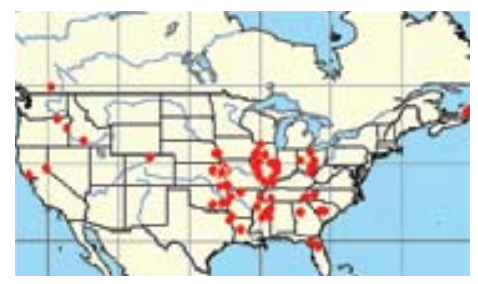
tance between other two points; angle between basal and third points about $90^{\circ}$. Aedeagus with preatrium shorter than shaft; shaft curved dorsally, slender in lateral view, compressed in crossection, with long dorsal distal lobe; apex acuminate in ventral view, with distinct apical spicules. Aedeagus without processes. Dorsum yellow or white, with orange or red color pattern; vertex with parallel submedial lines, midline red; anteclypeus dark; pronotum dark with pale lateral margins or pale with two longitudinal strips; mesonotum pale, with reddish lateral triangles; thoracic venter entirely dark; forewing with broken oblique vittae; clavus with separate basal and distal vittae; dark spot at costal margin; apical cell II without distal spot; inner apical cell without brown spot.

Type locality: Holotype $\widehat{o}$, USA, Kansas, Douglas Co., X 1923, (Robinson), (KSEM).

Distribution: USA, southern Canada.

Host plants: Cornus spp.
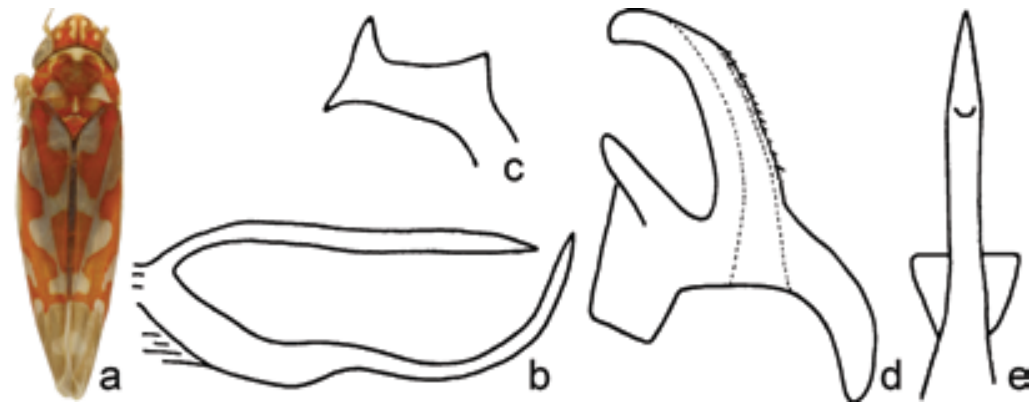

Figure 52. E. corni Robinson. b, c - from Beamer 1938; e - Hepner, unpublished.

\section{Erythroneura bidens McAtee, 1924 (Fig. 53)}

Erythroneura comes var. bidens McAtee, 1924a:39

Erythroneura comes var. suffusa McAtee, 1924a:39

Erythroneura bidens Beamer, 1938:287

Description: Length $2.8-3.2 \mathrm{~mm}$. $2 \mathrm{~S}$ abdominal apodemes small, narrow, extended dorsomesad. Pygofer lobe rounded; dorsal appendages extended beyond pygofer apex, C-shaped;

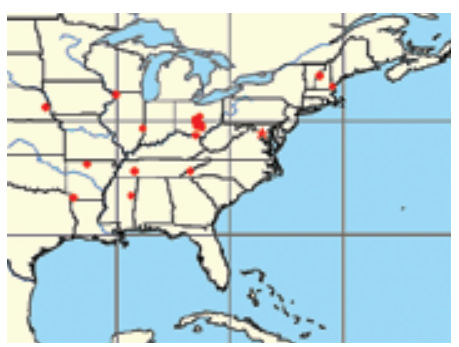


ventral branch about twice as long as dorsal, twisted and extended at apex. Second point of style apex very short, tooth like; third point subequal in size with second; angle between basal and third points about $90^{\circ}$. Aedeagus with preatrium shorter than shaft; shaft straight and slender in lateral view, compressed in crossection, with long dorsal distal lobe; apex acuminate in ventral view, with distinct apical spicules. Aedeagus without processes. Dorsum yellow or white, with reddish or orange color pattern; vertex with parallel submedial lines, midline red; anteclypeus dark; pronotum dark with pale lateral margins or pale with two longitudinal strips; mesonotum pale, with reddish lateral triangles; thoracic venter entirely dark; forewing with broken oblique vittae; clavus with separate basal and distal vittae; dark spot at costal margin; apical cell II without distal spot; inner apical cell without brown spot.

Type locality: Holotype + , USA, Virginia, Fairfax Co., Scotts Run Nature Preserve, Stubblefield Falls, on Pinus virginiana, 23 X 1921 (Malloch), (USNM).

Distribution: Central and eastern USA.

Host plants: Cornus spp.
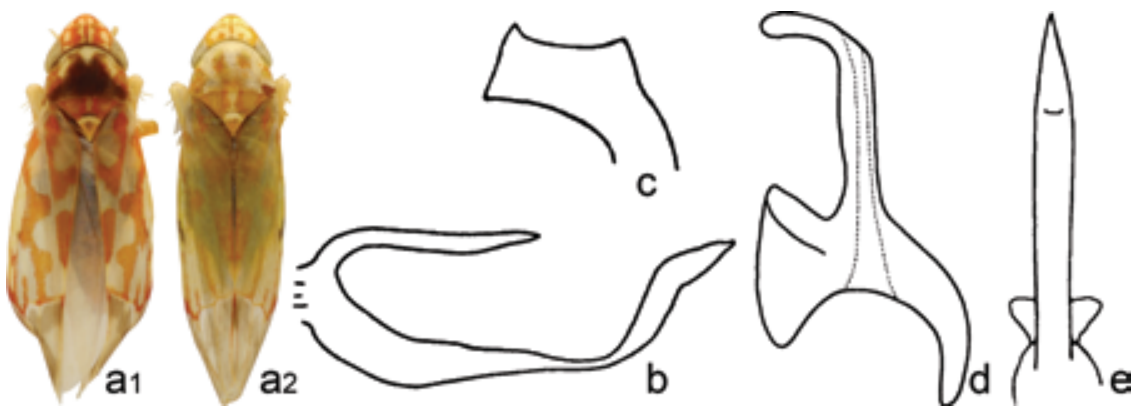

Figure 53. E. bidens McAtee. a1 - holotype; a2 - var. suffusa. b, c - from Beamer 1938; e - from Hepner, unpublished.

\section{Erythroneura ontari Robinson, 1924 (Fig. 54) \\ Erythroneura ontari Robinson, 1924a:60}

Description: Length $2.5-2.8 \mathrm{~mm}$. $2 \mathrm{~S}$ abdominal apodemes large, broad, reach $3 \mathrm{~S}$ posterior margin. Pygofer lobe rounded; dorsal appendages extended beyond pygofer apex, C-shaped; ventral branch about twice as long as dorsal. Second point of style apex very short, tooth like; third point subequal in size

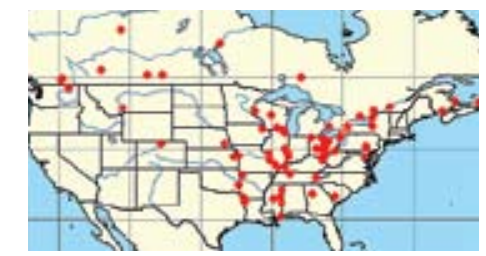
with second; angle between basal and third points about $90^{\circ}$.

Aedeagus with preatrium shorter than shaft; shaft straight and slender in lateral view, compressed in crossection, with long dorsal distal lobe; apex acuminate in ventral view, with distinct apical spicules. Aedeagus without processes. Coloration similar to E. corni Robinson.

Type locality: Holotype $\widehat{o}$, Canada, Ontario, Vineland, I 1923, (Robinson), (KSEM).

Distribution: Northwestern, central, and eastern USA, southern Canada.

Host plants: Cornus spp.

Note: E. ontari Robinson may be a variant of E. corni Robinson rather than a distinct species. They are often collected together and differ primarily in the length of the dorsal branch of the pygofer process. However, intermediate forms were not found.
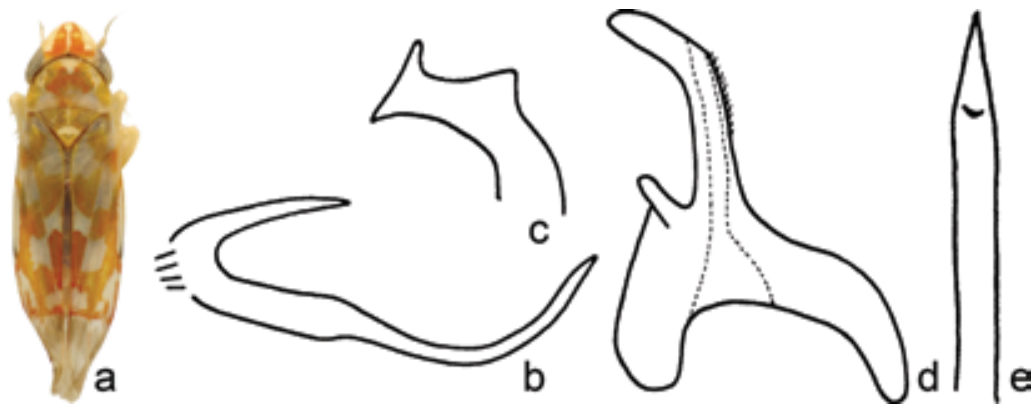

Figure 54. E. ontari Robinson. b, c-from Beamer 1938; e - Hepner, unpublished. 
Genus Erasmoneura Young, 1952

Erythroneura (Erasmoneura) Young, 1952:80 (Type: Erythroneura vulnerata Fitch, 1851) Erasmoneura Dietrich \& Dmitriev, 2006:139

Description: Length 2.2-3.4 mm, relatively slender. Head narrower than pronotum; crown fore margin strongly produced and angulate medially; ocelli absent or vestigial. Face depressed in profile, less than $45^{\circ}$ from horizontal; anteclypeus narrow in both sexes. Forewing outer apical cell short, less than $2 \mathrm{X}$ longer than width or about $2 \mathrm{X}$ as long as wide; second apical cell quadrate (ir crossvein present); third apical cell parallel sided, straight; $\mathrm{CuP}$ shorter than segment of $\mathrm{CuA}$ between $\mathrm{Cu}$ and MP; basal segment of MP shorter than basal segment of $\mathrm{CuA}$; inner apical cell with distinctly angulate base; Pcu not visible. Hindwing with truncate apex; submarginal vein not extended to wing apex; RA present; MP and $\mathrm{CuA}$ fused for short distance or separated by m-cu crossvein, convergent distally. Front femur AV row with one basal seta distinctly larger than others; PV row without fine basal setae. $2 \mathrm{~S}$ abdominal apodemes small, narrow, extended dorsomesad. Pygofer apex not extended to apex of subgenital plate; dorsal emargination extended to base of segment; basolateral setae in distinct group, small; distal setae undifferentiated; long fine setae present or absent; apex with rigid setae on internal surface. Pygofer dorsal appendage movably articulated, or at least with distinct basal suture separating it from lobe; simple or bifurcate; ventral appendage absent. Subgenital plates free; lateral margin with angulate subbasal projection; section basad of medial constriction shorter than distal section; with 4 basal macrosetae, uniseriate along margin; marginal short rigid setae forming continuous row. Style preapical lobe prominent; apex with 3 points. Aedeagus articulated to connective; dorsal apodeme broadly expanded in lateral view, with distinct V-shaped ligaments connected to pygofer appendages; shaft symmetrical, with processes. Connective median anterior lobe absent; arms long; stem well developed, depressed. Anal tube without processes. Coloration variable.

Distribution: North America; E. vulnerata Fitch recently established in northern Italy (Duso at al., 2005).

Host plants: Vitis spp. and herbs.

\section{Key to Species of the Genus Erasmoneura ${ }^{1}$}

1. Aedeagus shaft very short, with ventral processes; processes as long as or longer than shaft; without distal processes (Fig. 55e). Pygofer with dorsal appendage bifurcate (Figs. 55b, 56b).

1'. Aedeagus shaft long, without ventral processes, with distal processes (Fig. 58e). Pygofer with dorsal appendage not bifurcate (Fig. 58b).

2(1). Pygofer dorsal appendage bifurcate far from base, branches very short; dorsal branch slightly curved upward (Fig. 55b). 55. E. vulnerata Fitch

2'. Pygofer dorsal appendage bifurcate closer to base, branches longer than basal part of appendage; dorsal branch straight or curved downward (Figs. 56b, 57b).

3(2). Branches of pygofer appendage subequal in length (Fig. 56b).

56. E. fulmina McAtee

3 '. Dorsal branch of pygofer appendage about twice as long as ventral (Fig. 57b).

57. E. variabilis Beamer

4(1). Third point of style apex shorter than half distance between other two points (Fig. 58c).

58. E. nigra Gillette

4'. Third point of style apex longer than half distance between other two points (Fig. 60c). ....... 5

5(4). Third point of style apex more than $2 X$ longer than distance between other two points (Fig. 59c). 59. E. nigerrima McAtee

5'. Third point of style apex as long or only slightly longer than distance between other two points (Fig. 60c).

6(5). Ground color of dorsum dark brown or black (Figs. 60a, 61a). ........................................ 7

6'. Ground color of dorsum yellow, reddish, or light brown (Figs. 62a, 63a). .............................. 8

7(6). Aedeagus distal processes longer than dorsal distal lobe (Figs. 60d, 60e). Dorsum with pale spots (Fig. 60a).

60. E. atra Johnson

${ }^{1}$ E. bipentagona Beamer, known only from the female holotype, is not included. 
7'. Aedeagus distal processes not longer than dorsal distal lobe (Figs. 61d, 61e). Dorsum without pale spots (Fig. 61a).

61. E. caerula Beamer

8(6). Aedeagus depressed in crossection, broad in ventral view (Figs. 62d, 62e).

8'. Aedeagus round in crossection, slender in ventral view (Figs. 64d, 64e).

9(8). Aedeagus distal processes directed basad in ventral view (Fig. 62e). Vertex pale; forewing yellow or pink (Fig. 62a).

62. E. rubricata Van Duzee

9'. Aedeagus distal processes directed latarad in ventral view (Fig. 63e). Vertex and forewing reddish brown (Fig. 63a).

63. E. margaritae sp.n.

10(8). Shaft of aedeagus curved dorsally in lateral view; dorsal distal lobe longer than distal processes (Fig. 64d).

64. E. emeljanovi sp.n.

10 '. Shaft of aedeagus curved ventrally in lateral view; dorsal distal lobe not longer than distal processes (Fig. 65d).

65. E. mixta Beamer

55. Erasmoneura vulnerata (Fitch, 1851) (Fig. 55, Plate 1e)

Erythroneura vulnerata Fitch, 1851:62

Typhlocyba vulneata Lugger, 1896:61, missp.

Erythroneura gradata Robinson, 1924a:58, syn.n.

Erasmoneura vulnerata Dietrich \& Dmitriev, 2006:140

Description: Length $2.7-3.2 \mathrm{~mm}$. $2 \mathrm{~S}$ abdominal apodemes small, narrow, extended dorsomesad. Pygofer lobe rounded; dorsal appendages bifurcate far from base, not extended beyond pygofer apex, curved upward. Second point of style apex very short, toothlike; third point elongate, not longer than half distance between other two points; angle between basal and third points about $90^{\circ}$. Aedeagus with preatrium longer than shaft;

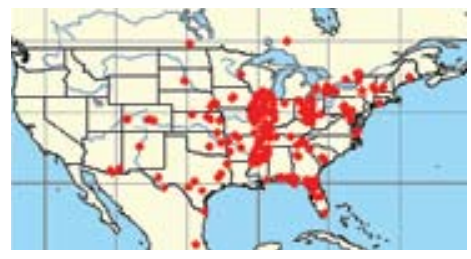
shaft very short membranous, straight and broad in lateral view, round in crossection; ventral processes placed basally, well separated from shaft, longer than shaft, divergent at base, then parallel; distal processes absent. Dorsum white or yellow, with reddish or brownish color pattern; vertex mostly dark, with small pale spots, midline pale; anteclypeus brown; pronotum and mesonotum almost entirely dark; thoracic venter with dark mesosternum, remainder pale; forewing with reddish and brownish patches; clavus largely or entirely dark; dark spot at costal margin; apical cell II with distal spot; inner apical cell without brown spot.

Type locality: Holotype $\widehat{\delta}$, USA, New York, (NYSM).

Distribution: Central and eastern USA, southeastern Canada, northern Mexico, Italy (introduced, Duso et al., 2005).

Host plants: Vitis spp. 

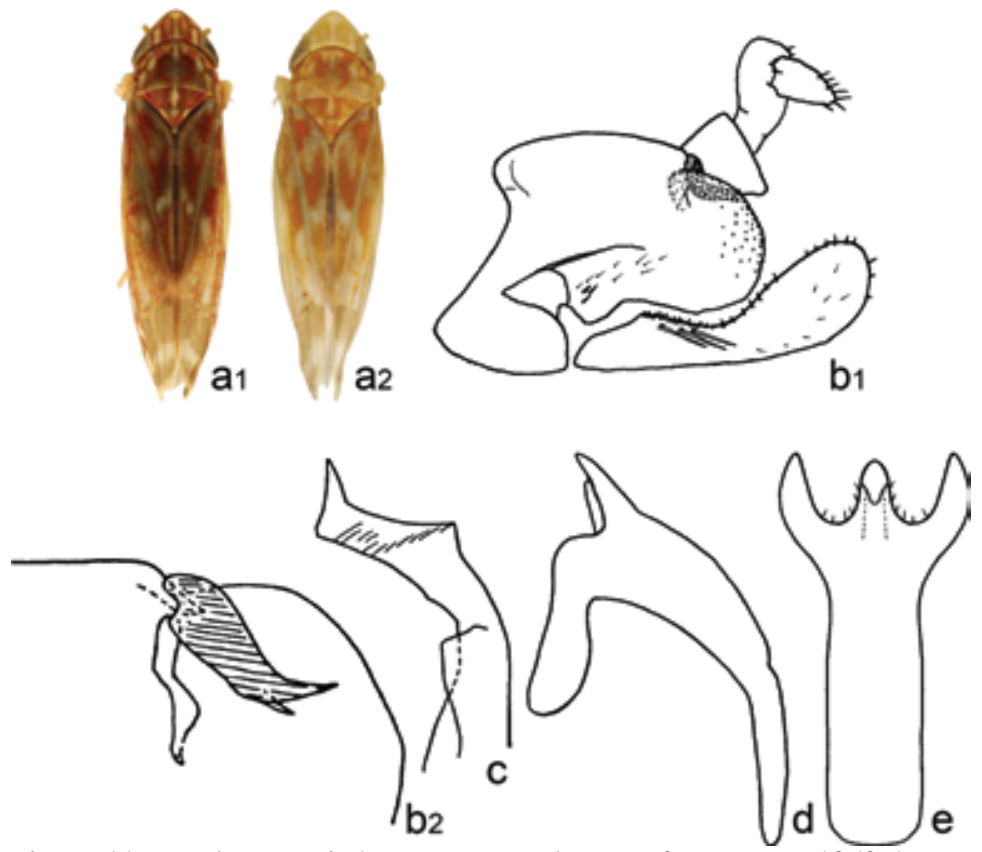

Figure 55. E. vulnerata Fitch. a2 - var. gradata. c - from Young 1952; b2 - from Ross 1965; b1 - from Dietrich \& Dmitriev 2006.

56. Erasmoneura fulmina (McAtee, 1920) (Fig. 56)

Erythroneura vulnerata var. fulmina McAtee, 1920:274

Erythroneura pulchella Robinson, 1924b:155

Erythroneura bicolorata Beamer, 1937:11, syn.n.

Erythroneura fulmina Beamer, 1946:17

Erasmoneura fulmina Dietrich \& Dmitriev, 2006:140

Description: Length 2.7-2.9 mm. 2S abdominal apodemes small, narrow, extended dorsomesad. Pygofer lobe rounded; dorsal appendages bifurcate near base, appendages parallel, not extended beyond pygofer apex, straight in lateral view.

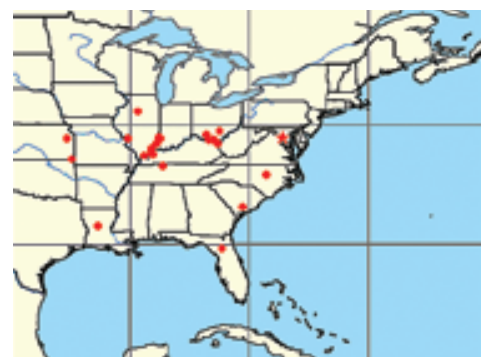
Second point of style apex very short, tooth like; third point elongate, longer than half distance between other two points; angle between basal and third points about $90^{\circ}$. Aedeagus with preatrium longer than shaft; shaft very short, membranous, straight and broad in lateral view, round in crossection; ventral processes placed basally, well separated from shaft, longer than shaft, divergent at base, than parallel; distal processes absent. Dorsum yellow or white, with reddish or brownish color pattern; vertex mostly dark, with small pale spots, midline pale; anteclypeus dark; pronotum almost entirely dark; mesonotum pale, with dark lateral triangles or entirely dark; thoracic venter entirely dark. Forewing with reddish brown and pale patches, in some cases basal half much darker than distal half; dark spot at costal margin; apical cell II with distal spot; inner apical cell without brown spot.

Type locality: Holotype + , USA, Maryland, Montgomery Co., Plummers Island, 1 VI 1907 (Fisher), (USNM).

Distribution: Central and eastern USA.

Host plants: Vitis spp. 


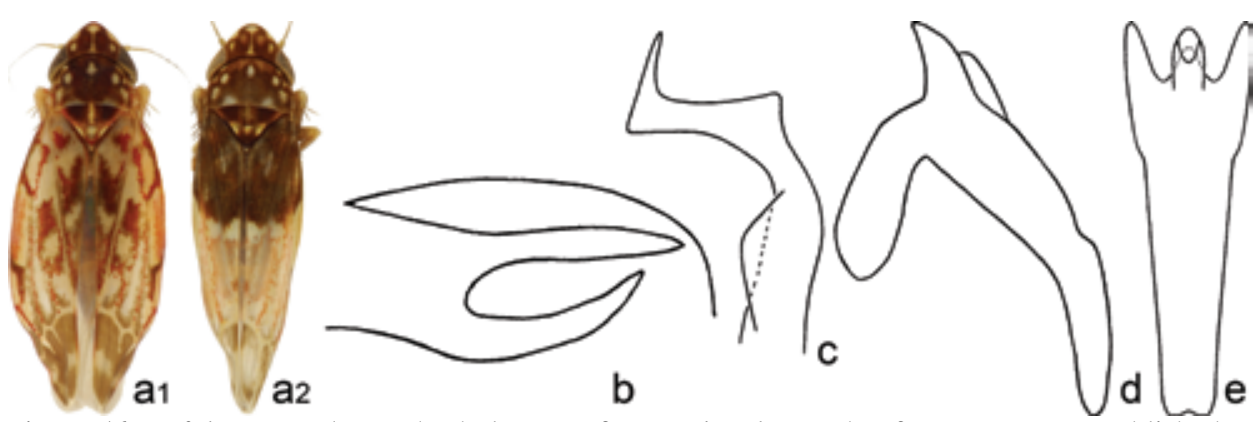

Figure 56. E. fulmina McAtee. a1 - holotype; a2 - var. bicolorata; b - from Hepner, unpublished.

57. Erasmoneura variabilis (Beamer, 1929) (Fig. 57)

Erythroneura variabilis Beamer, 1929:126

Erasmoneura variabilis Dietrich \& Dmitriev, 2006:140 Variegated leafhopper

Description: Length $2.9-3.1 \mathrm{~mm}$. 2S abdominal apodemes small, narrow, extended dorsomesad. Pygofer lobe rounded; dorsal appendages bifurcate near base, branches parallel to each other, not extended beyond pygofer apex. Second point of style apex very short, tooth like; third point elongate, not longer than half distance between other two points; angle between basal and third points about $90^{\circ}$. Aedeagus with preatrium longer than shaft; shaft very short, membranous, straight and broad in lateral view, round in crossection; ventral processes placed basally, well separated from shaft, longer than shaft, divergent at base, then parallel; distal processes absent. Coloration similar to E. vulnerata Fitch. Type locality: Holotype $\delta$, USA, Arizona, Yavapai Co., 9 VIII 1927 (Beamer), (KSEM).

Distribution: Arizona, California, northern Mexico.

Host plants: Vitis spp.

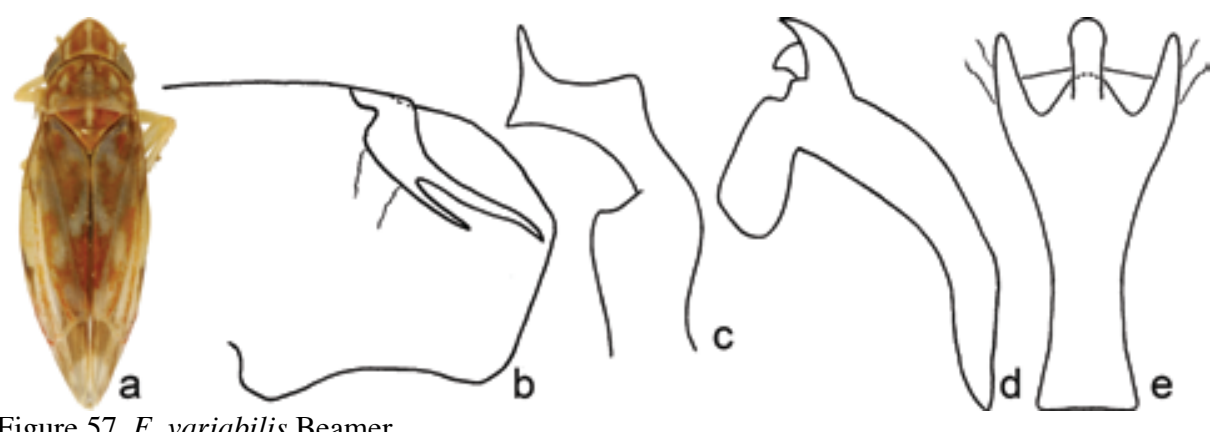

Figure 57. E. variabilis Beamer.

58. Erasmoneura nigra (Gillette, 1898) (Fig. 58, Plate 1f)

Typhlocyba vulnerata var. niger Gillette, 1898:765

Typhlocyba nigridorsum DeLong, 1916:110

Erythroneura niger Van Duzee, 1916:77

Erythroneura vulnerata var. decora McAtee, 1920:274, syn.n.

Erythroneura nigra Lawson, 1920:51

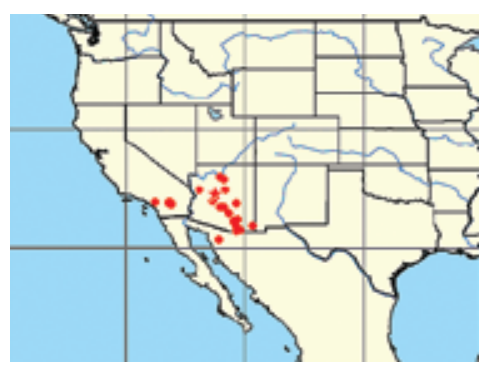

Erasmoneura nigra Dietrich \& Dmitriev, 2006:140

Description: Length $2.7-3.1 \mathrm{~mm}$. 2S abdominal apodemes small, narrow, extended dorsomesad. Pygofer lobe rounded; pygofer dorsal appendages simple, not extended beyond pygofer apex, 
slightly curved upward in lateral view. Second point of style apex very short, toothlike; third point elongate, not longer than half distance between other two points; angle between basal and third points about $90^{\circ}$. Aedeagus with preatrium about as long as shaft; shaft curved ventrally, broad in lateral view, round in crossection, with long dorsal distal lobe; ventral processes absent; distal processes long, subapical. Dorsum mostly black, with pale specks. Vertex mostly dark, midline pale; anteclypeus pale, concolorous with rest of face; pronotum with three pale specks at anterior margin; mesonotum almost entirely dark; thoracic venter with dark mesosternum, remainder pale. Forewing dark, with some pale specks and pale transverse veins.

Type locality: Holotype + , USA, Kansas, Pottawatomie Co., Onaga, (Crevecoeur), (USNM). Distribution: USA, southern Canada.

Host plants: Polygonum spp.
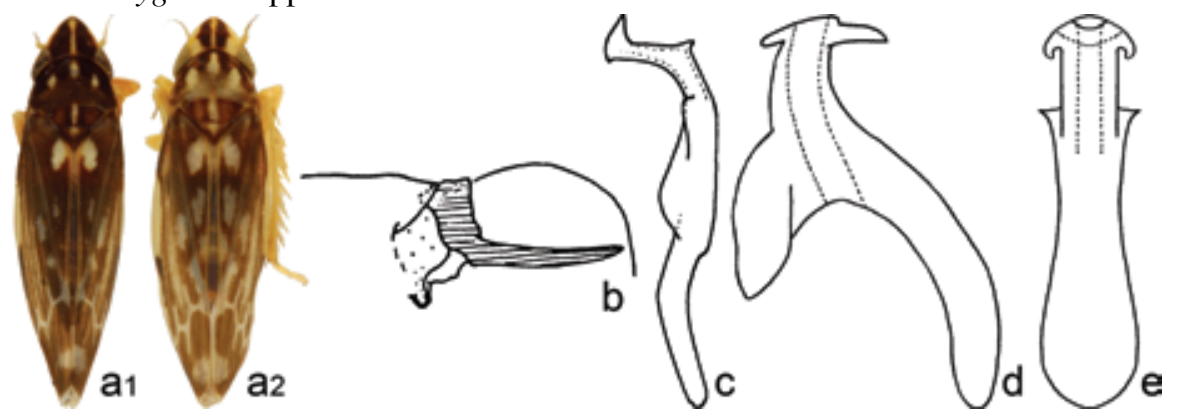

Figure 58. E. nigra Gillette. a2 - var. decora. b, c - from Ross 1965.

\section{Erasmoneura nigerrima (McAtee, 1920) (Fig. 59)}

Erythroneura vulnerata var. nigerrima McAtee, 1920:275

Erythroneura niger var. nigerrima Robinson, 1926:116

Erythroneura atrata Johnson, 1935:97, syn.n.

Erasmoneura nigerrima Dietrich \& Dmitriev, 2006:140

Description: Length $2.2-2.5 \mathrm{~mm}$. $2 \mathrm{~S}$ abdominal apodemes small, narrow, extended dorsomesad. Pygofer lobe rounded; pygofer dorsal appendages simple, movably articulated, extended beyond pygofer apex, curved downward in lateral view. Second point of style apex very short, tooth like; third point of

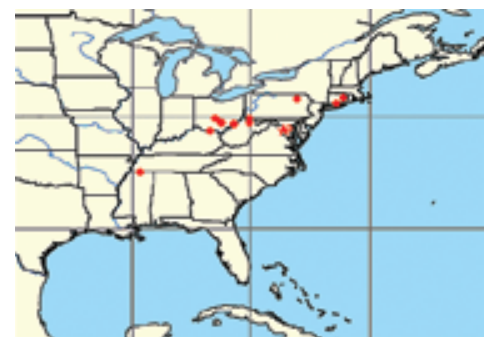
style apex more than twice longer than distance between other two points; angle between basal and third points less than $90^{\circ}$. Aedeagus with preatrium longer than shaft; shaft curved ventrally, broad in lateral view; round in crossection, with subapical dorsal lobe; ventral processes absent; distal processes long, subapical. Dorsum black, with pale fore margin of vertex, pale specks on pronotum and mesonotum, and costal margins of wings, crossveins pale; usually with red spot at costal margin of forewing at level of crossveins; anteclypeus pale, concolorous with rest of face; thoracic venter with dark mesosternum, remainder pale.

Type locality: Holotype + , USA, Virginia, Alexandria Co., Maywood, 20 II 1916 (McAtee), (USNM).

Distribution: Central and northeastern USA.

Host plants: Unknown.

Note: E. nigerrima McAtee was misidentified by Beamer (1946); see E. atra Johnson.

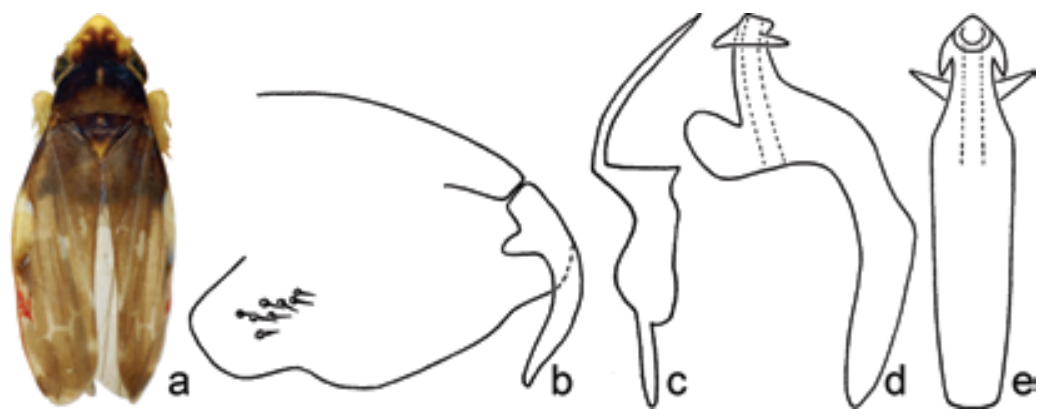

Figure 59. E. nigerrima McAtee. c - from Johnson 1935. 
60. Erasmoneura atra (Johnson, 1935), sp. revalid., new comb. (Fig. 60)

Erythroneura atra Johnson, 1935:96

Erythroneura nigerrima Beamer, 1946:18 not McAtee 1920, misid.

Description: Length 2.6-2.9 mm. 2S abdominal apodemes small, narrow, extended dorsomesad. Pygofer lobe rounded; pygofer dorsal appendages simple, not extended beyond pygofer apex, slightly curved upward in lateral view. Second point of style apex very short, toothlike; third point of style apex

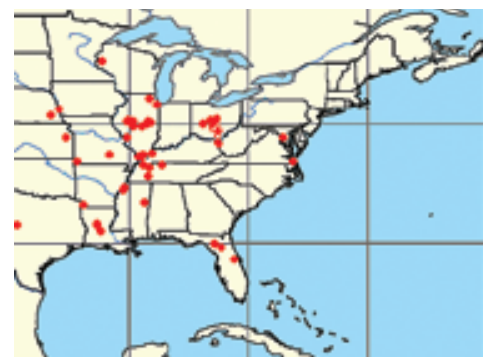
elongate, about as long or longer than distance between other two points; angle between basal and third points less than $90^{\circ}$. Aedeagus with preatrium about as long as shaft; shaft curved ventrally, slender in lateral view, round in crossection, with long dorsal distal lobe; ventral processes absent; distal processes long, subapical. Coloration similar to E. nigra Gillette.

Type locality: Holotype $\delta$, USA, Ohio, Hocking Co., Conkles Hollow, Hocking State Forest, 15 IV 1934 (Caldwell), (OSU).

Distribution: Central and eastern USA.

Host plants: Unknown.

Note: E. atra Johnson was mistakenly synonymised with E. nigerrima McAtee by Beamer (1946).
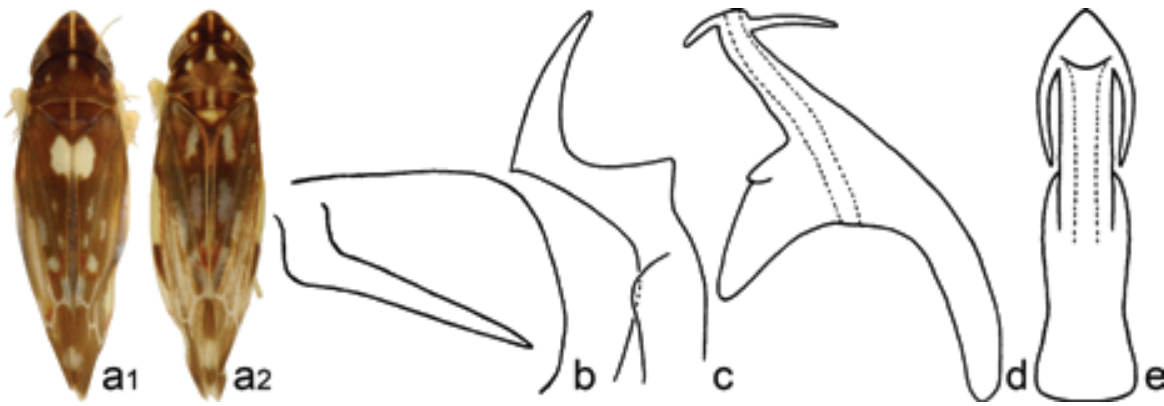

Figure 60. E. atra Johnson. a1, a2 - color variations; b - from Hepner, unpublished.

\section{Erasmoneura caerula (Beamer, 1937) (Fig. 61)}

Erythroneura caerula Beamer, 1937:10

Erasmoneura caerula Dietrich \& Dmitriev, 2006:140

Description: Length 3.1-3.4 mm. 2S abdominal apodemes small, narrow, extended dorsomesad. Pygofer lobe angulate; pygofer dorsal appendages simple, not extended beyond pygofer apex, straight in lateral view. Second point of style apex very short, tooth like; third point of style apex elongate, longer than distance between other two points; angle between basal and third points less than $90^{\circ}$. Aedeagus with preatrium about as long as shaft; shaft straight and slender in lateral view; round

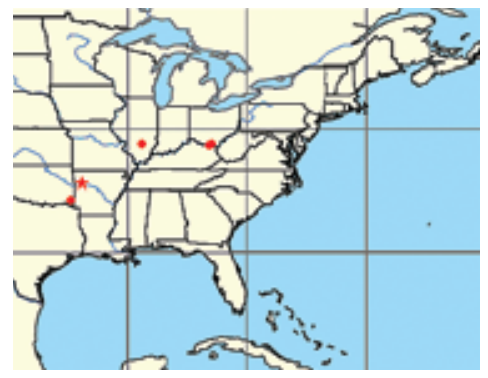
in crossection, with long dorsal distal lobe; ventral processes absent; distal processes long, subapical. Dorsum black; anteclypeus pale, concolorous with rest of face; thoracic venter with dark mesosternum, remainder pale.

Type locality: Holotype đ, USA, Arkansas, Franklin Co., Barnes, 8 VI 1931 (Beamer), (KSEM). Distribution: Central USA.

Host plants: Unknown.
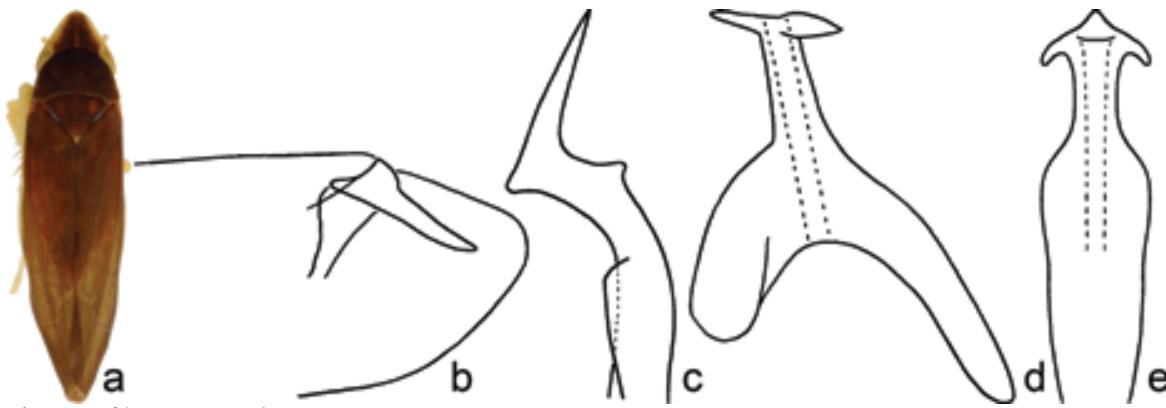

Figurer 61. E. caerula Beamer. 
62. Erasmoneura rubricata (Van Duzee, 1909) (Fig. 62)

Typhlocyba rubricata Van Duzee, 1909:229

Erythroneura rubricata Van Duzee, 1916:77

Erasmoneura rubricata Dietrich \& Dmitriev, 2006:140

Description: Length $2.6-3 \mathrm{~mm}$. $2 \mathrm{~S}$ abdominal apodemes small, narrow, extended dorsomesad. Pygofer lobe rounded; pygofer dorsal appendages simple, not extended beyond pygofer apex, slightly curved upward in lateral view. Second point of style apex very short, tooth like; third point of style apex elongate, about as long as distance between other

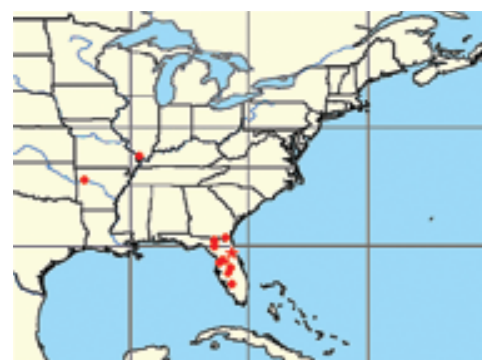
two points; angle between basal and third points about $90^{\circ}$.

Aedeagus with preatrium longer than shaft; shaft straight and broad in lateral view; depressed in crossection, with small dorsal distal lobe, with lateral lobes at base; distal processes long, apical. Uniformly yellow pronotum and forewings, except apices, pink; venter entirely pale.

Type locality: Lectotype + , USA, Florida, Putnam Co., Crescent City, Spring 1908, (Van Duzee), (CAS) - here designated.

Distribution: Central and southeastern USA.

Host plants: Ascyrum hypericoides, Hypericum densiflorum, H. aspalathoides, H. prolificum.

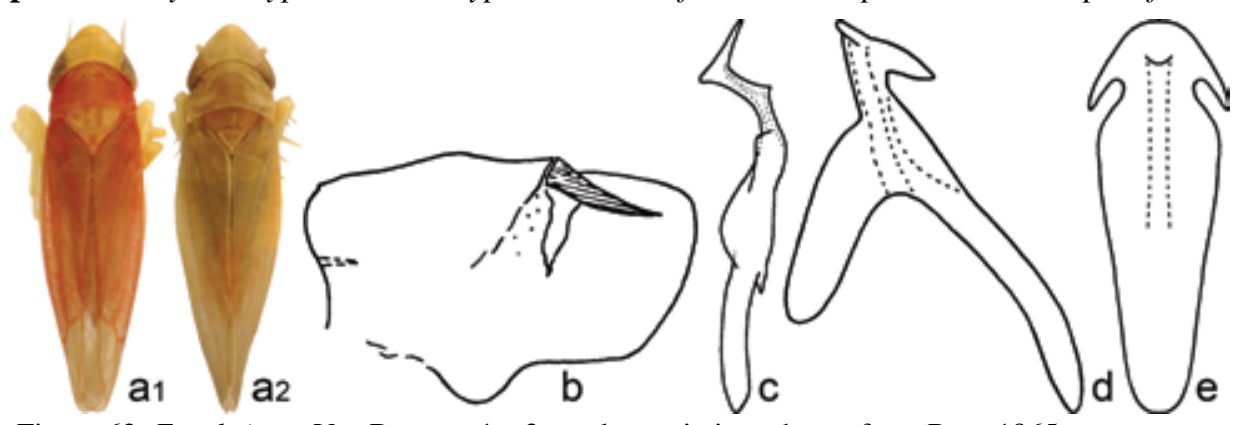

Figure 62. E. rubricata Van Duzee. a1, a2 - color variations; b, c - from Ross 1965.

63. Erasmoneura margaritae Dmitriev \& Dietrich sp.n. (Fig. 63)

Description: Length $2.7-2.9 \mathrm{~mm}$. 2S abdominal apodemes small, narrow, extended dorsomesad. Pygofer lobe angulate; dorsal appendages with distinct basal suture, but not movably articulated, simple, not extended beyond pygofer apex, straight or very slightly curved in dorsal view, slightly curved downward in lateral view. Second point of style apex very short, tooth like; third point elongate, about as long as distance between other two points; angle between basal and third points about $90^{\circ}$. Aedeagus with preatrium shorter than shaft; shaft

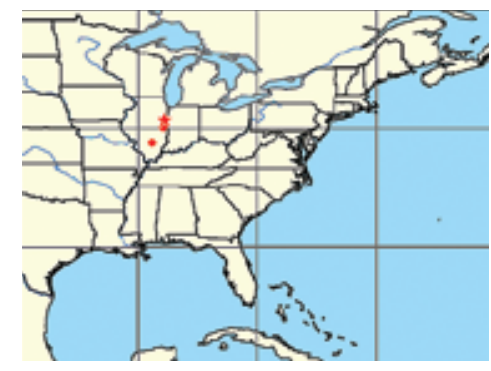
curved ventrally, slender in lateral view, smooth, depressed in crossection, with long dorsal distal lobe, with lateral lobes at base; distal processes long, apical, slender. Dorsum reddish brown; vertex mostly dark, with small pale spots, midline pale or dark; anteclypeus pale, concolorous with rest of face; pronotum almost entirely dark, with three pale specks at anterior margin. Mesonotum almost entirely dark; thoracic venter with dark mesosternum, remainder pale; forewing almost entirely dark, with pale spot at costal margin, and smoked apices.

Diagnosis: E. margaritae sp.n. is similar to E. rubricata Van Duzee, but the aedeagus shaft is longer and curved dorsally, its dorsal distal lobe is longer, its distal processes are shorter and directed laterad, and the overall coloration is darker.

Type locality: Holotype $\widehat{\jmath}$, USA, Illinois, Iroquois Co., on Hypericum sp., 25 IX 1962 (Ross \& Ross), (INHS). 


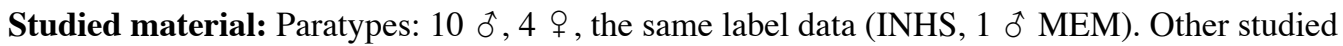
material from Illinois excluded from paratypes.

Distribution: Illinois.

Host plants: Hypericum sp.

Note: The species is named after the first author's wife Margarita Dmitrieva.

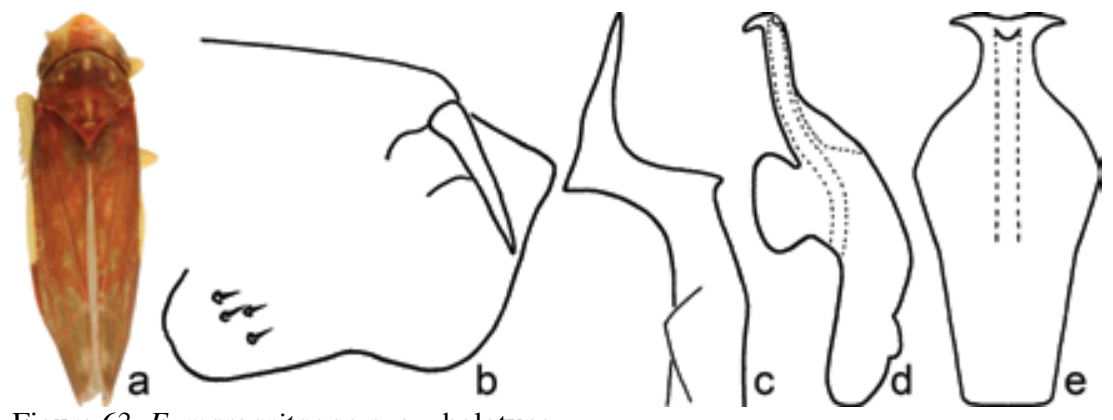

Figure 63. E. margaritae sp.n. a- holotype

64. Erasmoneura emeljanovi Dmitriev \& Dietrich sp.n. (Fig. 64)

Description: Length $2.6-3 \mathrm{~mm}$. 2S abdominal apodemes small, narrow, extended dorsomesad. Pygofer lobe angulate; dorsal appendages with distinct basal suture, but not movably articulated, simple, not extended beyond pygofer apex, straight, slightly curved upward in lateral view; ventral appendages absent. Second point of style apex very short, toothlike; third point elongate, longer than distance between other two points; angle between basal and third points less than $90^{\circ}$. Aedeagus with preatrium about as long as shaft; shaft

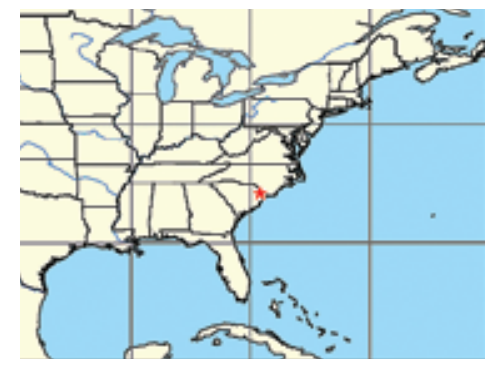
symmetrical, curved dorsally, slender in lateral view, smooth, round in crossection, with long dorsal distal lobe; ventral processes absent; distal processes short, apical, toothlike. Coloration uniformly pale yellow, without pattern.

Diagnosis: E. emeljanovi sp.n. is similar to E. mixta Beamer, but the aedeagus shaft is curved dorsally, with the distal lobe much longer.

Type locality: Holotype $\widehat{o}$, USA, South Carolina, Marion Co., Mullins, on Hypericum sp., 5 V 1932 (Oman), (KSEM).

Studied material: Paratypes: $9 \uparrow, 9$, the same label data.

Distribution: Known only from type locality in South Carolina.

Host plants: Hypericum sp.

Note: The species is named in honor of Prof. Alexandr F. Emeljanov (Zoological Institute, Russian Academy of Sciences, St. Petersburg), Ph.D. advisor of the first author.

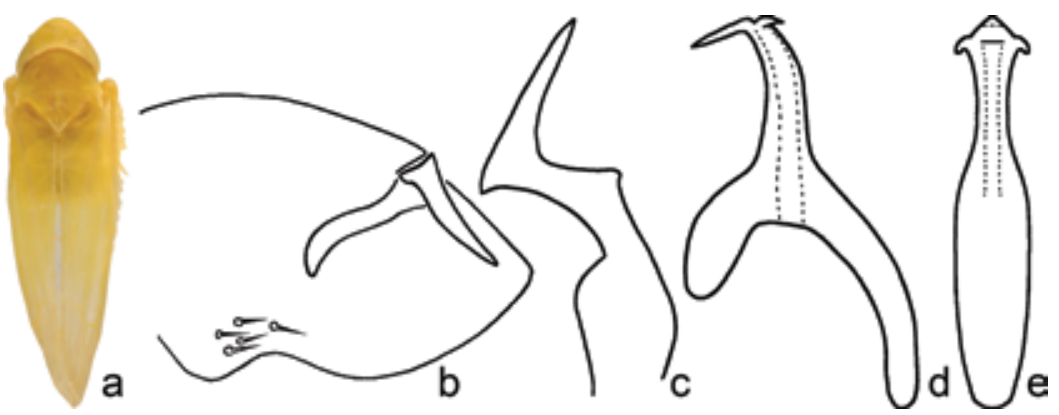

Figure 64. E. emeljanovi sp.n. a - holotype. 
65. Erasmoneura mixta (Beamer, 1932) (Fig. 65)

Erythroneura mixta Beamer, 1932i:183

Erasmoneura mixta Dietrich \& Dmitriev, 2006:140

Description: Length $2.4-2.7 \mathrm{~mm}$. 2S abdominal apodemes small, narrow, extended dorsomesad. Pygofer lobe rounded; dorsal appendages simple, not extended beyond pygofer apex, slightly curved upward in lateral view. Second point of style apex very short, tooth like; third point of style apex elongate, about as long as distance between other two points; angle between basal and third points about $90^{\circ}$. Aedeagus

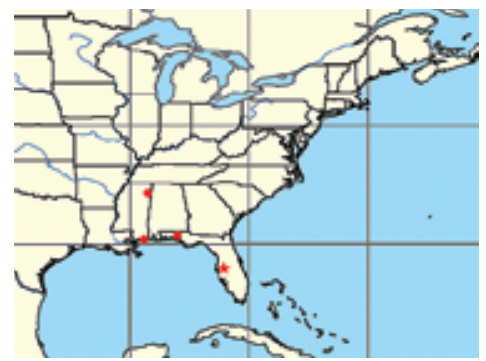
with preatrium about as long as shaft; shaft curved ventrally, slender in lateral view, round in crossection, with long dorsal distal lobe, with lateral lobes at base; distal processes long, apical. Dorsum yellow or pink; anteclypeus pale, concolorous with rest of face or darker; thoracic venter entirely pale or entirely dark.

Type locality: Holotype $\widehat{t}$, USA, Florida, Hillsborough Co., Plant City, on Hypericum fasciculatum, 15 VIII 1930 (Beamer), (KSEM).

Distribution: Southeastern USA.

Host plants: Hypericum fasciculatum, $H$. aspalathoides.
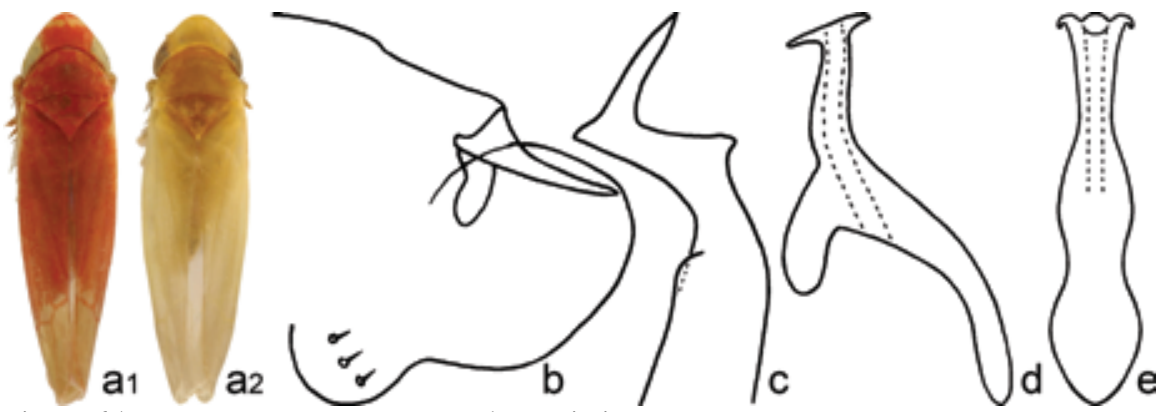

Figure 65. E. mixta Beamer. a1, a2 - color variations.

66. Erasmoneura bipentagona (Beamer, 1927) (Fig. 66)

Erythroneura bipentagona Beamer, 1927:31

Erasmoneura bipentagona Dietrich \& Dmitriev, 2006:140

Description: Length $2.7 \mathrm{~mm}$. Dorsum yellow with reddish brown color pattern; vertex unicolorous, pale; anteclypeus pale, concolorous with rest of face; pronotum almost entirely dark; mesonotum pale, with dark lateral triangles; thoracic venter with dark mesosternum, remainder pale; forewings with oblique vittae forming zigzag pattern; clavus largely dark; dark spot at costal margin; apical cell II with distal spot;

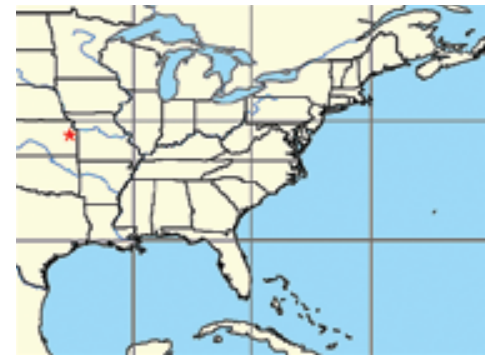
inner apical cell without brown spot.

Type locality: Holotype $q$, USA, Kansas, Douglas Co., (Beamer), (KSEM).

Distribution: Known only from the type locality in eastern Kansas.

Host plants: Unknown.

Notes: The species is known only from the female holotype. Based on the shape of female sternite VII and color pattern, it may be related to E. margaritae.

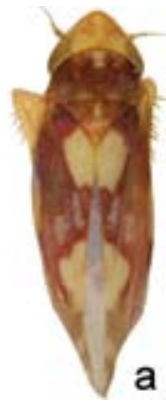

Figure 66. E. bipentagona Beamer. 
Genus Rossmoneura Dietrich \& Dmitriev, 2006

Rossmoneura Dietrich \& Dmitriev, 2006:148 (Type: Erythroneura tecta McAtee, 1920) Description: Length $2.5-3.6 \mathrm{~mm}$, moderately broad. Head narrower than pronotum; crown foremargin weakly produced, broadly rounded apically; ocelli absent; face depressed in profile, less than $45^{\circ}$ from horizontal. Forewing outer apical cell about $2 \mathrm{X}$ as long as wide; second apical cell quadrate (ir crossvein present); third apical cell parallel sided, straight; $\mathrm{CuP}$ shorter than segment of $\mathrm{CuA}$ between $\mathrm{Cu}$ and MP; basal segment of MP shorther than basal segment of $\mathrm{CuA}$; inner apical cell with distinctly angulate base; vannal vein on forewings not visible. Hindwing submarginal vein not extended to wing apex; RA vein present; MP and CuA touching at one point or separated by m-cu crossvein, convergent distally. Front femur AV row with one basal seta distinctly larger than others; PV row without fine basal setae. 2S abdominal apodemes narrow, or broad, extended to posterior margin of sternite III. Pygofer with apex not extended to apex of subgenital plate; lobe rounded; dorsal emargination extended to base of segment; basolateral setae in distinct group, small; with rigid setae on internal surface. Pygofer dorsal appendages not articulated; simple; ventral appendages absent. Sternite IX with median longitudinal internal ridge. Subgenital plates free; lateral margin with angulate subbasal projection; section basad of medial constriction shorter than distal section; with four basal macrosetae uniseriate along margin; with distinct marginal rigid setae forming continuous row. Style preapical lobe prominent; apex with three points; second point long, often longer than third; third point subequal in size or shorter than second; angle between basal and third points about $90^{\circ}$. Aedeagus articulated to connective; dorsal apodeme broadly expanded in lateral view, with distinct V-shaped ligaments connected to pygofer appendages; shaft without dorsal process; with small dorsal distal lobe; with unpaired short ventral process placed basally or near midlength of shaft, close to shaft. Connective median anterior lobe absent; arms long; stem well developed, depressed. Anal tube without processes. Dorsum yellow or white, with reddish brown color pattern; vertex usually with pair of dark preapical spots.

Distribution: Central and eastern USA, southern Canada.

Host plants: Herbs.

\section{Key to Species of the Genus Rossmoneura}

1. Pygofer dorsal appendage straight in lateral view (Fig. 67b).

67. R. carbonata McAtee

1'. Pygofer dorsal appendage curved upward in lateral view (Figs. 68b, 69b).

2(1). Pygofer dorsal appendage only slightly curved in lateral view (Fig. 68b).

68. R. tecta McAtee

2'. Pygofer dorsal appendages hook-shaped in lateral view (Fig. 69b).

69. R. calva Beamer

67. Rossmoneura carbonata (McAtee, 1920) (Fig. 67, Plate 1g)

Erythroneura tecta var. carbonata McAtee, 1920:289

Erythroneura carbonata Beamer, 1946:22

Rossmoneura carbonata Dietrich \& Dmitriev, 2006:149

Description: Length $2.5-3 \mathrm{~mm}$. 2S abdominal apodemes large, broad, reach $3 \mathrm{~S}$ posterior margin. Pygofer lobe rounded; dorsal appendages extended beyond pygofer apex, straight in lateral view. Second point of style apex longer than third; third point very short. Aedeagus with preatrium about as long as shaft; shaft straight and broad in lateral view; round in crossection, with small dorsal distal lobe; with ventral upnaired process arising near midlength of shaft; distal processes absent. Dorsum yellow or white, with brownish or reddish brown color pattern; vertex with pair of black preapical spots; anteclypeus brown or black. Pronotum mostly dark; mesonotum pale, with black lateral triangles; thoracic venter with dark mesosternum, remainder pale. Forewing mostly dark, with several pale specks, large spots at base and apex of clavus, and at costal margin.

Type locality: Holotype $\widehat{\delta}$, USA, Maryland, Montgomery Co., Plummers Island, 14 XII 1913 
(McAtee), (KSEM).

Distribution: Central and eastern USA, southern Canada.

Host plants: Steironema ciliatum, Glaux maritima, Lysimachia lanceolata.

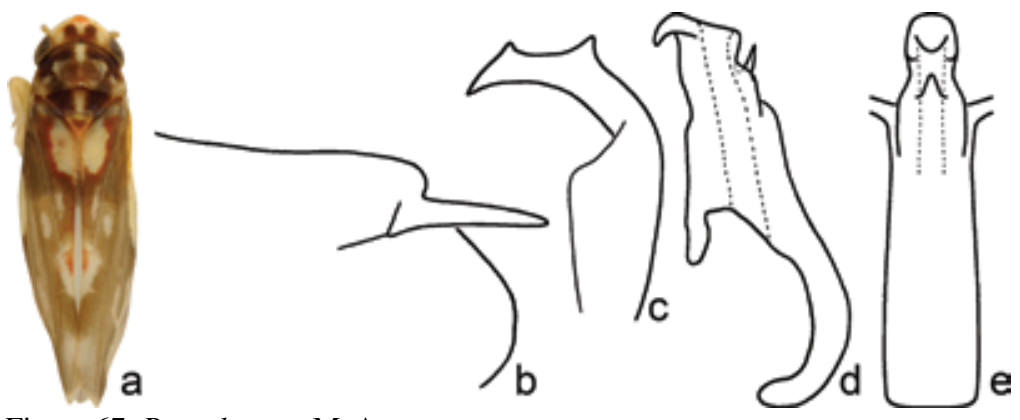

Figure 67. R. carbonata McAtee.

68. Rossmoneura tecta (McAtee, 1920) (Fig. 68)

Erythroneura tecta McAtee, 1920:288

Erythroneura sexpunctata Malloch, 1921:25

Rossmoneura tecta Dietrich \& Dmitriev, 2006:149

Description: Length 3.1-3.6 mm. 2S abdominal apodemes small, narrow, extended dorsomesad. Pygofer lobe rounded; dorsal appendages extended beyond pygofer apex, slightly curved upward

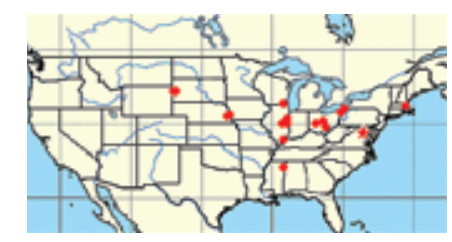
in lateral view. Second point of style apex longer than third; third point very short. Aedeagus with preatrium about as long as shaft; shaft curved ventrally, broad in lateral view; round in crossection, with small dorsal distal lobe, ventral process unpaired, placed basally, close to shaft, shorter than shaft; distal processes short, apical. Dorsum yellow or white, with reddish or brownish color pattern; vertex with pair of black preapical spots; anteclypeus dark. Pronotum dark with pale lateral margins or pale with two longitudinal strips; mesonotum pale, with black lateral triangles; thoracic venter with dark mesosternum, remainder pale; forewing usually with oblique vittae forming zigzag pattern; clavus with separate basal and distal vittae.

Type locality: Holotype + , USA, Maryland, Montgomery Co., Plummers Island, among mullen leaves, 25 I 1914 (McAtee), (USNM).

Distribution: Central and eastern USA.

Host plants: ? Verbascum sp.

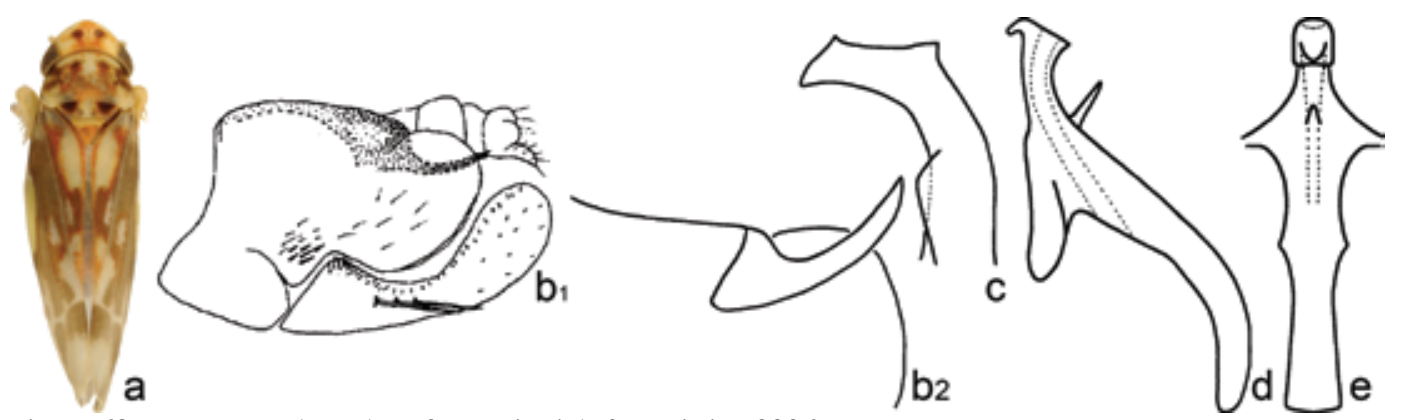

Figure 68. R. tecta McAtee. b1 - from Dietrich \& Dmitriev 2006. 
69. Rossmoneura calva (Beamer, 1946) (Fig. 69)

Erythroneura calva Beamer, 1946:22

Rossmoneura calva Dietrich \& Dmitriev, 2006:149

Description: Length 3-3.6 mm. 2S abdominal apodemes small, narrow, extended dorsomesad. Pygofer lobe rounded; dorsal appendages not extended beyond pygofer apex, strongly curved

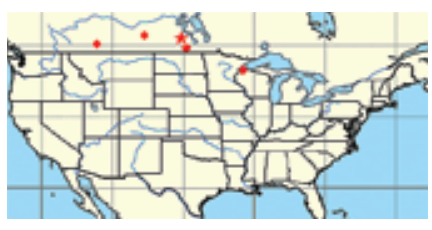
upward in lateral view. Second point of style apex well devel-

oped; third point subequal in size to second. Aedeagus with preatrium about as long as shaft; shaft curved ventrally, broad in lateral view; round in crossection, with small dorsal distal lobe; ventral process unpaired, arising near midlength of shaft; distal processes short, apical. Coloration similar to $R$. carbonata McAtee but paler and without dark spots on crown.

Type locality: Holotype $\delta$, Canada, Manitoba, Keld, 8 VIII 1937 (Beamer), (KSEM).

Distribution: North-central USA, southern Canada.

Host plants: Unknown.

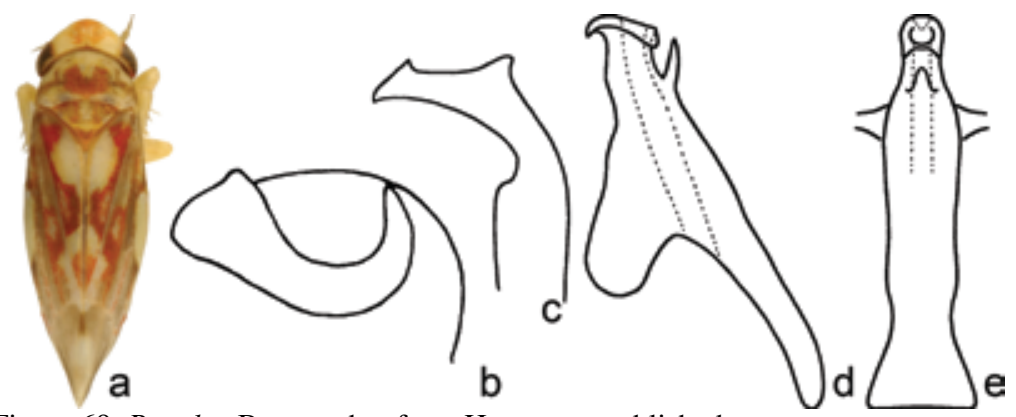

Figure 69. R. calva Beamer. $\mathrm{b}$ - from Hepner, unpublished.

\section{Genus Hymetta McAtee, 1919}

Hymetta McAtee, 1919:121 (Type: Tettigonia trifasciata Say, 1825)

Description: Length 3-3.7 mm, moderately broad. Head narrower than pronotum; crown foremargin strongly produced and angulate medially; ocelli absent; face depressed in profile, less than $45^{\circ}$ from horizontal. Forewing outer apical cell about $2 \mathrm{X}$ as long as wide; second apical cell quadrate (ir crossvein present); third apical cell widened distally, straight; $\mathrm{CuP}$ longer than segment of $\mathrm{CuA}$ between $\mathrm{Cu}$ and MP; basal segment of MP shorther than basal segment of $\mathrm{CuA}$; inner apical cell with distinctly angulate base; Pcu not visible. Hindwing submarginal vein not extended to wing apex; RA present; MP and $\mathrm{CuA}$ touching at one point or separated by $\mathrm{m}-\mathrm{cu}$ crossvein, convergent distally. Front femur AV row with one basal seta distinctly larger than others; PV row without fine basal setae. $2 \mathrm{~S}$ abdominal apodemes large, broad, extended to posterior margin of sternite III. Pygofer apex not extended to apex of subgenital plate; lobe rounded; dorsal emargination extended to base of segment; basolateral setae in distinct group, small; apex with rigid setae on internal surface. Pygofer dorsal appendage with distinct basal suture, but not movably articulated, simple, not extended beyond pygofer apex, straight or very slightly curved in dorsal view, straight in lateral view; ventral appendage absent. Sternite IX without median longitudinal internal ridge. Subgenital plates free; lateral margin with angulate subbasal projection; section basad of medial constriction shorter than distal section; with four basal macrosetae, uniseriate, along margin; with distinct marginal rigid setae forming continuous row. Style preapical lobe prominent; apex truncate and expanded; third point absent. Aedeagus articulated to connective; dorsal apodeme broadly expanded in lateral view, triangular, without distinct connection to anal tube or pygofer appendages; preatrium about as long as shaft; shaft symmetrical, curved dorsally, broad in lateral view, without dorsal process, with basal processes, with or without distal processes. Connective median anterior lobe absent; arms long; stem well developed, depressed. Anal tube without processes. Dorsum yellow or white, with reddish or brown color pattern; vertex, pronotum, and mesonotum pale, apex of scutellum black; forewing with characteristic numerous irregular red or 
brownish dots, with or without brown crossband; without dark spot at costal margin; apical cell II without distal spot; inner apical cell without brown spot.

Distribution: USA.

Host plants: Three species recorded from Vitis spp., host plants for other two species unknown.

\section{Key to Species of the Genus Hymetta}

1. Aedeagus with one pair of ventral processes; processes well separated from shaft (Fig. 71d).

1'. Aedeagus with two pairs of ventral processes; processes placed close to shaft

(Figs. 73d, 74d).

2(1). Aedeagus with distal processes (Figs. 71d, 71e).

2'. Aedeagus without distal processes (Figs. 70d, 70e)

70. H. kansasensis Fairbairn

3(2). Aedeagus ventral processes evenly curved in lateral view; distal processes broad

in lateral view (Fig. 71d).

71. H. balteata McAtee

3'. Aedeagus ventral processes S-curved in lateral view; distal processes narrow in lateral view (Fig. 72d).

72. H. anthisma McAtee

4(1). Aedeagus ventral processes narrow, shorter than shaft; shaft curved dorsad in lateral view (Fig. 73d).

73. H. trifasciata Say

4'. Aedeagus ventral processes as long or longer than shaft; one pair much broader

than another; shaft straight in lateral view (Fig. 74d).

74. H. arizoniana Fairbairn

70. Hymetta kansasensis Fairbairn, 1928 (Fig. 70)

Hymetta kansasensis Fairbairn, 1928b:90

Description: Length 3.2-3.5 mm. Aedeagus depressed in crossection; apex truncate in ventral view; ventral processes placed basally, well separated from shaft, longer than shaft, parallel to each other on ventral side of aedeagus; distal processes absent. Coloration as described for genus.

Type locality: Holotype + , USA, Kansas, Douglas Co., 1925 (Lawson), (KSEM).

Distribution: Central and southeastern USA.

Host plants: Vitis spp.
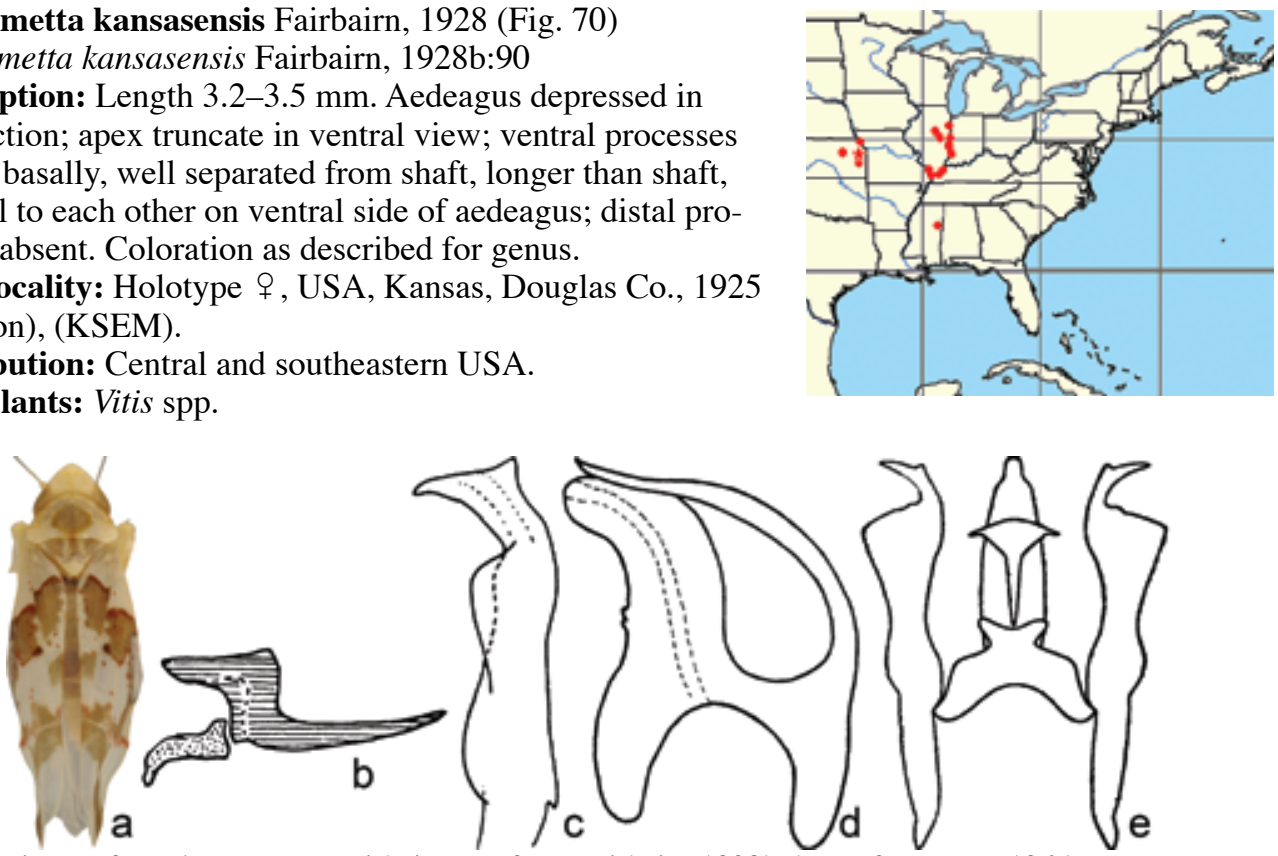

Figure 70. H. kansasensis Fairbairn. e - from Fairbairn 1928b; b, c - from Ross 1965. 
71. Hymetta balteata McAtee, 1919 (Fig. 71, Plate 1h) Hymetta trifasciata var. balteata McAtee, 1919:123

Hymetta trifasciata var. albata McAtee, 1919:123, syn.n. Hymetta balteata Fairbairn, 1928b:88

Hymetta balteata var. mediana Fairbairn, 1928b:89, syn.n. Description: Length 3.1-3.4 mm. Aedeagus compressed in crossection; apex truncate in ventral view; ventral processes placed basally, well separated from shaft, shorter than shaft, parallel to each other on ventral side of aedeagus; distal processes apical, flattened, triangular. Coloration variable, either

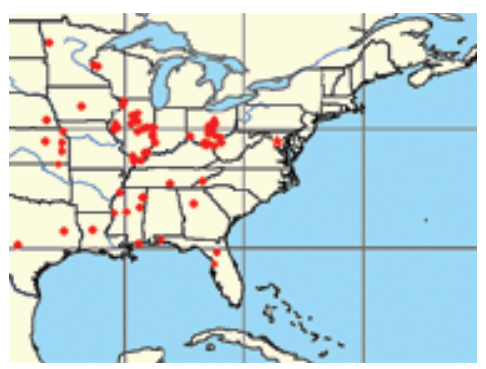
as described for genus or paler overall.

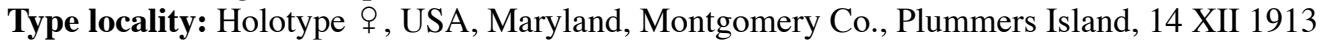
(McAtee), (USNM).

Distribution: Central and eastern USA.

Host plants: Vitis spp.

Note: In the original description (McAtee 1919) recorded the collection date of the holotype incorrectly as 4 XII 1913.
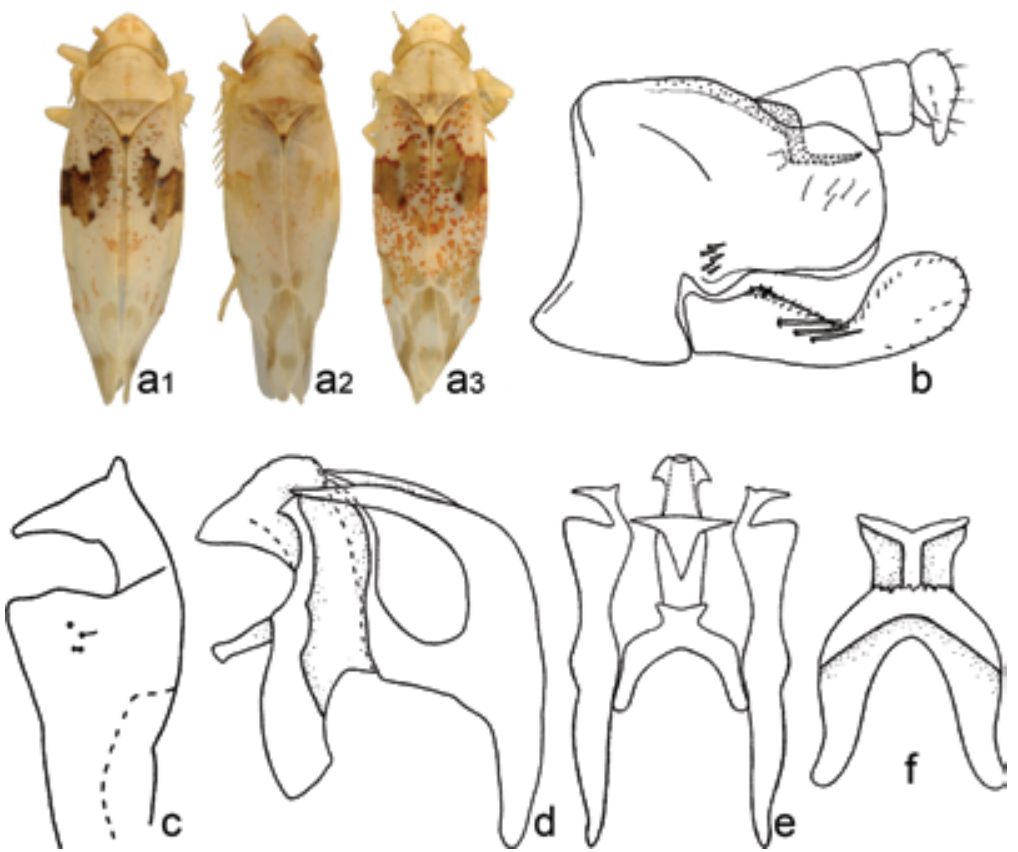

Figure 71. H. balteata McAtee. a2 - var. albata; a3 - var. mediana. e - from Fairbairn 1928b; c, d, f - from Young 1952; b - from Dietrich \& Dmitriev 2006.

72. Hymetta anthisma McAtee, 1919 (Fig. 72)

Hymetta trifasciata var. anthisma McAtee, 1919:123

Hymetta distincta Fairbairn, 1928b:87, syn.n.

Hymetta balteata var. anthisma Fairbairn, 1928b:89

Hymetta anthisma Osborn, 1928b:352

Description: Length 3.3-3.6 mm. Aedeagus round in crossection; apex truncate in ventral view; ventral processes placed basally, well separated from shaft, longer than shaft, parallel to each other on ventral side of aedeagus, sinuate in lateral view; distal processes subapical, slightly flattened. Coloration

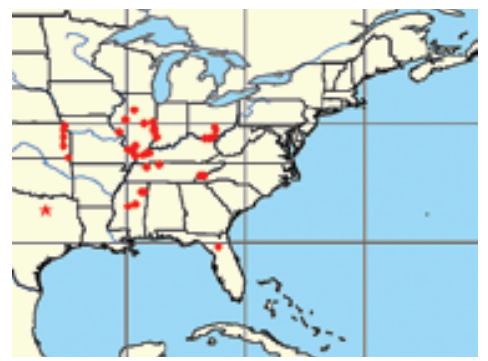


typical for genus, wings usually densely covered with red dots.

Type locality: Holotype + , USA, Texas, Dallas, on Vitis sp., 12 IX 1907, (USNM).

Distribution: Central and eastern USA.

Host plants: Vitis spp.

Note: Fairbairn (1928b) mistakenly listed H. anthisma McAtee as a variety of H. balteata McAtee. Young (1952) listed the former as a separate species.
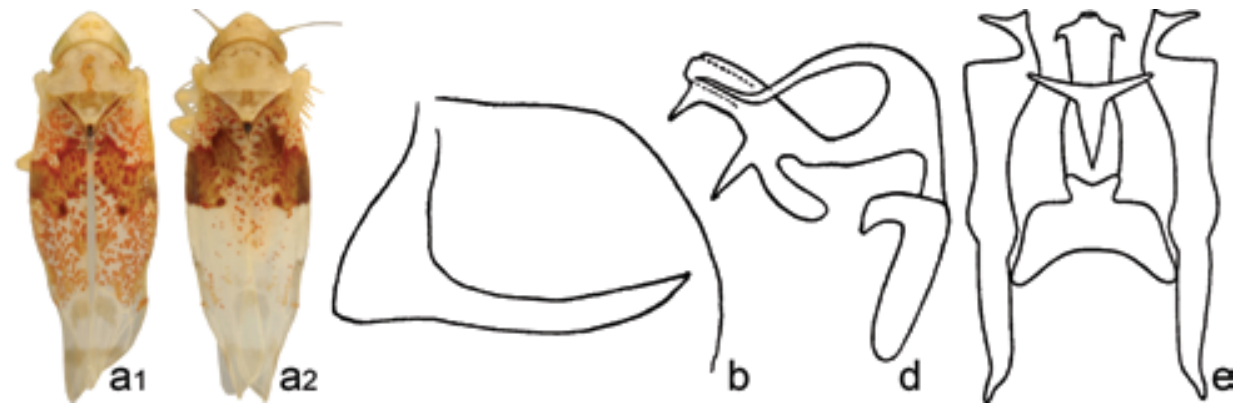

Figure 72. H. anthisma McAtee. a2 - var. distincta; d, e - from Fairbairn 1928b; b - from Hepner unpublished.

73. Hymetta trifasciata (Say, 1825) (Fig. 73)

Tettigonia trifasciata Say, 1825:343

Typhlocyba trifasciata Woodworth, 1889:213

Typhlocyba trifascaita Osborn, 1900:12, missp.

Erythroneura trifasciata Van Duzee, 1916:77

Hymetta trifasciata McAtee, 1919:121

Description: Length 3-3.4 mm. Aedeagus compressed in crossection; apex acuminate in ventral view; two pairs of ventral processes placed basally, close to shaft, short; distal processes absent. Coloration as described for genus.

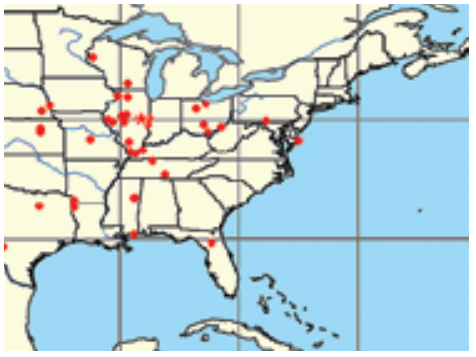

Type locality: Neotype $\widehat{\sigma}$, USA, Illinois, Urbana, on Cercis canadensis, 19 IX 1934, (INHS) - here designated.

Distribution: Central and eastern USA.

Host plants: Vitis spp.

Note: Because Say's holotype is lost, we designate a neotype to stabilize the concept of this species, the type of the genus. This concept equals that of previous revisers (Fairbairn 1928b, Young 1952).

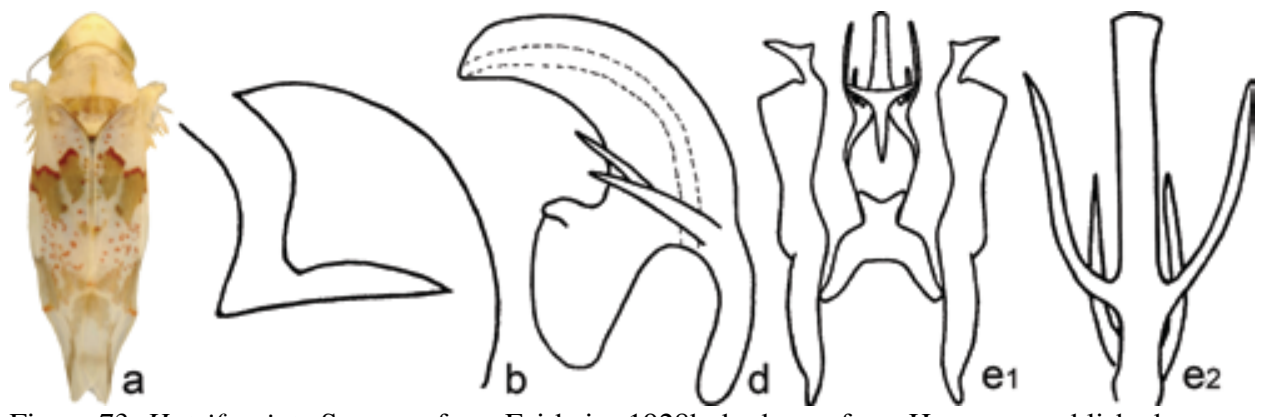

Figure 73. H. trifasciata Say. e1 - from Fairbairn 1928b; b, d, e2 - from Hepner unpublished. 
74. Hymetta arizoniana Fairbairn, 1928 (Fig. 74)

Hymetta arizoniana Fairbairn, 1928b:90

Description: Length $3.3-3.7 \mathrm{~mm}$. Aedeagus round in crossection; apex truncate in ventral view; two pairs of aedeagus ventral processes placed basally, close to shaft, placed basally; one pair of processes longer than shaft flattened, another pair not flattened, little shorter than shaft; distal processes absent. Coloration typical for genus.

Type locality: Holotype $\widehat{\delta}$, USA, Arizona, Coconino Co., 13 VIII 1927 (Beamer), (KSEM).

Distribution: Arizona.

Host plants: Unknown.
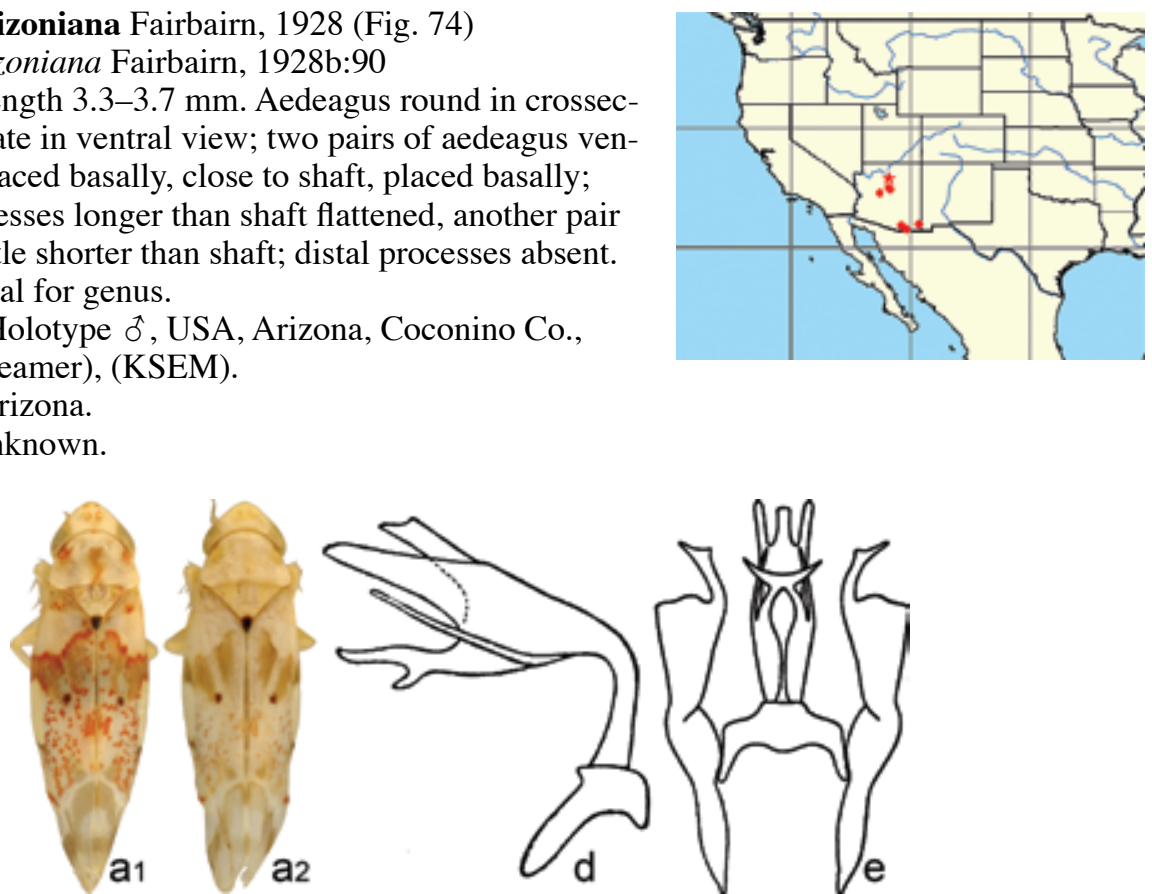

Figure 74. H. arizoniana Fairbairn. a1, a2 - color variations. d, e - from Fairbairn 1928b. 


\section{References}

Beamer, R.H. 1927. New species of Erythroneura (Homoptera: Cicadellidae). Canadian Entomologist 59:30-31.

Beamer, R.H. 1929. Erythroneura (Homoptera, Cicadellidae) from the Southwest. Ann. Entomol. Soc. America 22(1):115-129.

Beamer, R. H. 1930a. Two Erythroneura (grape leaf hoppers) damaging apple in Kansas (Homoptera, Cicadellidae). $J$. Kansas Entomol. Soc. 3(2):49-50.

Beamer, R.H. 1930b. Some Erythroneura of the obliqua group (Homoptera, Cicadellidae). Ann. Entomol. Soc. America 23: 417-456.

Beamer, R.H. 1931a. Some Erythroneura (grape leaf hoppers) of the maculata group (Homoptera, Cicadellidae). Canadian Entomologist 63:127-135.

Beamer, R.H. 1931b. Some Erythroneura (grape leaf hoppers) of the maculata group (Homoptera, Cicadellidae). Canadian Entomologist 63:240-244.

Beamer, R.H. 1931c. Some Erythroneura (grape leaf hoppers) of the maculata group (Homoptera, Cicadellidae). Canadian Entomologist 63:268-270.

Beamer, R.H. 1931d. Some Erythroneura (grape leaf hoppers) of the maculata group (Homoptera, Cicadellidae). Canadian Entomologist 63:285-289.

Beamer, R.H. 1932a. Some Erythroneura (grape leaf hoppers) of the maculata group (Homoptera, Cicadellidae). Canadian Entomologist 64:12-17.

Beamer, R.H. 1932b. Erythroneura collected on apple with description of a new species. J. Kansas Entomol. Soc. 5(2): 62-64.

Beamer, R.H. 1932c. Some Erythroneura (grape leaf hoppers) of the maculata group (Homoptera, Cicadellidae). Canadian Entomologist 64:45-48.

Beamer, R.H. 1932d. Some Erythroneura (grape leaf hoppers) of the maculata group (Homoptera, Cicadellidae). Canadian Entomologist 64:69-72.

Beamer, R.H. 1932e. Some Erythroneura (grape leaf hoppers) of the maculata group (Homoptera, Cicadellidae). Canadian Entomologist 64:82-88.
Beamer, R.H. 1932f. Some Erythroneura (grape leaf hoppers) of the maculata group (Homoptera, Cicadellidae). Canadian Entomologist 64:134-144.

Beamer, R.H. 1932g. Some Erythroneura (grape leaf hoppers) of the maculata group (Homoptera, Cicadellidae). Canadian Entomologist 64:158-162.

Beamer, R.H. 1932h. Some Erythroneura (grape leaf hoppers) of the maculata group (Homoptera, Cicadellidae). Canadian Entomologist 64:174-181, 3 pl.

Beamer, R.H. 1932i. A new Erythroneura related to Erythroneura rubricata (Van D.) (Homoptera, Cicadellidae). PanPacific Entomologist 8(4):183-184.

Beamer, R.H. 1937. Five new species of leafhoppers (Homoptera - Cicadellidae). J. Kansas Entomol. Soc. 10(1):10-13.

Beamer, R.H. 1938. Species of Erythroneura of the comes group (Homoptera - Cicadellidae). Univ. Kansas Sci. Bull. 1936 24(14):261-307.

Beamer, R.H. 1946. The Erythroneura of the vulnerata group (Homoptera - Cicadellidae). J. Kansas Entomol. Soc. 19(1):15-22.

Bremer, K. 1994. Branch support and tree stability. Cladistics 10:295-304.

DeLong, D.M. 1916. The leafhoppers or Jassoidea of Tennessee. Bull. Tennessee St. Board Entomol. 5(2:17):1-113.

DeLong, D.M., and J.S. Caldwell. 1937. Check list of the Cicadellidae (Homoptera) of America, north of Mexico. Ohio State University. IV+93 pp.

Dietrich, C.H., and D.A. Dmitriev. 2006. Review of the New World genera of the leafhopper tribe Erythroneurini (Hemiptera: Cicadellidae: Typhlocybinae). Bull. Illinois Natur. Hist. Surv. 37(5): I-IV, 119-190.

Dmitriev, D.A. 2006. 3I, a new program for creating Internet-accessible interactive keys and taxonomic databases and its application for taxonomy of Cicadina (Homoptera). Rus. Entomol. J. 15(3): 263-268.

Dmitriev, D.A., and C.H. Dietrich. 2003 onward, Web site: Erythroneurini database. Http://ctap.inhs.uiuc.edu/dmitriev/ 
Duso, C., A. Bressan, L. Mazzon, and V. Girolami. 2005. First record of the grape leafhopper Erythroneura vulnerata Fitch (Hom., Cicadellidae) in Europe. J. Appl. Entomol. 129(3):170-172.

Fairbairn, V.M. 1928a. The life history of Erythroneura ziczac Walsh (Homoptera: Cicadellidae). J. Kansas Entomol. Soc. 1:79-84.

Fairbairn, V.M. 1928b. The genus Hymetta (Homoptera, Cicadellidae). J. Kansas Entomol. Soc. 1(4):84-92.

Fitch, A. 1851. Catalogue with references and descriptions of the insects collected and arranged for the State Cabinet of Natural History. Ann. Rpt. State Cab. Natur. Hist. 4:43-69.

Fitch, A. 1856. Third report on noxious and other insects of the State of New York. Trans. N.Y. State Agr. Soc. 16: 315-490, pl. 1-4.

Gillette, C.P. 1892. Observations upon injurious insects, season of 1891. Bull. Colorado Agr. Expt. Sta. 19:1-32.

Gillette, C.P. 1898. American leaf-hoppers of the subfamily Typhlocybinae. Proc. U.S. Nat. Mus. 20(1138):709-773.

Gillette, C.P., and C.F. Baker 1895. A preliminary list of the Hemiptera of Colorado. Bull. Colorado Agr. Expt. Sta. 31:1-137.

Gillette, C.P., and G.M. List 1921. Twelfth annual report of the State Entomologist of Colorado. Cir. Colorado State Ent. 34:1-56, pl. I-VI.

Hamilton, K.G.A., and D.W. Langor. 1987. Leafhopper fauna of Newfoundland and Cape Breton islands (Rhynchota: Homoptera: Cicadellidae). Canadian Entomologist 119(7-8):663-695.

Harris, T.W. 1831. Locust. Encyclopaedia Americana. A popular dictionary of arts, sciences, literature, history, politics, and biography, brought down to the present time; including a copious collection of original articles in American biography; on the basis of the seventh edition of the German Conversations-lexicon 8:40-43.

Johnson, D.M. 1934. Some Erythroneura of the comes group (Homoptera: Cicadellidae). Ohio J. Sci. 34(4):258-263.
Johnson, D.M. 1935. Leafhoppers of Ohio. Subfamily Typhlocybinae (Homoptera: Cicadellidae). Bull. Ohio Biol. Surv. 31:39-122.

Kaloostian, G.H. 1952a. A current report on vectors of Western X-disease Virus of stone fruits. Proc. Utah State Hort. Soc. 1952:19-21.

Knull, D.J. 1945. Eleven new leafhoppers with notes on others (Homoptera: Cicadellidae). Ohio J. Sci. 45(3):103-110.

Knull, D.J. 1946. Erythroneura of the obliqua group from Ohio and Tennessee (Homoptera: Cicadellidae). Ohio J. Sci. 46(1):45-49.

Knull, D.J. 1951a. Sixteen new leafhoppers and notes (Homoptera: Cicadellidae). Ohio J. Sci. 51(4):169-178.

Knull, D.J. 1951b. Eight new leafhoppers from the United States (Homoptera: Cicadellidae). Ohio J. Sci. 51(4):179-183.

Knull, D.J. 1954a. New Erythroneura (Eratoneura) of the dira group with notes (Homoptera, Cicadellidae). Ohio J. Sci. 54(3):170-174.

Knull, D.J. 1954b. A Frigartus from California and an Erythroneura from South Dakota (Homoptera: Cicadellidae). Entomol. News 65(2):37-39.

Knull, D.J. 1955. Some new texan Erythroneura (Eratoneura) of the dira group (Homoptera: Cicadellidae). Ohio J. Sci. 55(4):245-246.

Lawson, P.B. 1920. The Cicadellidae of Kansas. Kansas Univ. Sci. Bull. 12:5-306.

Lawson, P.B. 1922. A list of the Cicadellidae of Kansas. Trans. Kans. Acad. Sci. 30:331-336.

Lindberg, H. 1948. On the insect fauna of Cyprus. Results of the expedition of 1939 by Harald Håkan and P.H. Lindberg. II. Heteroptera and Homoptera Cicadina der Insel Zypern. Comm. Biol. 10(7):23-175.

Lugger, O. 1896. Grape-vine leafhoppers (Typhlocyba spec.), and the celery treehopper (Cicadula 4-lineata Forbes). Bull. Minn. Agr. Expt. Sta. 48: 61-66.

Mahmood, S.H. 1967. A study of the typhlocybine genera of the Oriental region (Thailand, the Philippines and adjoining areas). Pacific Ins. Monogr. $12: 1-52$. 
Malloch, J.R. 1921. A new species of Erythroneura (Typhlocybidae, Hem.-Hom.). Bull. Brooklyn Entomol. Soc. 16: 25.

Martinson, T.E., and T.J. Dennehy. 1995. Varietal preferences of Erythroneura leafhoppers (Homoptera: Cicadellidae) feeding on grapes in New York. Environ. Entomol. 24(3):550-558.

Matsumura, S. 1932. The Typhlocybid genera of the late Distant. Insecta Matsumurana 6:190-191.

McAtee, W.L., 1918. Notes on Nova Scotian eupteryid leafhoppers including descriptions of two new species. Canadian Entomologist 50:360-361.

McAtee, W.L. 1919. A new genus for Tettigonia trifasciata Say (Homoptera; Eupterygidae). Proc. Biol. Soc. Washington 32:121-124.

McAtee, W.L. 1920. Key to the Nearctic species and varieties of Erythroneura (Homoptera; Eupterygidae). Trans. American Entomol. Soc. 46:267-321, pl. XII.

McAtee, W.L. 1924a. Notes on eupterygid leafhoppers with descriptions of a few forms (Homoptera). Florida Entomologist 8(3-4):33-39.

McAtee, W.L. 1924b. Records of species of the genus Erythroneura (Homoptera; Eupterygidae) with descriptions of new forms. Proc. Biol. Soc. Washington 37:131-134.

McAtee, W.L. 1924c. Notes on a collection of Erythroneura and Hymetta (Eupterygidae) chiefly from Illinois, with descriptions of new forms. Bull. Illinois Natur. Hist. Surv. 15(2):39-44.

McAtee, W.L. 1926. Notes on Homoptera from Illinois, with descriptions of new forms, chiefly Eupteryginae. Bull. Illinois Natur. Hist. Surv. 16(3):127-136.

Merrill, D.E. 1915. The grape leafhopper. Bull. N. Mex. Agr. Expt. Sta. 94:33, 1 pl.

Metcalf, Z.P. 1968. General catalogue of the Homoptera. VI. Cicadelloidea. 17. Cicadellidae. Washington: US Dept. Agr. VII+1513 pp.

Oman, P.W. 1949. The Nearctic leafhoppers (Homoptera: Cicadellidae). A generic classification and check list. Mem. Entomol. Soc. Washington 3:VII+253 pp.
Osborn, H. 1900. A list of Hemiptera collected in the vicinity of Bellaire, Ohio. Ohio Nat. 1:11-12.

Osborn, H. 1928a. Neotropical Homoptera of the Carnegie Museum. Part 6. Report on the subfamily Typhlocybinae, with descriptions of new species. Ann. Carnegie Mus. 18:253-298, pl. 13-16.

Osborn, H. 1928b. Leafhoppers of Ohio (Cicadellidae). Bull. Ohio Biol. Surv. 3(4):199-374.

Osborn, H. 1932. Supplemental records and notes on Ohio leafhoppers. Ohio J. Sci. 32(6):513-517.

Oshanin, V.T. 1912. Katalog der paläarktischen Hemipteren (Heteroptera, Homoptera - Auchenorhyncha und Psylloideae). P. I-XVI, 1-187.

Padley, C. 1941. A list of the leaf hoppers (Cicadellidae) in the Iowa insect survey collection. Proc. Iowa Acad. Sci. 47:393-395.

Rathvon, S.S. 1869. Homoptera. Pages 550551 in Mombert's, An authentic history of Lancaster County, in the state of Pennsylvania.

Robinson, W. 1924a. Some new species of Erythroneura (Homoptera, Cicadellidae). Canadian Entomologist 56(3):58-62.

Robinson, W. 1924b. Additional new species of Erythroneura (Homoptera, Cicadellidae). Canadian Entomologist 56:154-157.

Robinson, W. 1924c. Additional new species of Erythroneura (Homoptera, Cicadellidae). Canadian Entomologist 56:290-292.

Robinson, W. 1926. The genus Erythroneura north of Mexico (Homoptera, Cicadellidae). Kansas Univ. Sci. Bull. 16(3):101-155.

Ross, H.H. 1965. The phylogeny of the leafhopper genus Erythroneura (Hemiptera, Cicadellidae). Zool. Beitrage 11(1-2):247-270.

Ross, H.H., and D.M. DeLong. 1953. Biological and taxonomic notes on Erythroneura (Homoptera, Cicadellidae). Ohio J. Sci. 53(2):77-90. 
Say, T. 1825. Descriptions of new Hemipterous insects collected in the expedition to the Rocky Mountains, performed by order of Mr. Calhoun, Secretary of War, under command of Major Long. J. Acad. Natur. Sci. Philadelphia 4:307-345.

Smith, J.B. 1890. Sub-order Homoptera. Catalogue of insects found in New Jersey. Geological Survey of New Jersey. Final report of the State Geologist 2(2):436-447.

Swofford, D.L. 1998. PAUP*: Phylogenetic Analysis Using Parsimony (*and other methods), version 4. Sinauer, Sunderland, Massachusetts.

Van Duzee, E.P. 1909. Observation on some Hemiptera taken in Florida in the spring of 1908. Bull. Buffalo Soc. Natur. Sci. 9:149-230.

Van Duzee, E.P. 1914. A preliminary list of the Hemiptera of San Diego County, California. Trans. San Diego Soc. Natur. Hist. 2:1-57.
Van Duzee, E.P. 1916. Suborder Homoptera Latr. 1810. Section Auchenorhyncha A. \& S. 1843. Check list of Hemiptera (excepting the Aphididae, Aleurodidae, and Coccidae) of America North of Mexico. 1916: I-XI, 55-85.

Walsh, B.D. 1862. Fire blight. Two new foes of the apple and pear. Prairie Farmer (N.S.) 10:147-149.

Wirtner, P.M. 1904. A preliminary list of the Hemiptera of western Pennsylvania. Ann. Carnegie Mus. 3:183-232.

Woodworth, C.W. 1889. North American Typhlocybini. Psyche 5:211-214.

Young, D.A. 1952. A reclassification of Western Hemisphere Typhlocybinae (Homoptera, Cicadellidae). Univ. Kansas Sci. Bull. 35(1:1):3-217.

Zachvatkin, A.A. 1946. Notes on some Homoptera from Yemen. Trans. London Entomol. Soc. 96:151-162.

Zimmerman, R., B. Kondratieff, E. Nelson, and C. Sclar. 1996. The life history of two species of grape leafhoppers on wine grapes in western Colorado. J. Kansas Entomol. Soc. 69:337-345. 
Index

$a$ Fitch .83

accepta McAtee $59,95,96$

aclys McAtee $62,67,88,89$

acuticephala Robinson i, $62,67,88$

albata McAtee $.59,120$

amanda McAtee $62,66,76$

ancora Beamer.

anfracta Beamer. 63, 68, 101 anthisma McAtee $63,68,93,94$ arizoniana Fairbairn. $59,63,119,120,121$ atra Johnson $63,119,122$ atrata Johnson 59, 63, 107, 111, 112 attenuata Johnson 59,111 aza Robinson. $62,67,86$ Aztegina .60

Bakera. 65

bakeri sp.n. $59,63,68,92,93$

Bakerini 65

balteata McAtee........i, ii, 59, 63, 119, 120, 121 beameri Robinson

$62,67,80,81$ bicolorata Beamer

$59,109,110$ bidens McAtee $63,69, \mathbf{1 0 5}, 106$ bipentagona Beamer $62,63,107,115$ bistrata McAtee.... $62,67,89$ breakeyi Johnson .79 browni sp.n. $59,62,66,72,73$ caerula Beamer $63,108,112$ caestra DeLong \& Caldwell 102 caetra McAtee calva Beamer 63, 69, 102, 103 calycola Osborn 63, 116, 118 calycula McAtee cancellata McAtee ..i, 59, 62, 67, 84, 85 carbonata McAtee $62,68,91$ carinata sp.n. i, 63, 116, 117, 118 celoradensis Merrill $59,62,67,82,83$ cherokee Robinson 59,75 coloradensis Gillette $63,68,98$ colorado Gillette \& List .98 coloradoensis Gillette. . .98 comes Say $62,66,67,72,73,74,76,77,78,86,99$ complementa McAtee 59,72 compta McAtee 59,75 corni Robinson. corona McAtee 63, 69, 105, 106 $. .97,98$ cymbium McAtee decora McAtee $59,110,111$ delicata McAtee $59,63,68,95,96$ delictata Young .95 disjuncta McAtee $.59,84$

distincta Fairbairn $59,120,121$ diva McAtee $59,62,66,72,83$ elegans McAtee $63,68,95$ elegantula Osborn $62,65,67,87,92$ emeljanovi sp.n. $59,63,108,114$ erasa McAtee $.59,84,85$

Erasmoneura. $59,60,62,107$

Eratoneura $60,62,63$

Erthroneura ....65

Erythridula 60,62

Erythroneura. Erythroneurini Erythroueura 65,66 Eurythroneura 65 festiva Beamer. 665 fiduciaria Knull $62,66,78$ flava Robinson $62,66,70,71$ fraxa Robinson .97, 98 fulmina McAtee 63, 68, 99 59, 63, 107, 109, 110 fusco-clava Beamer . .89 gilensis Beamer. $62,66,77,78,79$ glabra sp.n. $59,62,67,86,87$ gradata Robinson 59, 108, 109 Hepzygina 60 Hymetta $59,60,62,118,119$ Illinigina. 60,62 infuscata Gillette....................... i, 62, 67, 90, 91 integra McAtee $62,67,82$ irrorata Robinson 63,119

kansasensis Fairbairn $62,66,70$ kanwakae Robinson kennedyi Knull $63,68,100,101$ kerzhneri sp.n. 59, 63, 68, 99, 100 lacta Robinson . .95 mallochi McAtee 103 margaritae sp.n. $59,63,108,113,114$ maritima Hamilton. 59,71 mediana Fairbairn $.59,120$

Mexigina 60 mixta Beamer 63, 108, 114, 115

Nelionidia. 60

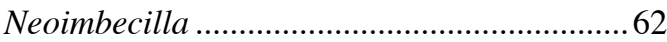

Neozygina. 60 niger Gillette 110

nigerrima Beamer 
nigerrima McAtee. $.59,63,107,111,112$ nigra Gillette i, 59, 63, 107, 110, 111, 112 nigridorsum DeLong. 110 nigroscuta Johnson 59,75 noncincta Johnson. $59,84,85$ nudata McAtee. $62,66,76,77$ octolineata Lawson octonotata Walsh. octo-notata Walsh $59,62,66,75$ omaska Robinson $63,69,104$ ontari Robinson $63,69,106$ ornata Osborn .105

ortha sp.n. $59,62,66,73,77$ palimpsesta McAtee i, $62,66,80$ pontifex McAtee. portea Robinson $62,66,79$

prima Beamer. prosata Johnson pulchella Robinson reflecta McAtee repetita McAtee rosa Robinson Rossmoneura rubra Gillette rubranotum Robinson rubravitta Robinson rubrella McAtee. rubricata Van Duzee. rufomaculata McAtee rufromaculata Oman .75 scripta Robinson 59,95 sexpunctata Malloch ................................. 117 stricta McAtee .89 suffusa McAtee ................................... 105, 106 tacita Beamer $63,69,102$ tecta McAtee $63,116,117$ triapitsyni sp.n....................59, 62, 68, 92, 93 tricincta Fitch......................60, 62, 65, 67, 83 trifascaita Osborn 121 trifasciata Say tudella Robinson $63,118,119,121$ vaga Beamer $.59,95$ vaga Johnson. $63,68,99$ vagabunda Knull......................62, 67, 85, 86 variabilis Beamer.........................63, 107, 110 venusta McAtee ............................................97 vitifex Fitch.....................................63, 68, 96 vitifix Padley ............................................... 96 vitis Harris ................................63, 68, 97, 98 vulneata Lugger .......................................... 108 vulnerata Fitch......i, 59, 63, 107, 108, 109, 110 walshi Beamer.......................................59, 94 ziczac Walsh................................59, 63, 68, 94 zigzag Wirtner ................................................ 94 zizac Kaloostian ...............................................94

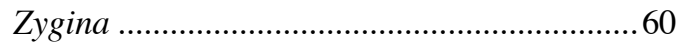

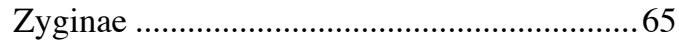

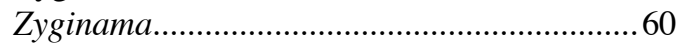



Illinois Natural History Survey

I-Building

1816 South Oak Street

Champaign, Illinois 61820

217-333-6880

A Division of the Illinois Department of Natural Resources

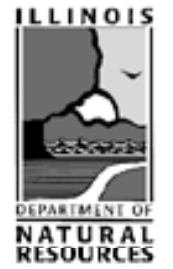

